\title{
Los colgantes de la cueva de Praileaitz I (Deba, Gipuzkoa) y sus características formales
}

\author{
Praileaitz I (Deba, Gipuzkoa, Euskal Herria) haitzuloaren zintzilikarioak \\ eta beraien ezaugarri formalak
The pendants of the Praileaitz I cave (Deba, Gipuzkoa, Basque Country) and their characteristics

PALABRAS CLAVE: Praileaitz I, Euskal Herria, Paleolítico, Magdaleniense Inferior, Colgantes líticos, Arte mueble, Actividad ritual . GAKO-HITZAK: Praileaitz I, Euskal Herria, Paleolito, Behe-Madeleinea, Harrizko zintzilikarioak, Arte higigarria, Jarduera errituala. KEYWORDS: Praileaitz I, The Basque Country, Palaeolithic, Lower Magdalenian, Stone pendants, Portable art, Ritual activity.

Xabier PEÑALVER ${ }^{(1)}$, Jose Antonio MUJIKA-ALUSTIZA(2)

\section{RESUMEN}

Se describen 29 piezas líticas y óseas con perforación, decoradas en su mayor parte, halladas en diferentes espacios de la cueva (vestíbulo y primera sala interior) de Praileaitz I (Gipuzkoa, Euskal Herria), generalmente agrupadas en conjuntos. Entre ellas destaca un collar formado por catorce elementos, situados de forma ordenada. Todos estos restos corresponden al Magdaleniense Inferior.

\section{LABURPENA}

Praileaitz I kobako (Gipuzkoa,Euskal Herria) gune ezberdinetan aurkitutako zulodun harrizko eta hezurrezko 29 ale, gehienak apainduak, deskribatzen dira. Hauek, orokorki multzoetan aurkitu dira. Hauetatik nabarmentzekoa da 14 alez, era ordenatuan aurkituak, osatutako lepokoa. Hauek denak Behe Madeleine aldikoak dira.

\section{ABSTRACT}

29 perforated, and mostly decorated, lithic and bony pieces found in different areas (usually grouped into sets) of the Praileaitz I cave (the foyer and the first interior room) are described. Among them stands out a necklace formed by fourteen elements, placed in an ordered way. All these remains correspond to the Lower Magdalenian.

\section{1.- INTRODUCCIÓN}

La singularidad de Praileaitz I reside en la serie de evidencias recuperadas en la ocupación correspondiente al Magdaleniense Inferior. Ésta no destaca por el volumen de restos aportados, sino por la presencia de un hogar, junto a un bloque-asiento de notables dimensiones, algo de industria lítica (menos de un centenar de restos de sílex, varios ocres, unos brutos y otros con indicios de abrasión) y ósea, además de un poco de fauna, todas ellas evidencias de una efímera ocupación a las que, sin embargo, acompañaba una nutrida colección de colgantes. Estos son 29, de ellos 3 sobre incisivos de cabra y otros 26 sobre cantos rodados de varios tipos de rocas (lutita, etc.), llamativos por su coloración oscura (a veces negra brillante en la humedad) y por la sugerente forma de algunos de ellos, además de por la presencia de grabados lineales en la mayoría (PEÑALVER, 2014).
Estos colgantes aparecieron distribuidos tanto en el vestíbulo como en la primera sala (Fig. 1), en alguna ocasión a modo de sarta, y plantean diversas cuestiones (la razón de la selección, el proceso de fabricación y dónde se realizaron, la forma de ataviarse con ellos, su simbolismo (individual y/o colectivo), la amortización (abandono, etc.), que quedarán parcialmente pendientes o sin respuesta satisfactoria (PEÑALVER, MUJIKA, 2005).

\section{Colgante $n^{\circ} 1$ (P.A.12B.291.50)}

Se trata de un delgado canto rodado de lutita de color negruzco, perforado a modo de colgante en uno de los extremos (Figs. 2, 3, 40 y 41). Su forma es romboidal y tres de sus lados son ligeramente cóncavos y los vértices en los que convergen convexos o redondeados. Su sección es muy plana y sus dimensiones máximas

\footnotetext{
(1) Departamento de Arqueología Prehistórica. Sociedad de Ciencias Aranzadi. Zorroagaina, z.g. 20014 Donostia. praileaitz@gmx.com (2) Facultad de Letras (UPV-EHU).
} 


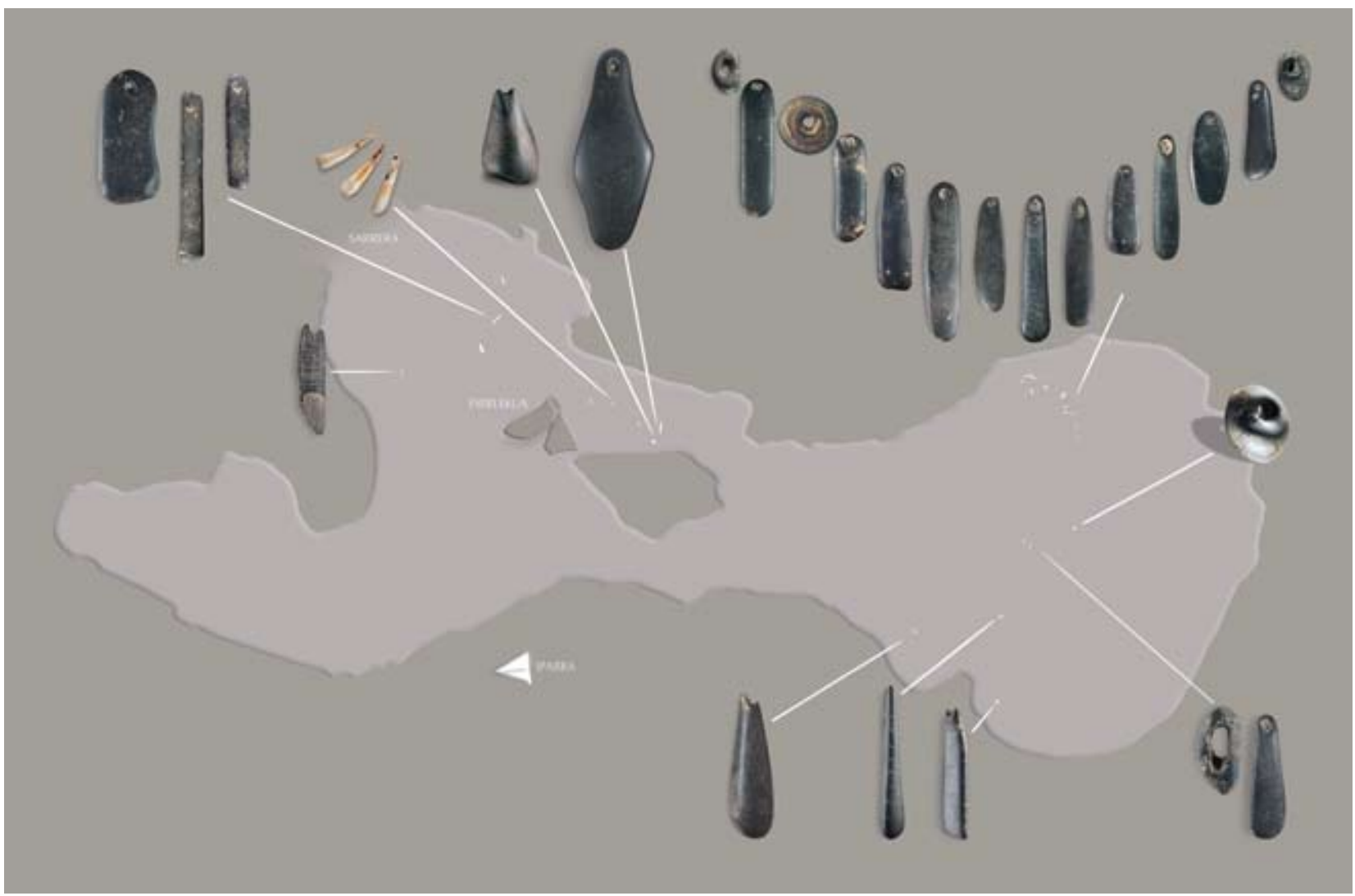

Fig. 1. Localización de los 29 colgantes del nivel Magdaleniense Inferior dentro del vestíbulo y la primera sala interior (X. Otero). / Location of the 29 pendants from the Lower Magdalenian inside the vestibule and the first inner room (X. Otero).

son: $120 \times 53 \times 8,5 \mathrm{~mm}$. Su silueta en natural, no muestra ningún trabajo de preparación, y evoca a algunas de las venus paleolíticas europeas más clásicas (Fig. 4).

En su extremo más estrecho se preparó una superficie rugosa de la cual se conservan indicios a modo de cúpulas puntiformes y de incisiones longitudinales, quizás más profundas en la zona perforada. A continuación se practicó una perforación bicónica finalizada por rotación muy regular y cuyo diámetro interior es de 3,3 $\mathrm{mm}$ y el exterior de 7,8 $\mathrm{mm}$. El peso del colgante es de $113,5 \mathrm{gr}$.

En una de las caras mayores del extremo opuesto a la perforación se aprecian dos series de finas incisiones transversales paralelas, formadas por cuatro y tres trazos no bien ordenadas. Sus longitudes oscilan entre los 8 y los $12 \mathrm{~mm}$.

Los colgantes sobre cantos o plaquetas no son muy frecuentes, a pesar de que esta materia prima era muy accesible y de que su conservación sería mejor que en el caso de los soportes óseos. El ejemplar que tratamos evoca, por su silueta natural, a algunas venus paleolíticas, en concreto a las halladas en Barma Grande de Grimaldi, fabricada en esteatita ambarina, a "La Rombo" de Grimaldi (Italia), a las venus I de Willendorf (Austria), Kostienki (Rusia) o la de Lespugue así como al contorno del relieve de la Dama del cuerno de Laussel (Francia). Por otro lado, queremos señalar que la mayoría de las venus no muestran indicios de que hayan sido utilizadas suspendidas como colgante, aunque dos ejemplares de Malta poseen una perforación en un extremo (ABRAMOVA, 1990).

Leroi-Gourhan (1984a, 515) al analizar las representaciones femeninas paleolíticas de Kostienki, Lespugue y Willendorf, señalaba que "la posición de los diámetros transversales máximos juega un papel en el equilibrio material y visual de las esculturas: centrado en las caderas de las estatuillas", e interpreta que el encuadre en rombo regular constituiría una característica simplificada de la mayor parte de las estatuillas paleolíticas europeas. Las tres venus citadas, fabricadas en marfil de mamut las dos primeras y en piedra la tercera, y en su modelo general responden a un estado figurativo sintético del cuerpo humano. Todas ellas tendrían en común el encuadre, aunque con formas más o menos marcadas según los casos. El eje vertical divide en dos mitades prácticamente iguales la pieza, situándose en su anchura máxima las caderas, que a su vez distribuye los volúmenes simétricamente hacia arriba y hacia abajo. En la figura no 4 hemos representado sobre la silueta del colgante $n^{\circ} 1$ de Praileaitz I, de $120 \mathrm{~mm}$ de altura, la de Lespugue de $147 \mathrm{~mm}$ y la venus $\mathrm{n}^{\circ} 3$ de Kostienki de $114 \mathrm{~mm}$, tras 


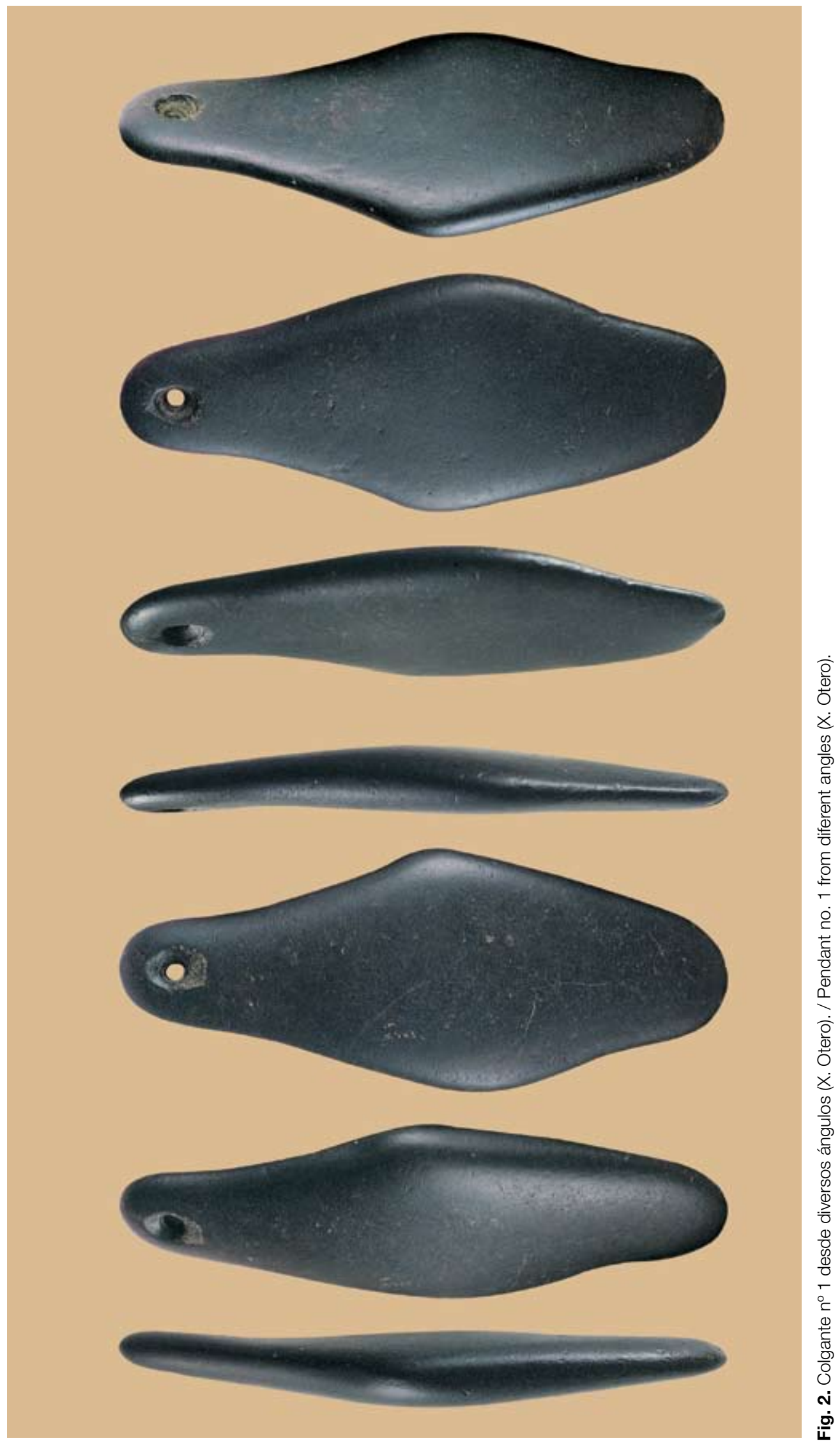




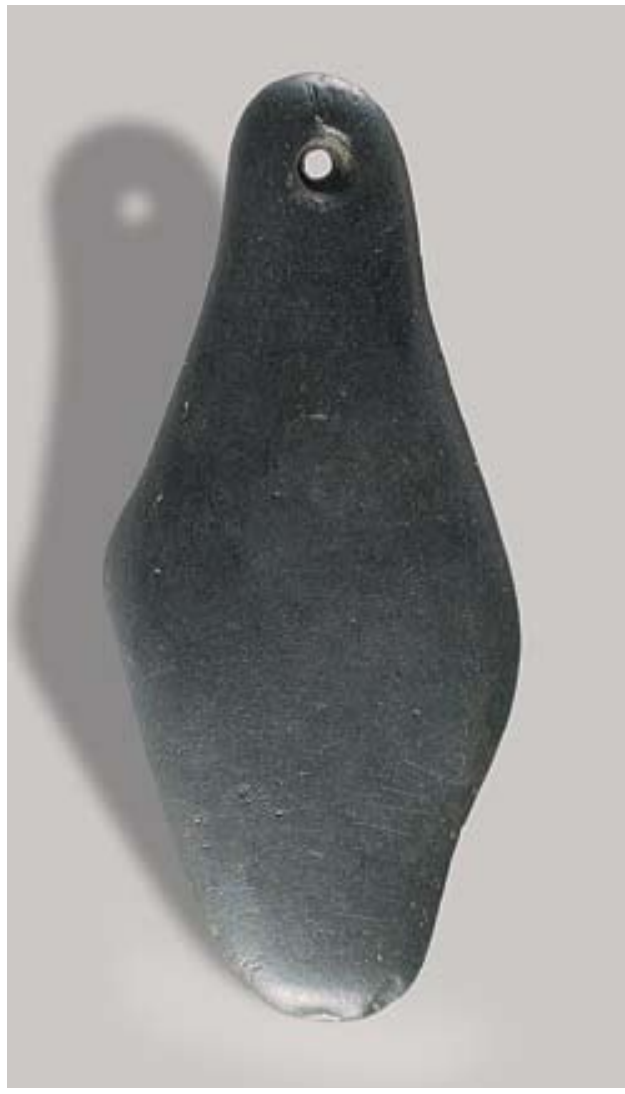

Fig. 3. Colgante $n^{\circ} 1$ (X. Otero). /

Pendant no. 1 (X. Otero).

la adaptación de las escalas de las dos venus para su comparación con el colgante de Praileaitz l.

En la pieza de Praileaitz es evidente que su contorno es natural, pero también es notorio que hubo voluntad de seleccionar un soporte de determinadas características físicas, así como de una sugerente silueta. Las modificaciones que presenta son la perforación que se le ha realizado en un extremo y unas finas incisiones transversales que nos recuerdan, a pesar de su ligereza, a las que presentan algunas representaciones femeninas (Lespugue, Kostienki, venus XIV de marfil de Vestonice -DELPORTE, 1982: 145-).

La representación de figuras humanas de bulto redondo en el arte mobiliar no es frecuente en el entorno del Golfo de Bizkaia, donde contamos con algunas referencias, como el bastón de mando de El Pendo que sugiere una controvertida forma femenina (CARBALLO,
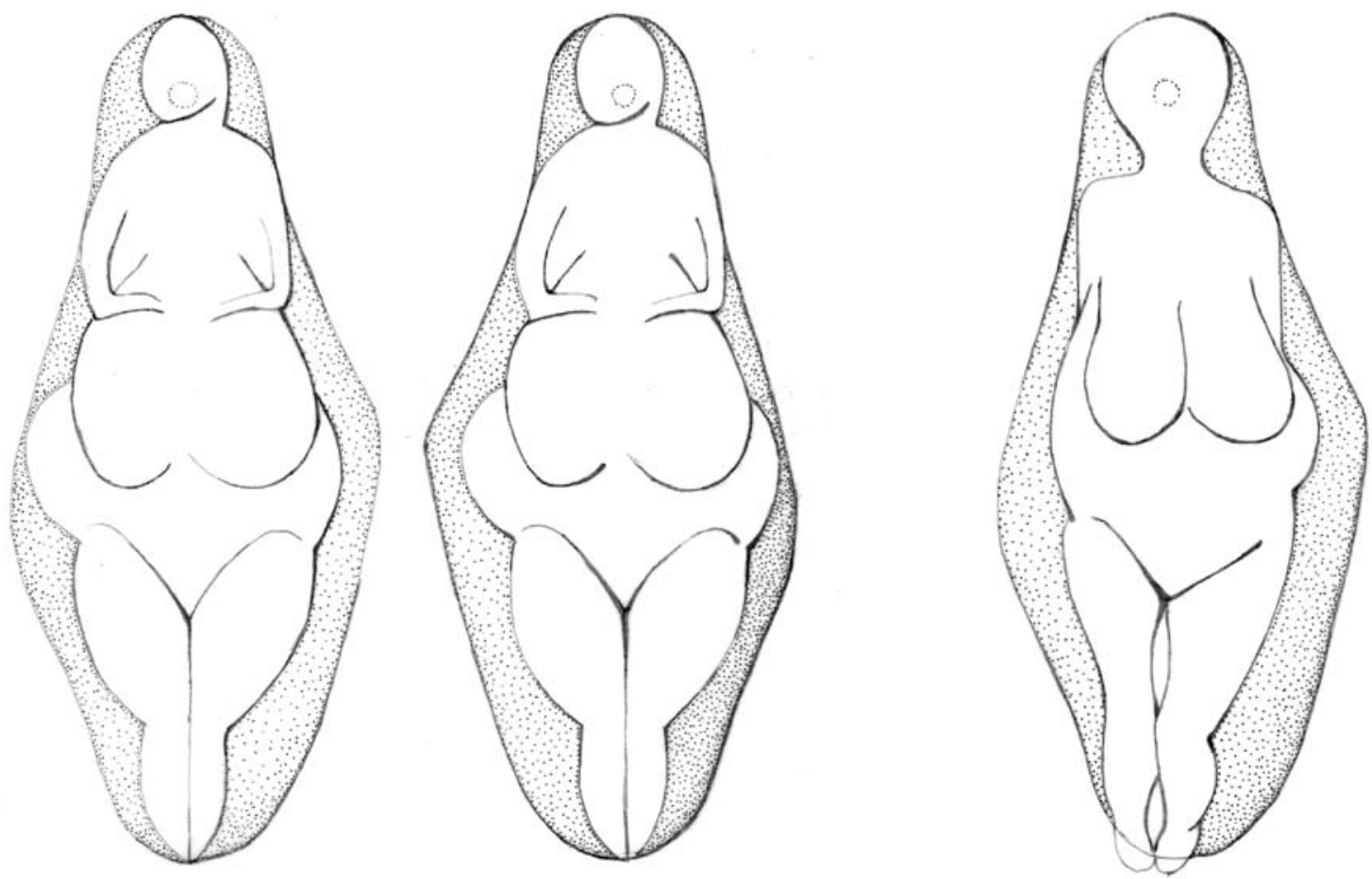

Fig. 4. Colgante $n^{\circ} 1$ de Praileaitz I con superposición, tras adaptar las escalas, de las venus de Lespugue (izquierda y centro), en ambas caras del colgante, y Kostienki (derecha) realizadas por A. Leroi-Gourhan (1984a, 514). / Pendant no. 1 from Praileaitz I with superposition, after adapting the scales, of the images of the venuses of Lespugue (left) and Kostienki (right) made by A. Leroi-Gourhan (1984a, 514). 
GONZÁLEZ ECHEGARAY, 1952; RIPOLL, 1958; BARANDIARÁN, 1973; CORCHÓN, 1986); las dos varillas de Tito Bustillo (MOURE, 1984), la cabeza de Entrefoces (GONZÁLEZ MORALES, 1990) y "La Venus" de Las Caldas (CORCHÓN, 1990b). Sin embargo, existen en el arte mueble otra serie de representaciones humanas grabadas sobre diferentes soportes, que no trataremos en esta ocasión como la de Torre (BARANDIARÁN, 1971), Isturitz (SAINT-PÉRIER, 1930; 1936), la posible de Les Harpons (ALLARD, 1989), etc.

\section{Colgante $n^{\circ} 2$ (P.A.10B.298.28)}

Se trata de un canto rodado cuya forma general es de tendencia cónica oblicua y la sección oblonga (Figs. 5 y 42). El soporte, en la zona conservada, no presenta indicios de manipulación de su silueta para adaptarla a la imagen mental del objeto -probablemente, un canino atrofiado de ciervo- que se deseaba replicar, salvo en lo que hace referencia a sus dimensiones, que son notablemente mayores. Igual que sucedía en el ejemplar anterior, es evidente que en su selección se tuvieron en cuenta el tipo de soporte, tanto por sus características físicas como por su silueta, así como por el simbolismo del objeto original. Las dimensiones máximas de la pieza son: 52,4×33,1×24,9 mm. El peso del colgante es de $53,3 \mathrm{gr}$.

El canto se perforó en el extremo más delgado -el espesor es de $8 \mathrm{~mm}$ - y estrecho, en la parte correspondiente a la raíz del "canino", lo que facilitaría la suspensión equilibrada del colgante. Su fabricación se llevó a cabo, como en el ejemplar anterior y en muchos otros del Pa- leolítico Superior, en dos fases. En la primera se preparó la superficie a perforar, creando una ligera depresión en cada cara mediante cortas incisiones, o una superficie rugosa mediante suaves percusiones efectuadas sobre un objeto punzante que incidía puntualmente en el canto. De esta manera, en la segunda fase, al igual que en el caso de algunos dientes perforados, esta preparación previa facilitaría la realización del orificio por rotación bipolar al permitir un mejor control del perforador.

Este colgante está decorado en una de sus caras y en todas sus aristas con trazos transversales regularmente dispuestos. Los de las dos aristas mayores, que dividen simétricamente la pieza según su eje mayor, son profundos y cortos (de entre 3,5 y $6 \mathrm{~mm}$ ), y se disponen más o menos regularmente (la distancia entre ellos se sitúa entre los 2 y 5 mm. En una de las aristas, de 44,3 $\mathrm{mm}$, se realizaron 12 trazos transversales, y en la opuesta, en 35,2 mm, se aprecian otros tantos.

Por otra parte, en la zona central del lateral derecho hay diez trazos transversales muy finos, y su longitud oscila entre los $24 \mathrm{~mm}$ del inferior y los 9 del superior. Las siete incisiones de más desarrollo son ligeramente quebradas o curvadas, ya que están ejecutadas en dos movimientos debido a la convexidad de dicha cara.

Finalmente, en el perímetro de la base mayor, de forma oblonga o elíptica, hemos contabilizado trece profundas incisiones, las dos primeras y la última de la serie más finas y otras aparentemente dobles por rectificaciones. A continuación, hay un pequeño desconchado, previo a la elaboración del colgante, situado en la convergencia de la arista delantera con la porción de base sin incisiones, y a continuación otro tramo con cuatro
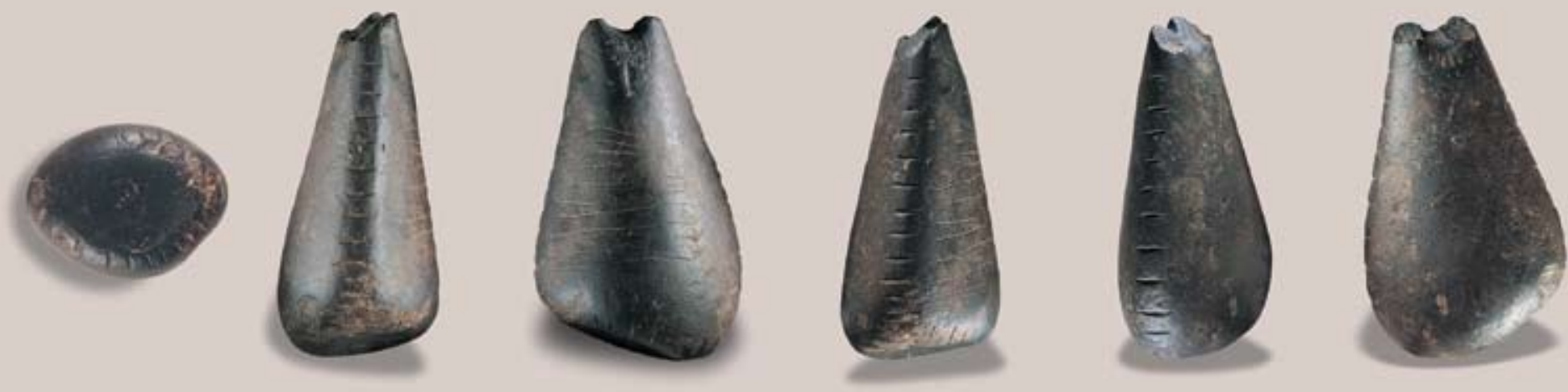

Fig. 5. Colgante $\mathrm{n}^{\circ} 2$ (X. Otero). / Pendant no. 2 (X. Otero). 

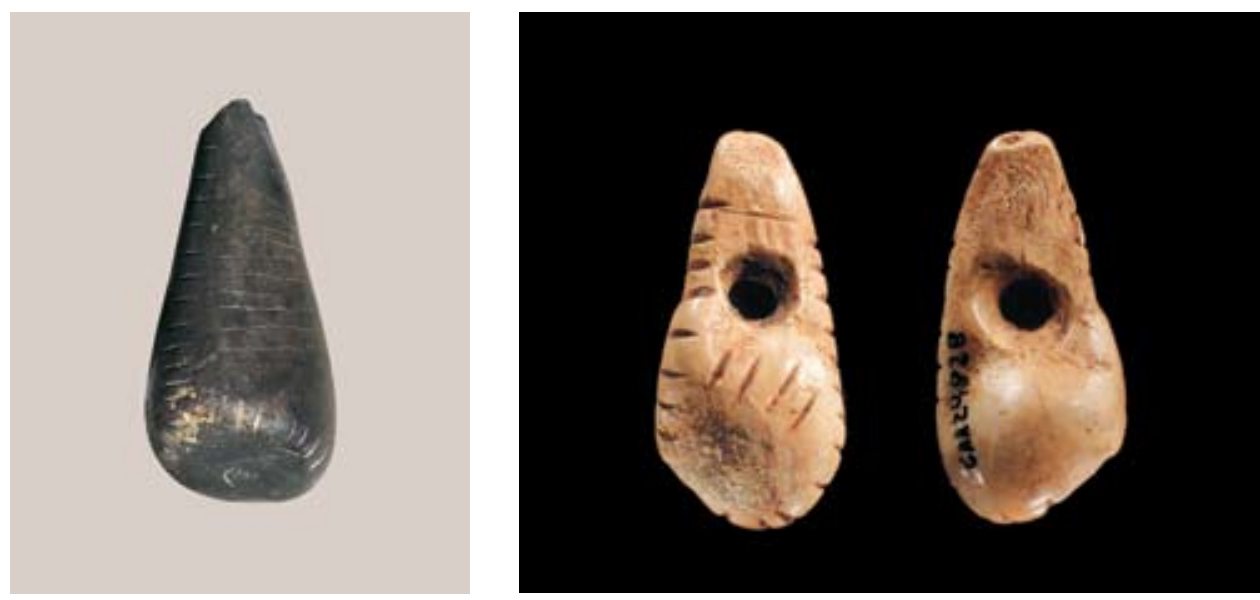

Figs. 6 y 7. A la derecha, canino perforado de ciervo de la cueva de La Garma (Cantabria) (L. Teira) con motivos decorativos similares al colgante $\mathrm{n}^{\circ} 2$ de Praileaitz I situado a la izquierda (X. Otero). / At the right, perforated canine tooth of a deer from La Garma cave (Cantabria) (L. Teira) with decorative motifs similar to the pendant no. 2 from Praileaitz I located at the left (X. Otero).

profundas incisiones. Hay, también, otras tres más finas agrupadas que quizás pudieran ser fugas del útil, rectificadas con posterioridad y, finalmente, la porción de arista perimetral correspondiente a un cuadrante que tampoco está decorada.

Esta pieza, que evoca de forma inmediata a un canino atrofiado de ciervo, viene a incrementar el escaso repertorio de representaciones de bulto redondo inventariadas. Entre sus paralelos podemos señalar dos conjuntos, uno, el formado por los caninos naturales perforados -decorados o no- , y el otro constituido por réplicas o imitaciones en diferentes soportes (hueso o piedra -esteatita, talquita, etc.-). Todos ellos, posiblemente, poseerían la misma simbología; la atribuida a la pieza dentaria original, que en opinión de Barge (1982) serían símbolos de virilidad.

Entre los primeros se conocen ejemplares en niveles auriñacienses y gravetienses de Morín, en el Auriñaciense evolucionado de El Pendo, en el Magdaleniense Arcaico de Rascaño, en el Magdaleniense Inferior de El Juyo y Erralla, en el Magdaleniense Superior-Final de Urtiaga, etc., y ya en el Holoceno los encontramos -normalmente sin decorar- en niveles azilienses (Arenaza, etc.), en dólmenes (Peña Guerra I, etc.) y en cuevas sepulcrales (Pico Ramos -ZAPATA, 1995-, etc.) y ya en fechas mucho más recientes asociado a un enterramiento infantil de cronología medieval (Santa Mª la Real -Zarautz- MUJIKA, 2007 2008; MUJIKA, TARRIÑO 2009). Entre los ejemplares más próximos y decorados con incisiones transversales en sus aristas o en sus caras, se pueden citar los correspondientes a diversos momentos del Paleolítico Superior: Tito Bustillo (MOURE, 1975), Cova Rosa, La Paloma y Las Caldas (CORCHÓN, 1986), El Rascaño (GONZÁLEZ ECHEGARAY, BARANDIARÁN, 1981), Bolinkoba, La Loja, Morín, El Juyo (BARANDIARÁN 1973; 1985) y La Garma (ARIAS, ONTAÑÓN, 2004) (Figs. 6 y 7).

Entre los segundos tenemos ejemplares elaborados en diferentes tipos de rocas (esquisto, talquita esteatita, etc.), a veces sin determinar con garantías, o en materias óseas (marfil, asta) como los de los niveles auriñacienses de Pair-non-Pair, Abeilles, Saint-Jean-de-Verges, Isturitz o Gatzarria, El Pendo, Pavlov II, Harpons (LUQUET, 1926; OTTE, 1981; SÁENZ DE BURUAGA, 1991).

\section{Colgante $n^{\circ} 3$ (P.A.10G.256.65 + P.A.8G'.331.1)}

Fragmento medial de un colgante fabricado sobre un canto alargado y aplanado (P.A.10G.256.65) (Figs. 8 y 43). Junto a la fractura se observan restos de una perforación bipolar ligeramente descentrada, que quedaría enmarcada por un extremo ojival o semicircular que en la actualidad no se conserva. Al igual que en otros colgantes, inicialmente, se efectuó un trabajo de vaciado con el fin de crear una ligera depresión para finalizar realizando el orificio por rotación. Las dimensiones totales del colgante en su estado actual son: $64,5 \times 17,1 \times 8,4 \mathrm{~mm}$, y su peso de 16,5 gr.

Sus cuatro caras están decoradas con incisiones transversales dispuestas a distancias más o menos regulares. En el lateral recto se conservan 10 profundas incisiones transversales de entre 3,7 y 5,2 mm de longitud y de $1 \mathrm{~mm}$ de anchura, oscilando la distancia entre ellas entre los 4,5 y 7,5 mm. El lado opuesto tiene delineación convexa, y en $27 \mathrm{~mm}$ se concentran 6 trazos de entre 4 y $5,5 \mathrm{~mm}$ de longitud, oscilando la distancia existente entre ellos de 4,5 a 6,3 mm, y siendo la anchura de la incisión de 0,80 mm.

Las caras mayores están decoradas con incisiones transversales más finas que se extienden a todo lo ancho, situándose su longitud entre 10,5 y 13,5 mm. Su delineación es a veces ligeramente cóncava y en otras sinuosa u oblicua, y los trazos se efectúan en dos movimientos. En una de las caras se contabilizan 14 incisiones regularmente dispuestas a intervalos que oscilan 


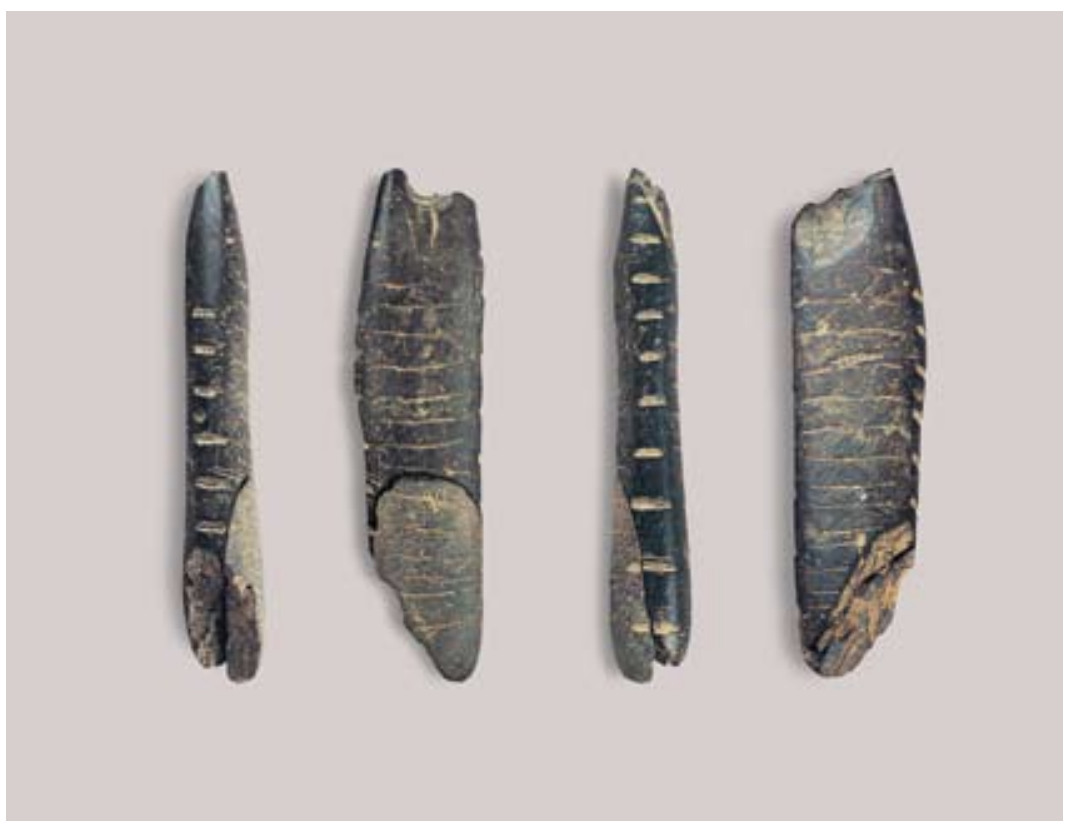

Fig. 8. Colgante $n^{\circ} 3$ (X. Otero). / Pendant no. 3 (X. Otero).

entre los 1,8 y $4 \mathrm{~mm}$ y en la opuesta únicamente 8 incisiones a intervalos de entre 2,7 y $4,4 \mathrm{~mm}$.

La silueta de este ejemplar recuerda, a pesar de su estado fragmentario, a una forma pisciforme a la que le faltaría la parte posterior y el extremo de la anterior. La línea de contorno curvada del canto podría corresponder a la arista dorsal del animal, de forma que el extremo de aquella, la zona donde se ubica la perforación, recordaría el inicio de la cabeza a la altura del opérculo. Hay que subrayar que a partir del punto donde se acentúa la curvatura desaparece la decoración en una de las aristas, así como en los laterales.

Un fragmento más pequeño de este colgante se localizó en la primera sala interior (P.A.8G'.331.1). Se trata de un fragmento de sección planoconvexa que se une en el extremo proximal del hallado en el vestíbulo. Sus

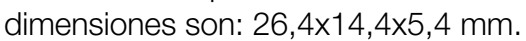

En su cara convexa muestra 6 incisiones transversales regularmente distanciadas y realizadas en dos movimientos (en la zona media presentan bifurcación o la línea se quiebra). En uno de los laterales conserva restos de dos incisiones y de una en el lado opuesto.

La longitud total del colgante (con los dos fragmentos) es de $66,5 \mathrm{~mm}$ y el número total de incisiones transversales en su cara mayor es de 14.

Entre sus paralelos podemos tomar en consideración el canto hallado en Espélugues (Lourdes), decorado con dos hileras transversales que cubren un tercio de una de las caras del objeto, o el hallado en el Magdaleniense Superior de Mas d'Azil que sobre sus dos caras cuenta con líneas transversales ligeramente oblicuas e irregulares (CHOLLOT-VARAGNAC, 1980). Asimismo se producen variaciones de estos temas en cantos magdalenienses (Gazel -Aude-, etc.) y perduraciones de cronología Aziliense en los abrigos de Dufaure (Landes), Rochedane (Doubs), o algo más tardías en Pommeraye (Maine-et-Loire) (COURAUD, 1985).

No obstante, en otras ocasiones, se constatan hileras de incisiones transversales en sus caras en colgantes de piedra (BARANDIARÁN, 1973; SACCHI, 1990; TABORIN, 1990), siendo éste el caso del cantito perforado del Magdaleniense Inferior de Balmori (Asturias) y el de los procedentes del Auriñaciense de Isturitz (Behenafarroa) y del Gravetiense de Morín (Cantabria). También están presentes en los bordes y parte de las caras de dos posibles colgantes de marfil del solutrense de Las Caldas, motivo ya presente en el gravetiense de Bolinkoba, Morín y Pendo, aunque al parecer alcanzan su máximo desarrollo en el Solutrense Superior -Cueto de la Mina, Altamira, Cova Rosa...-(CORCHÓN, 1981).

En el caso de admitirse como posible la hipótesis de que nos halláramos ante un colgante pisciforme, podrían tomarse en consideración algunas figuraciones de peces del arte parietal y mueble, en este caso sobre distintas materias primas (preferentemente hueso o asta), utilizando técnicas de fabricación diferentes, y que recuerdan en algunos aspectos a la pieza estudiada. En las figuraciones realistas de peces (BARANDIARÁN, 1972), son frecuentes las incisiones cortas, a modo de entalladuras, que inciden sobre una o dos aristas; los trazos cruzados en retícula rellenando el espacio interior de los flancos laterales (Isturitz, El Pendo...); trazos paralelos ligeramente oblicuos al eje longitudinal de la pieza y menos frecuentemente punteados, trazos cortos, líneas longitudinales paralelas, etc. (Valle, Isturitz...).

El contorno de un ejemplar de Mas d'Azil (CHOLLOT-VARAGNAC, 1980), fabricado sobre una costilla, presenta en las aristas dorsal y ventral una delineación recta en un caso y ligeramente curva en otro, similares 
Fig. 9. Colgante $n^{\circ} 4$ (X. Otero). / Pendant no. 4 (X. Otero).

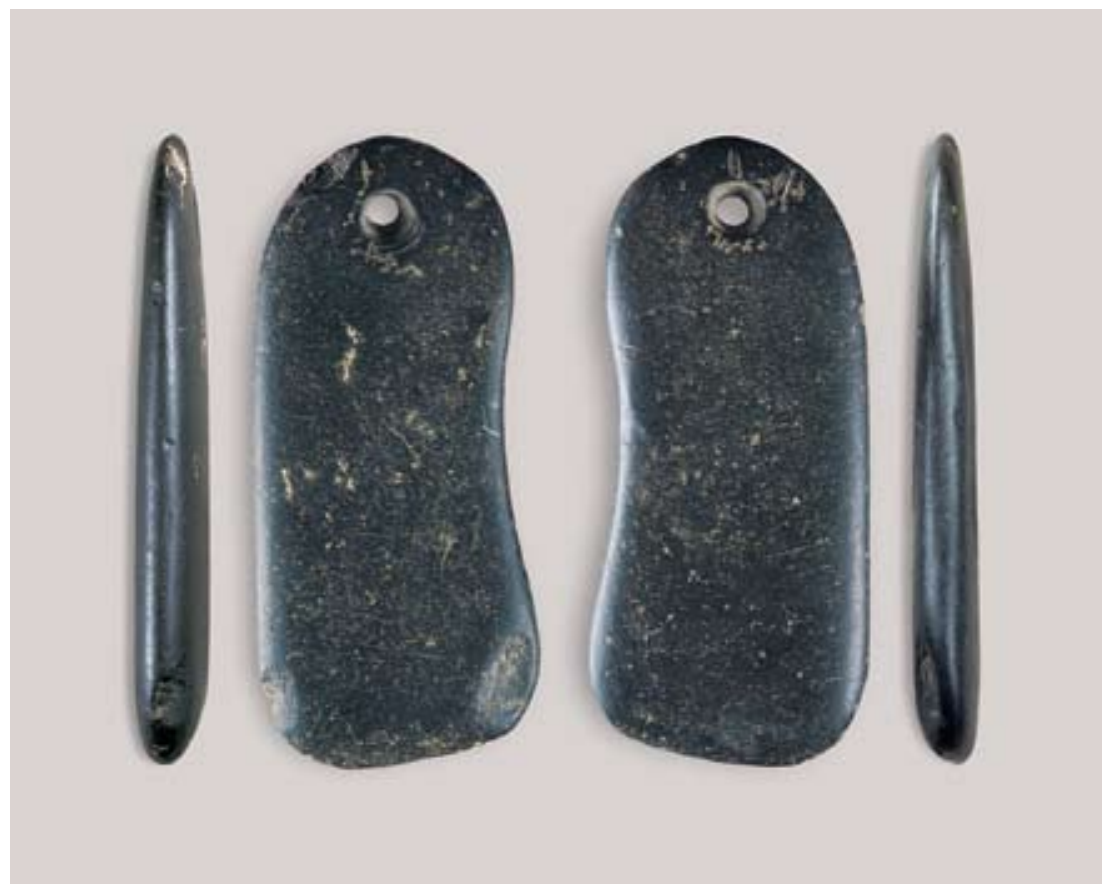

a las de Praileaitz I. También muestran similitud por las incisiones transversales cortas y profundas regularmente dispuestas que afectan a las mencionadas aristas.

La desaparición de las incisiones a la altura del inicio de la cabeza en el ejemplar de Praileaitz I se constata también en otras piezas de arte mobiliar (ZERVOS, 1959), por ejemplo en una pieza de asta magdaleniense de La Madeleine decorada en sus dos caras por sendos peces de estas características, así como en otros ejemplares de arte parietal (Altxerri) o mobiliar (LaugerieBasse, Lorthet, etc.).

\section{Colgante $n^{\circ} 4$ (P.A.12F.289.19)}

Colgante fabricado sobre un canto rodado aplanado de color negro. Su forma es de tendencia subrectangular con ángulos redondeados, y bordes laterales, uno suavemente convexo y el opuesto cóncavo (Figs. 9 y 44). En una de las caras mayores presenta tres desconchados, dos de ellos en los dos ángulos del extremo opuesto a la perforación, erosionados antes de la recogida del soporte de un cauce. El extremo donde se localiza la perforación es de tendencia ojival-semicircular y el opuesto recto, aunque ligeramente oblicuo. La perforación, bicónica, es ovalada. El diámetro interior del orificio es de 3,8 mm y el exterior de $7 \mathrm{~mm}$. Sus dimensiones máximas son: $81 \times 37 \times 8,7 \mathrm{~mm}$. Su peso es de 49,4 gr.

En su extremo más estrecho se localiza el orificio de suspensión que fue realizado en dos fases. De la primera parte de esta labor son testimonio algunas incisiones cortas -quizás líneas de fuga-y pequeños puntos incisos irregulares realizados para facilitar la posterior realización de la perforación por rotación.
Entre los paralelos de este colgante liso, cuya silueta no tiene forma especial alguna, podemos citar algunos ejemplares procedentes de las excavaciones del Conde Vega de Sella en Balmori -Asturias- (BARANDIARÁN, 1973), donde por cierto había también una azagaya de base hendida similar a la del yacimiento que estudiamos, Isturitz -Behenafarroa- (SAINT-PÉRIER, R. 1930, 1936; SAINT-PÉRIER, R. et S., 1952), Pavlov II -Moravia(OTTE, 1981).

\section{Colgante $n^{\circ} 5$ (P.A.12D.266.27)}

Incisivo de cabra con doble perforación bicónica en la raíz (Figs. 10 y 45). La distancia entre el centro de ambos orificios es de $7 \mathrm{~mm}$ y su elaboración ha tenido dos fases, una de vaciado, muy poco intensa, y otra posterior de rotación. El diámetro de uno de los orificios es de 2 $\mathrm{mm}$ y el del situado en el extremo de la raíz, algo más reducido y ligeramente elíptico, de 1,7 mm.

\section{Colgante $n^{\circ} 6$ (P.A.12C.267.15)}

Incisivo de cabra con doble perforación bicónica en su raíz (Figs. 10 y 45). La distancia entre el centro de ambos orificios es de 10,8 mm. El diámetro interior del mayor de ellos es de $2 \mathrm{~mm}$ y el del situado en el extremo de la raíz, ligeramente más pequeño, de 1,5 mm. A ambos lados de la cara frontal de la corona, en la zona de convergencia con el lateral, presenta cortas incisiones transversales, tres en el derecho y cuatro en el izquierdo. Hay que subrayar que en el lado izquierdo de la raíz se conserva una mancha de ocre claramente visible. 


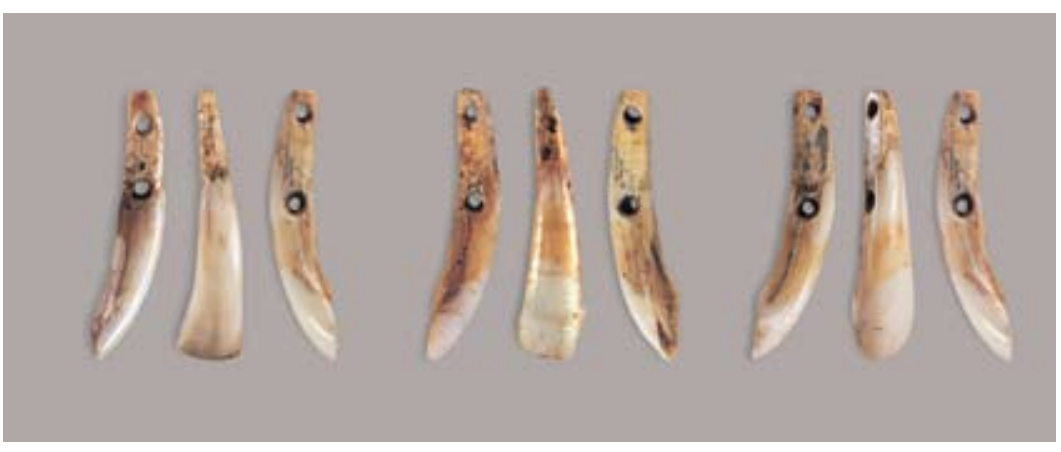

Fig. 11. Colgantes $n^{\circ} 5,6$ y 7 (X. Otero). / Pendants no. 5, 6 and 7 (X. Otero).
Fig. 10. Colgantes $n^{\circ} 5,6$ y 7 (X. Otero). / Pendants no. 5, 6 and 7 (X. Otero).

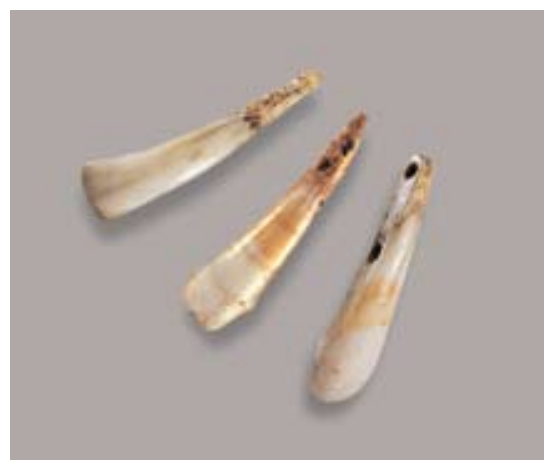

\section{Colgante $\mathrm{n}^{\circ} 7$ (P.A.12C.270.16)}

Incisivo de cabra con doble perforación bicónica en la raíz (Figs. 10 y 45). La distancia entre el centro de ambos orificios es de 11,4 mm y el diámetro interior de ellos de 1,8 mm. En el lado derecho de la cara frontal o vestibular de la corona tiene dos cortas incisiones transversales paralelas entre sí.

La técnica de elaboración de estos tres colgantes en dientes (Fig. 11), y que ha sido frecuentemente descrita también en otros yacimientos, ha tenido probablemente dos fases, si bien sólo es evidente la de rotación bipolar en la raíz. Junto a uno de los orificios quedan restos de la labor de vaciado extrayendo pequeñas virutas. No existen huellas de adelgazamiento de la raíz mediante raspado longitudinal.

Los paralelos de estas piezas dentarias no son muy abundantes, pero se conocen incisivos de caballo y de cérvidos decorados y con doble perforación en diferentes niveles magdalenienses de la cornisa Cantábrica y del territorio norpirenaico. Se pueden enumerar algunos ejemplares hallados en la cercana cueva de Ermittia, Arenaza (dos fragmentos relacionables junto con otros objetos con el ajuar del santuario paleolítico -GORROTXATEGI, 2000-), Isturitz, Mas d'Azil, Tito Bustillo, etc.

Con relación a la mancha de ocre del colgante $\mathrm{n}^{\circ} 5$, cabe señalar que este tipo de restos se conservan en diferentes piezas, tanto de hueso o asta como de piedra, y si bien a veces se podría dudar sobre si el color ha sido dado de forma intencionada o se debe a procesos naturales, en otros queda clara la intervención humana. En nuestro caso no podemos inclinarnos en uno u otro sentido. Sin embargo hay que dejar constancia del hallazgo en este nivel, y en una zona próxima al colgante, de dos lápices de ocre y varios trozos brutos.

\section{Colgante $n^{\circ} 8$ (P.A.14F.296.252)}

Colgante sobre canto rodado alargado de forma tendente a rectangular (Figs. 12 y 46). Su sección es aplanada en su tercio distal y subrectangular en la zona

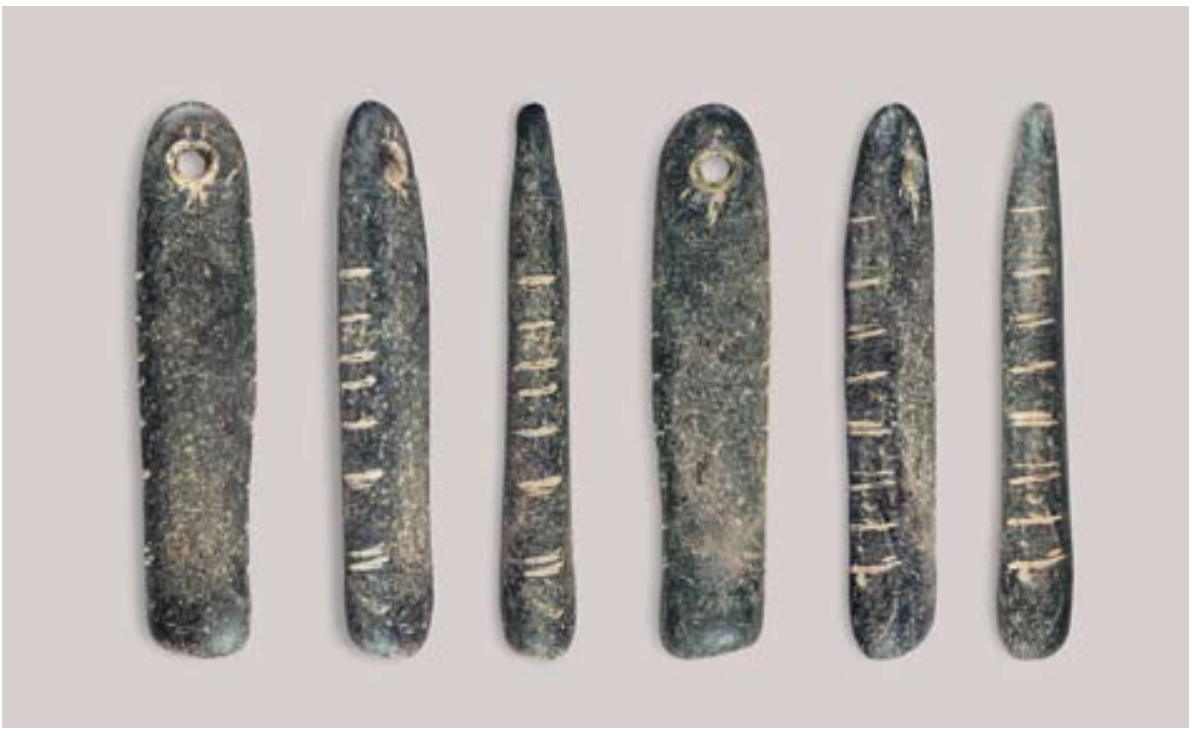

Fig. 12. Colgante $n^{\circ} 8(X$. Otero). / Pendant no. 8 (X. Otero). 
Fig. 13. Colgante $n^{\circ} g(X$. Otero). / Pendant no. 9 (X. Otero).

medial. El espesor mínimo de la pieza $(4,5 \mathrm{~mm})$ coincide con la zona perforada. El diámetro interior del orificio realizado mediante perforación bicónica, es de 3,2 mm, y el exterior de 6,6 $\mathrm{mm}$. El espesor aumenta progresivamente desde el extremo semicircular, donde se sitúa la perforación, hacia el opuesto, donde presenta un plano transversal ligeramente oblicuo. Las dimensiones máximas son las siguientes: $70,3 \times 15,1 \times 9,9 \mathrm{~mm}$. El peso del colgante es de 17,1 gr.

En sus caras laterales presenta profundas incisiones transversales de entre 5 y 6,3 mm, y de $1 \mathrm{~mm}$ de anchura, y paralelas a ellas, otras más finas. Una de las series de estas incisiones está constituida por 8 incisiones transversales que se distribuyen a lo largo de $36 \mathrm{~mm}$, oscilando la distancia entre ellas entre $2 \mathrm{~mm}$ y 9,7 mm. En el lateral opuesto se contabilizan 10 profundos trazos transversales que se distribuyen en $43 \mathrm{~mm}, \mathrm{y}$ oscilando la distancia entre ellos entre $1 \mathrm{~mm}$ y $7,7 \mathrm{~mm}$.

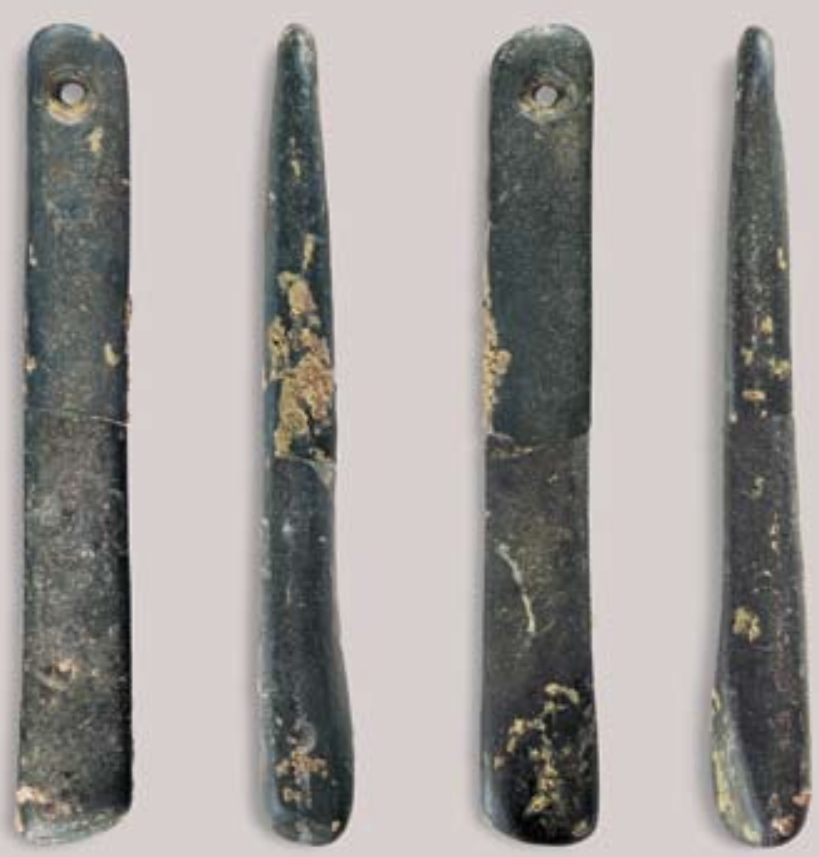

\section{Colgante n 9 (P.A.12F.306.377 + P.A.12F.309.376)}

Esta pieza se localizó bajo el gran bloque que se desprendió del umbral y pared de la entrada a la cavidad. Se halló fracturada en dos trozos.

El soporte es un canto rodado alargado de forma rectangular de aristas paralelas y sección también rectangular (Figs. 13 y 47). Las aristas son redondeadas y

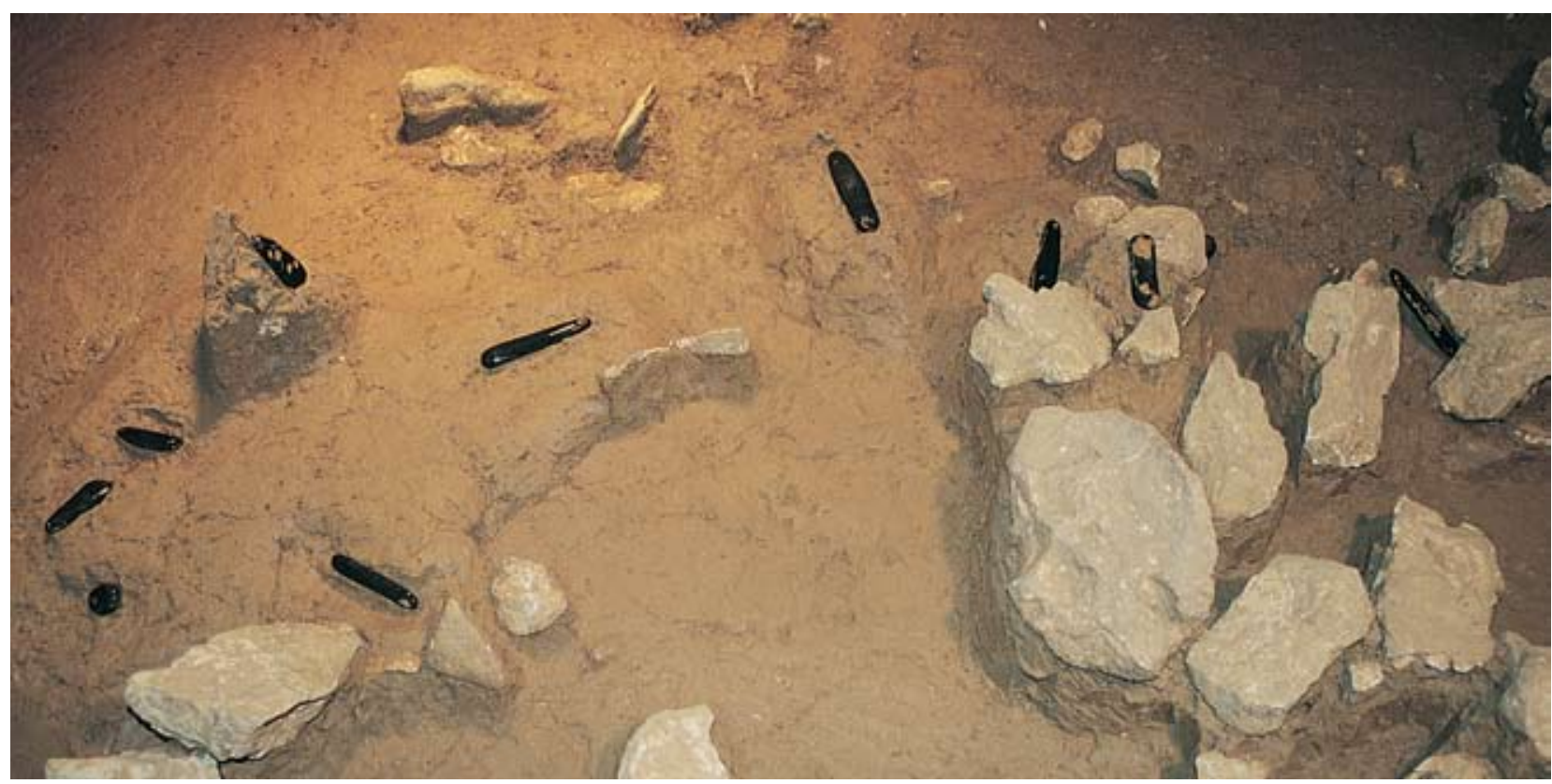

Fig. 14. Agrupación de colgantes en la primera sala interior. / Group of pendants in the first inner room. 
en una determinada zona se aprecian finas incisiones de abrasión. El espesor de los extremos varía notablemente por lo que la perforación se practicó en el extremo más delgado, donde tiene $5,4 \mathrm{~mm}$. El orificio está realizado por rotación bipolar, su diámetro interior es de 3,1 mm y el exterior de 7,7 mm. Las dimensiones máximas del colgante son: $104,5 \times 14,6 \times 12,3 \mathrm{~mm}$ y su peso es de 32,5 gr. Entre los paralelos de esta pieza podemos citar dos ejemplares del yacimiento checo de Býci skála (VALOCH, 1961, 2001).

\section{Colgante $n^{\circ} 10$ (P.A.18E'.336.9)}

Se trata de un pequeño nódulo de color marrón oscuro (Figs. 15 y 48). Su forma es de tendencia oblonga asimétrica y en sus caras mayores presenta una irregular perforación natural alargada; las dimensiones mayores de sus ejes son $6,4 \times 4,5 \mathrm{~mm}$. Sus dimensiones máximas son: $26,2 \times 17,4 \times 12,1 \mathrm{~mm}$. El peso del colgante es de 7,2 gr.

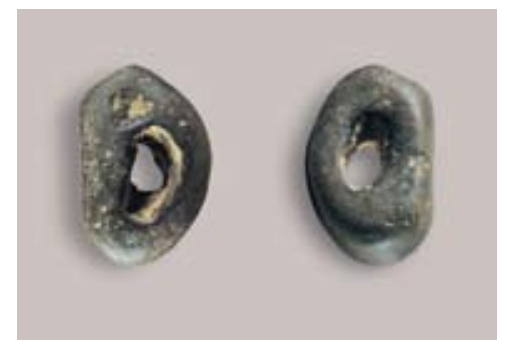

Fig. 15. Colgante $n^{\circ} 10(X$. Otero). / Pendant no. 10 (X. Otero).

\section{Colgante $\mathrm{n}^{\circ} 11$ (P.A.18E'.337-341.7)}

Colgante sobre canto rodado, simétrico y de color negro (Figs. 16 y 49). Su sección es aplanada, y su espesor es mayor en ambos extremos que en la zona central, donde además se produce un ligero estrechamiento. Sus dimensiones máximas son 82,9×21,6×8,2 mm, y su peso es de 28,6 gr.

La perforación se ubica en el extremo más delgado y está realizada por rotación desde ambos lados de la pieza. El diámetro exterior es de $7 \times 7 \mathrm{~mm}$ en una cara y de 7,6x7,6 mm en la opuesta; los diámetros interiores son de $3,3 \times 3 \mathrm{~mm}$ y de $3,6 \times 3 \mathrm{~mm}$, respectivamente.

La decoración se inicia a $17 \mathrm{~mm}$ del extremo perforado y se extiende por ambos bordes laterales y por el extremo proximal a modo de profundas incisiones transversales distribuidas regularmente (aproximadamente 33 agrupaciones), por lo general por pares o en agrupaciones.

\section{Colgante no 12 (P.A.18E'.345.10)}

Canto discoidal que presenta sucesivamente del interior a la superficie exterior distintas capas de color: un núcleo rojizo, capa verduzca y, finalmente, otra de color negruzco (Figs. 17 y 50). Ligeramente descentrada, presenta una perforación natural que la atraviesa y las dimensiones de sus ejes mayores son 7,4x8,4 mm. Las dimensiones máximas de la pieza son las siguientes: $34,5 \times 35 \times 13,1 \mathrm{~mm}$. El peso del colgante es de 21,5 gr.

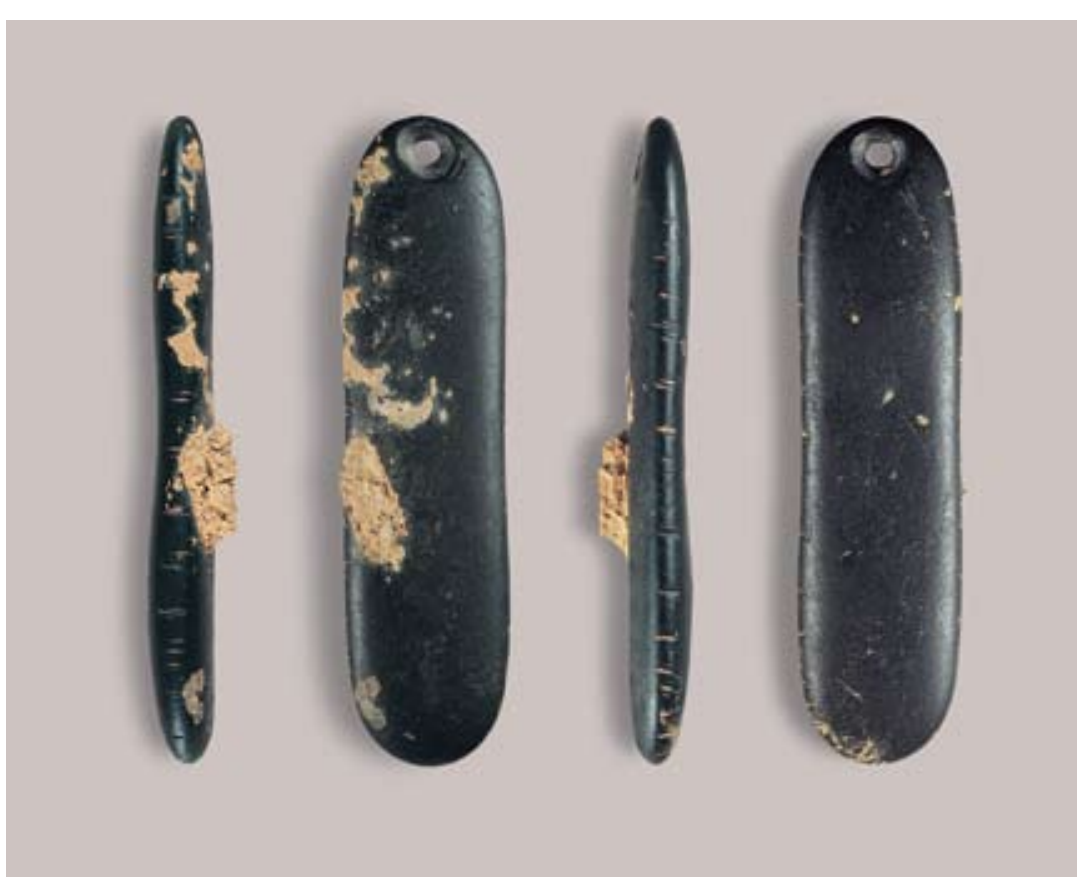

Fig. 16. Colgante $n^{\circ} 11(X$. Otero). / Pendant no. 11 (X. Otero). 


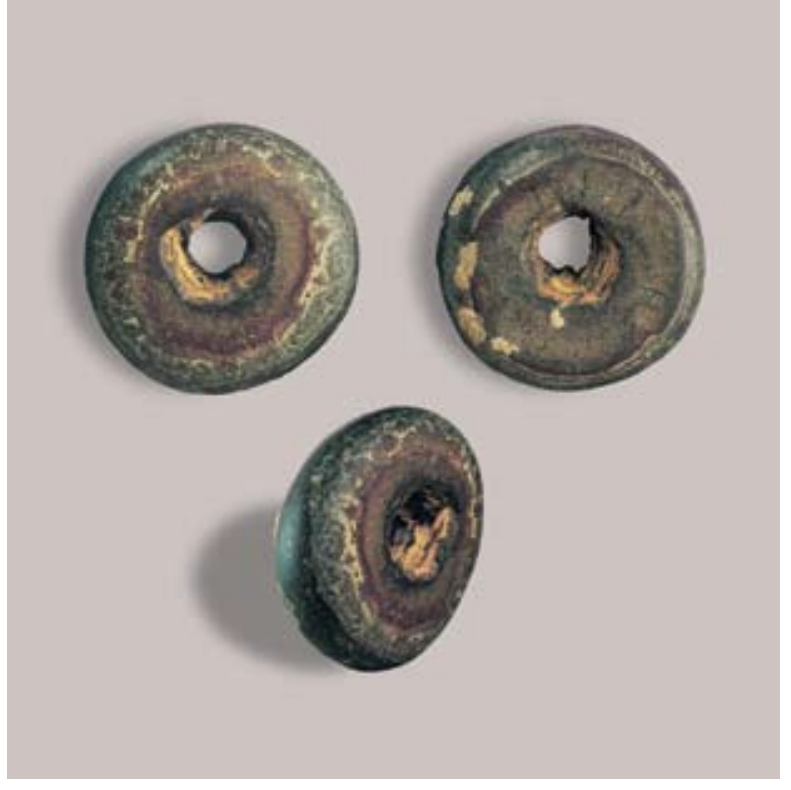

\section{Colgante $n^{\circ} 13$ (P.A.18E'.337.6)}

Canto rodado alargado de silueta ligeramente asimétrica -uno de los bordes laterales es recto y el opuesto suavemente cóncavo- y de color negro (Figs. 18 y 51). Su sección es aplanada. La perforación se sitúa en la zona más delgada, donde además se aprecian dos superficies biseladas de unos $12 \mathrm{~mm}$ de longitud -una en cada cara-, con numerosas líneas de abrasión longitudinales, realizadas con el fin de adelgazar aún más dicho extremo, que tiene una delineación semicircular y pequeños desconchados. Por el contrario, la otra mitad del colgante es ligeramente más gruesa y su extremo es un borde curvo, oblicuo y desviado. Las dimensiones máximas de la pieza son: 63,7×19,2×8,9 mm. El peso del colgante es de 19,4 gr.
Fig. 17. Colgante $n^{\circ} 12$ (X. Otero). / Pendant no. 12 (X. Otero).

El orificio se realizó en tres fases. Se comenzó el proceso abrasionando las superficies con el fin de adelgazar la zona de la perforación (su grosor pudo disminuir de unos 5,4 mm a 2,3 mm), y se prosiguió preparando la zona donde realizar el agujero (se conservan una serie de incisiones longitudinales en el límite de la perforación) con el fin de centrar el punto en el que trabajar, y finalmente, se actuaría mediante rotación. El orificio es asimétrico, y tiene un diámetro exterior de 4,7×6,1/6x6 mm e interior de 2,6×2,3/2,3×2,4 mm. En él se diferencian dos sectores bien definidos debido a los distintos gestos y orientación durante el proceso de fabricación: uno vertical, en el lado más extremo del orificio, y otro más oblicuo hacia el interior.

A $14 \mathrm{~mm}$ del extremo perforado se inicia la decoración, consistente en incisiones transversales regularmente dispuestas (23 agrupaciones) a lo largo de los bordes laterales y del extremo basal. La mayoría se disponen muy prietas formando agrupaciones (a veces pares, con rectificaciones) aumentando la distancia existente entre ellas al aproximarnos al extremo inferior, donde hay una agrupación de tres incisiones, otra de dos y, finalmente, otra aislada.

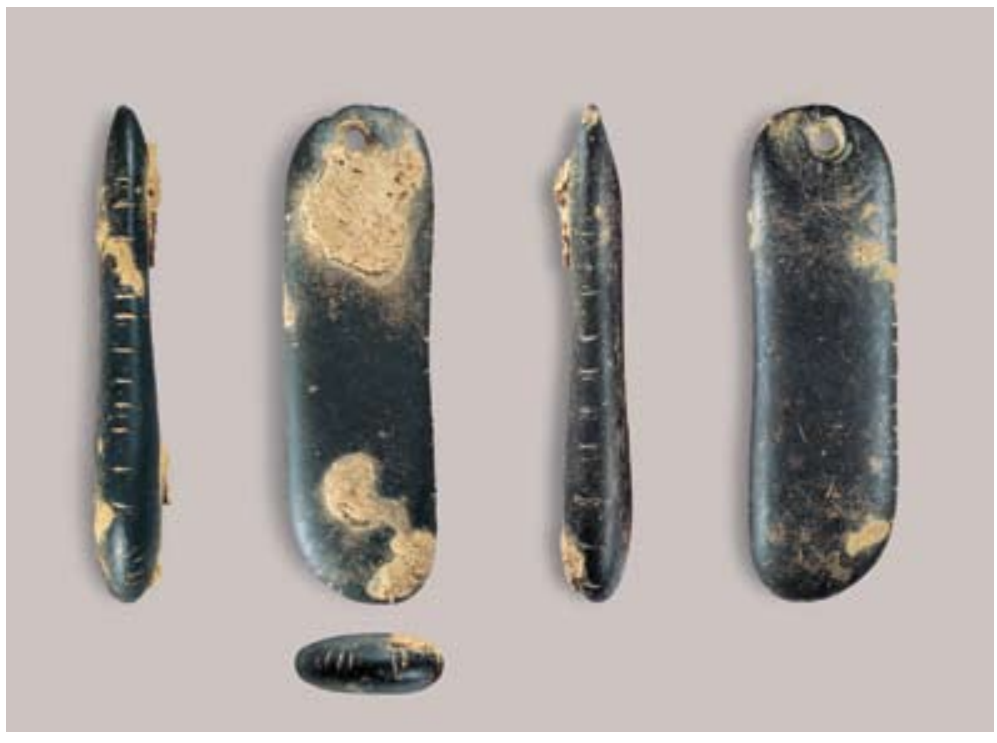

Fig. 18. Colgante $n^{\circ} 13$ (X. Otero). / Pendant no. 13 (X. Otero). 


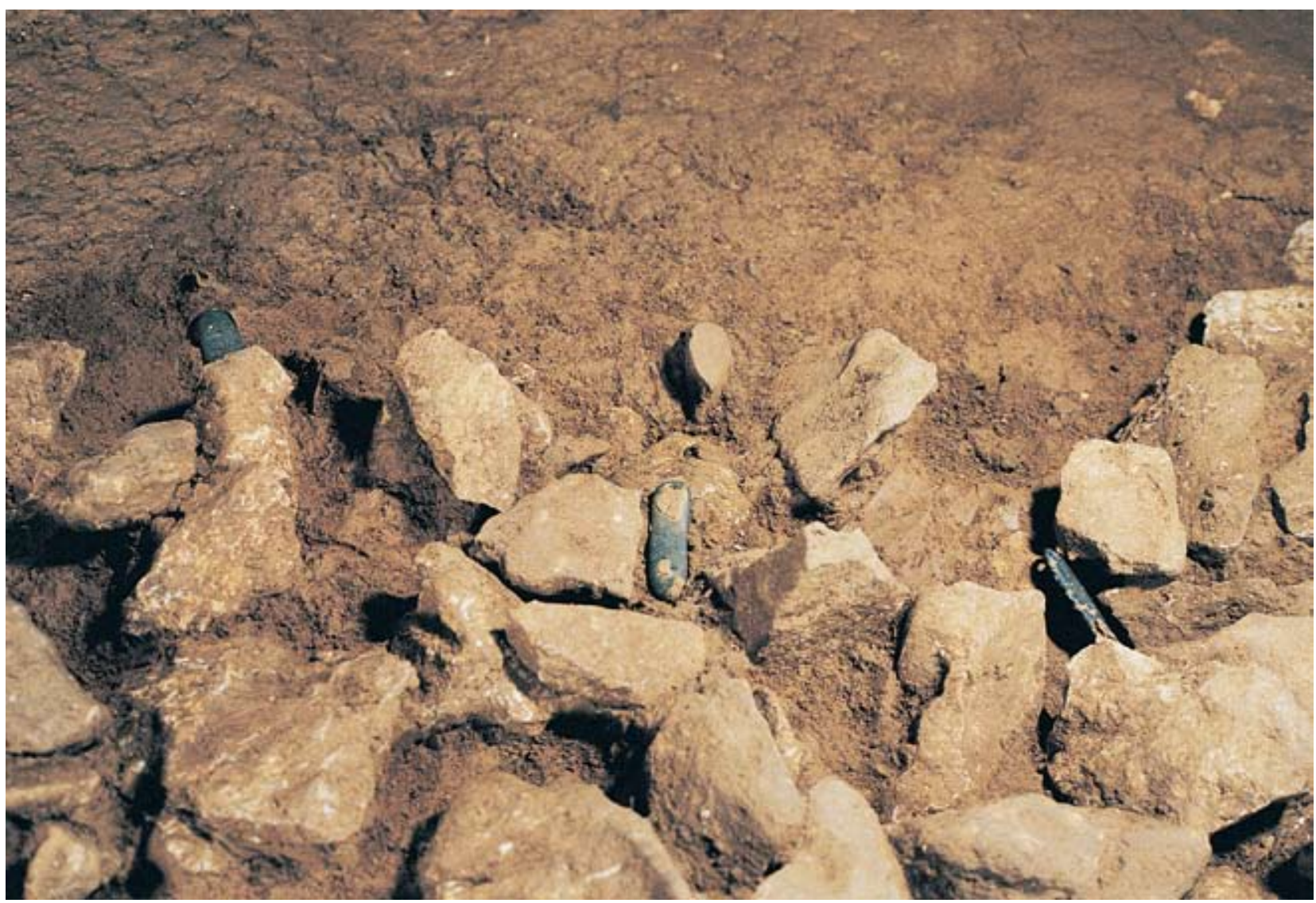

Fig. 19. Detalle de la aparición de varios de los colgantes (X. Otero). / Detail of the appearance of some of the pendants (X. Otero).

\section{Colgante nº 14 (P.A.18E'.342.3)}

Canto rodado alargado de forma asimétrica, de sección aplanada y de color negro. La perforación se sitúa en el extremo redondeado, más estrecho y delgado, que además ha sido abrasionado ligeramente por sus dos caras mayores, una de ellas ligeramente cóncava, mientras que la opuesta es convexa. El extremo opuesto termina en un plano recto transversal, ligeramente oblicuo al eje mayor. Sus dimensiones son $77,1 \times 21,5 \times 7,8 \mathrm{~mm}$, y el peso es de 24,5 gr (Figs. 20 y 52).
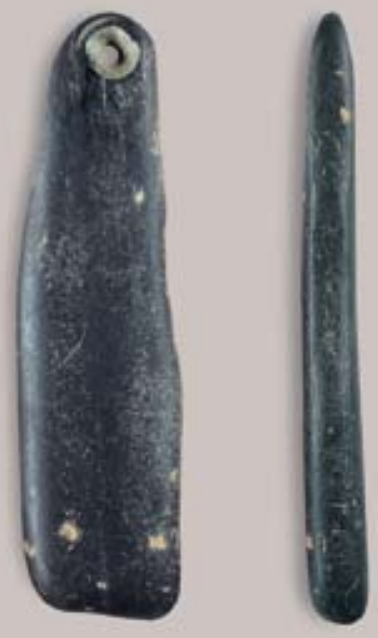

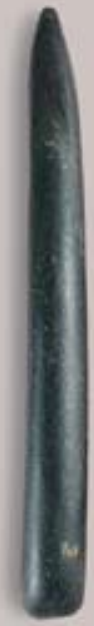

Fig. 20. Colgante $n^{\circ} 14(X$. Otero). / Pendant no. 14 (X. Otero). 
Los bordes laterales son también asimétricos, uno de ellos es sinuoso, mientras que el opuesto es de tendencia convexa y se estrecha ligeramente hacia la base y notablemente hacia el extremo perforado

El orificio es asimétrico, su diámetro exterior es de $7,3 \times 7,3 / 6,9 \times 6,7 \mathrm{~mm}$ y el interior de $2,4 \times 2,2 \mathrm{~mm}$. Se realizó probablemente en dos fases, y se distinguen dos sectores bien definidos como consecuencia de los distintos gestos y ángulo de ataque.

La cara cóncava del colgante está decorada con finas incisiones ligeramente oblicuas, algunas de ellas agrupadas por parejas, insinuando estrechas bandas. En el tercio inferior de uno de los laterales, ligeramente cóncavo, presenta incisiones transversales y regularmente distanciadas, que continúan en la zona media, siendo aquí muy prietas, pero apenas visibles.

\section{Colgante $n^{\circ} 15$ (P.A.18E'.339.8)}

Colgante sobre canto rodado alargado de forma bastante simétrica y de color negro (Figs. 21 y 53). Sus dimensiones son 97,5x22,7×9,2 mm, y su peso de 33,7 gr. Su sección es muy aplanada y en uno de los extremos muestra una perforación circular bicónica ligeramente asimétrica. Su diámetro exterior es de $7 \mathrm{~mm}$ y el interior de $3,5 \mathrm{~mm}$. Está fabricada en dos fases, en la primera se preparó el punto a perforar y a continuación se realizó por rotación.

Es el ejemplar más decorado del yacimiento. En la arista lateral más convexa, entre el extremo basal y el inicio de la convexidad, en $35 \mathrm{~mm}$, se observan 12 trazos desiguales ligeramente oblicuos. Por otra parte, en la zona medial del lado opuesto, en $38 \mathrm{~mm}$, hay otras 14 agrupaciones de trazos transversales bien marcados y regularmente distanciados; en las 10 inferiores hay otras líneas paralelas de rectificación o de fuga del instrumento.

Las caras mayores también estuvieron decoradas, al parecer con similar motivo, pero en una de ellas son difícilmente visibles, quizás por haberse ido desvaneciendo por su fricción con la vestimenta. En la cara mejor conservada se aprecian 20 fajas transversales paralelas, de entre 2 y $4 \mathrm{~mm}$ de altura variable y una anchura de $14 \mathrm{~mm}$. Se alternan las bandas lisas y decoradas, pero no de forma sistemática. Las tres superiores son lisas y a continuación hay una faja decorada con incisiones oblicuas orientadas del lado inferior izquierdo al superior derecho; tras ella hay dos bandas lisas, y otra con incisiones oblicuas entrecruzadas que organizan un somero motivo en retícula.

Ya en la zona media, se suceden tres fajas con un motivo en retícula, que están separadas entre sí por fajas lisas sin delimitar de forma neta, y a continuación otras tres separadas por otras tantas bandas estrechas lisas.

Finalmente, se prosigue con dos bandas lisas de desigual anchura y otra decorada con incisiones oblicuas orientadas del lado inferior izquierdo al superior derecho. En definitiva, en esta cara se han realizado una serie de incisiones a distancias variables que organizan bandas perpendiculares paralelas, intercalándose irregularmente las lisas y las decoradas. Entre éstas, las bandas rellenas

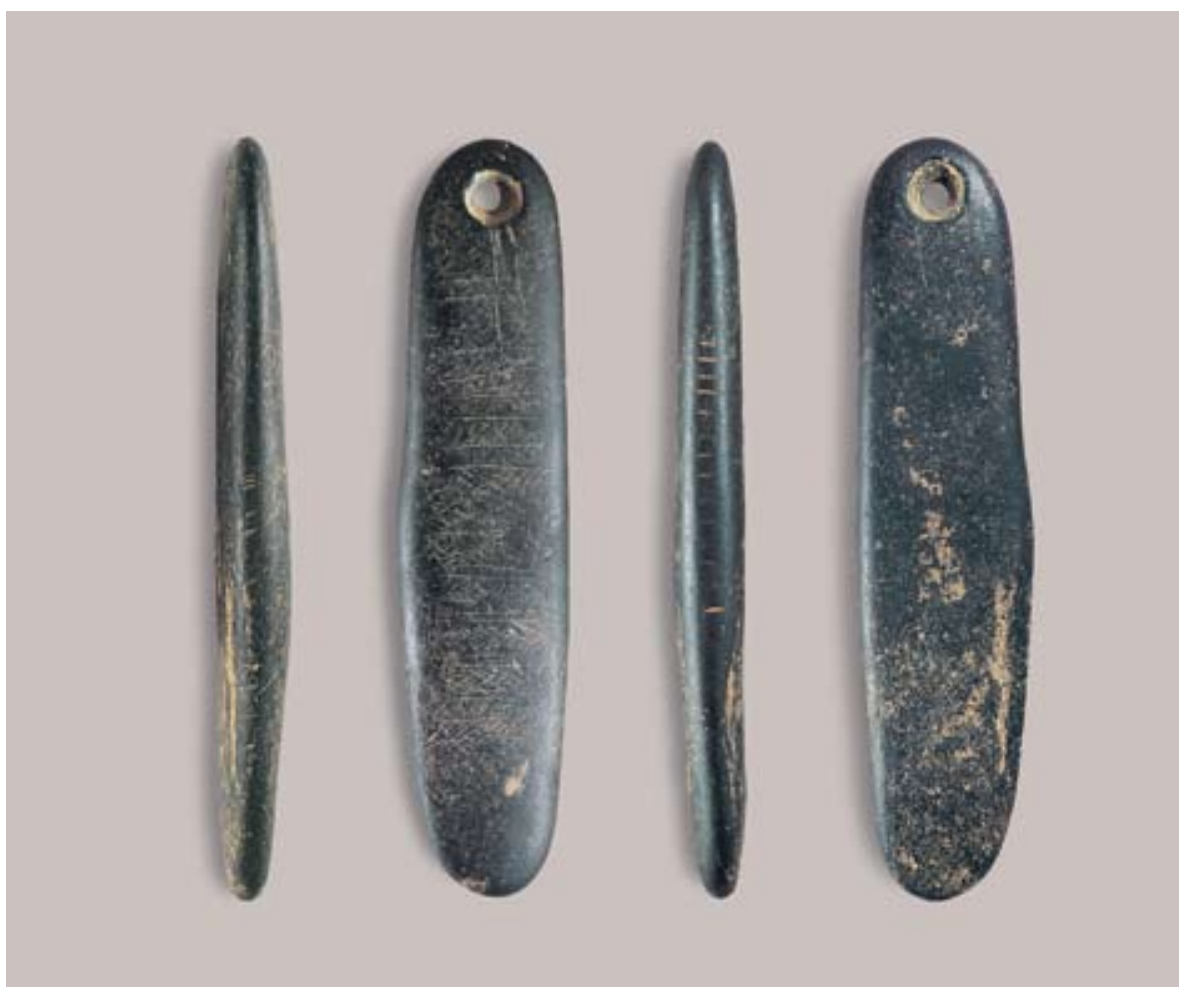

Fig. 21. Colgante $\mathrm{n}^{\circ} 15$ (X. Otero). / Pendant no. 15 (X. Otero). 
con líneas oblicuas paralelas se sitúan en los extremos, y las que tienen un motivo en retícula en las restantes, separadas entre si por una o dos bandas lisas.

Entre otros paralelos podemos destacar, por las características del soporte y por su decoración, un canto de esquisto procedente de Le Placard $-n^{\circ} 54940-$ de $15,1 \times 4 \mathrm{~cm}$, que muestra en el extremo más delgado y estrecho una ranura en diábolo. En las dos caras mayores cuenta con incisiones transversales muy próximas entre sí, que en algunas zonas son cruzadas por otras oblicuas que organizan un reticulado con motivos romboidales. En este colgante, como en los ejemplares de Praileaitz I el lugar del que se suspende se ubica en el extremo más delgado y el opuesto es un plano oblicuo (CHOLLOT-VARAGNAC, 1980). Este objeto de Le Placard es interpretado por A. Marshack como una silueta antropomorfa aprovechando las formas naturales (BARANDIARÁN, 2006).

Los motivos reticulados en el arte mobiliar paleolítico son relativamente frecuentes y se interpretan de diferente manera, unas veces como simple motivo no figurativo, como en el retocador lítico de Las Caldas del Solutrense Medio, o en una plaqueta de pizarra procedente de una ocupación del Magdaleniense Medio de La Paloma (CORCHÓN, 1994). Sin embargo, otras veces representa elementos o caracteres significativos de algunos animales: escamas de serpiente en Isturitz -SAINT-PÉRIER, 1936- y de pez en el Magdaleniense Final del Pendo -BARANDIARÁN, 1973-, el plumaje de las aves de La Madeleine -CRÉMADES, 1990-, e incluso el pelo de los mamíferos (uro del paleolítico terminal de La Borie-del-Rey, en un caballo de Pont-d'Ambon grabados sobre placas óseas (ROUSSOT, 1990; BARANDIARÁN, 2006).

En la región pirenaica podemos citar una lasca extraída de un canto, procedente del Magdaleniense Superior de Lortet, que muestra una retícula irregular $(\mathrm{CHO}$ LLOT, 1964, n 47268). También hay óvalos rellenos con líneas oblicuas que se entrecruzan formando retícula de rombos (a veces además encuadrada con otros motivos), sobre distintos soportes: en un bastón perforado y en dos esquirlas óseas de Laugerie-Basse $-n^{\circ}$ 53.951, 53.777; 56.772-, en dos láminas óseas de Marsoulas -n 50.973, 50.972A-, en láminas óseas de alisador cubriendo la mitad de una de sus caras - Le Placard, $n^{\circ} 55.182-$, sobre varillas en Mas d'Azil y Gourdan $-n^{\circ}$ 48602, 47574B, etc. (CHOLLOT-VARAGNAC, 1980). Un alisador del Magdaleniense de Isturitz, fabricado sobre una lámina de costilla, muestra sobre la superficie dorsal dos estrechas bandas paralelas de reticulados romboidales (PASSEMARD, 1944).

\section{Colgante no 16 (P.A.18E'.347.11)}

Canto rodado alargado de color negro y sección subtriangular perforado en el extremo más delgado, en el que previamente a la perforación se prepararon las superficies por abrasión, conformando dos planos a modo de biseles (Figs. 22 y 54). El orificio, bicónico, está realizado por rotación. Su diámetro exterior es de $5 \mathrm{~mm}$ y el interior de 2,2 $\mathrm{mm}$. Las dimensiones del colgante son $68,8 \times 18,8 \times 9,2 \mathrm{~mm}$, y su peso de 18,4 gr.

En la parte más próxima a la perforación de una de las aristas del lado recto se observan, a lo largo de 23 $\mathrm{mm}, 6$ profundas y cortas incisiones transversales y regularmente dispuestas. A continuación, en la otra mitad, muestra otras 8 cortas incisiones agrupadas y menos profundas en $18 \mathrm{~mm}$. En el lado paralelo, que es ligeramente convexo en el tercio opuesto a la perforación, presenta a lo largo de $55 \mathrm{~mm} 13$ trazos perpendiculares al eje regularmente distanciados.

\section{Colgante no 17 (P.A.18E'.340.2)}

Colgante sobre canto rodado alargado, aplanado y de color negro que se engrosa y ensancha progresivamente

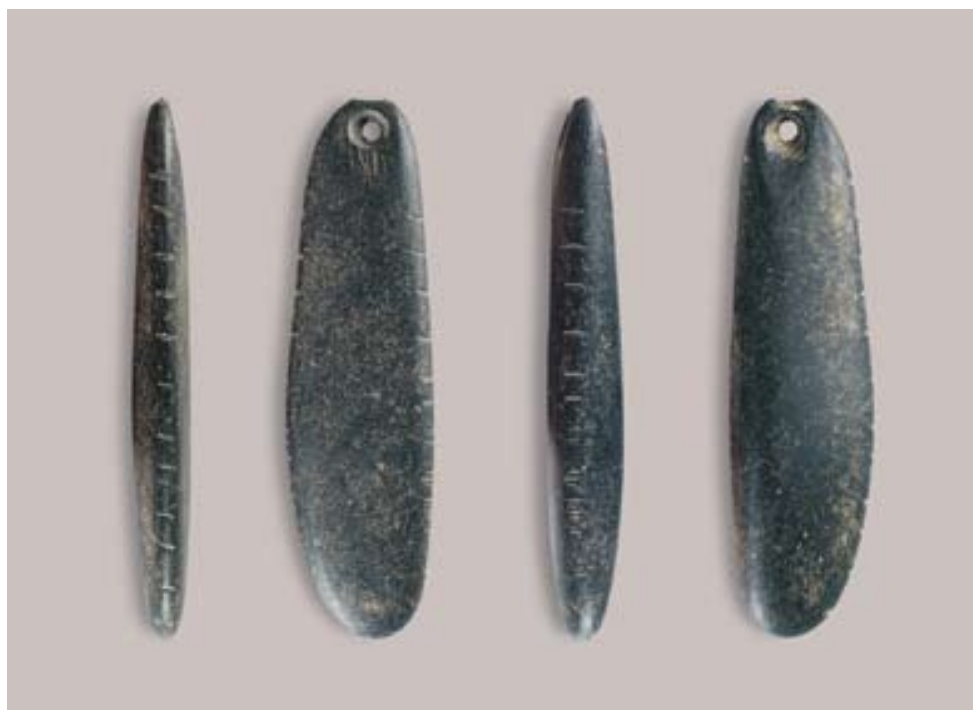

Fig. 22. Colgante $n^{\circ} 16$ (X. Otero). / Pendant no. 16 (X. Otero). 
Fig. 23. Colgante $n^{\circ} 17$ (X. Otero). / Pendant no. 17 (X. Otero).

de un extremo al otro. Sus dimensiones son $87,1 \times 17,5 \times 10,5 \mathrm{~mm}$, y su peso de $26,8 \mathrm{gr}$ (Figs. 23 y 55).

Como en los otros ejemplares la perforación bicónica, asimétrica, se localiza en el extremo más estrecho. En ella se definen dos partes diferenciadas por el distinto ángulo con el que se incide al perforar. Junto al orificio se observa una agrupación de pequeñas depresiones puntiformes. El diámetro exterior de la perforación es de 9x6,7/9x7,2 mm y el interior de 2,8x2,9 mm.

En una de las caras mayores, a $30 \mathrm{~mm}$ del extremo, presenta 9 finas incisiones oblicuas, regularmente distanciadas y tres más hacia el extremo perforado. Un par de incisiones más se prolongan ligeramente hacia el borde lateral. Uno de éstos no presenta decoración, y en el opuesto se repiten incisiones ligeramente oblicuas, observándose tres profundas y anchas en el extremo inferior y otras cuatro agrupaciones de líneas de diferente profundidad que llegan aproximadamente a la misma altura que las de una de las caras mayores.

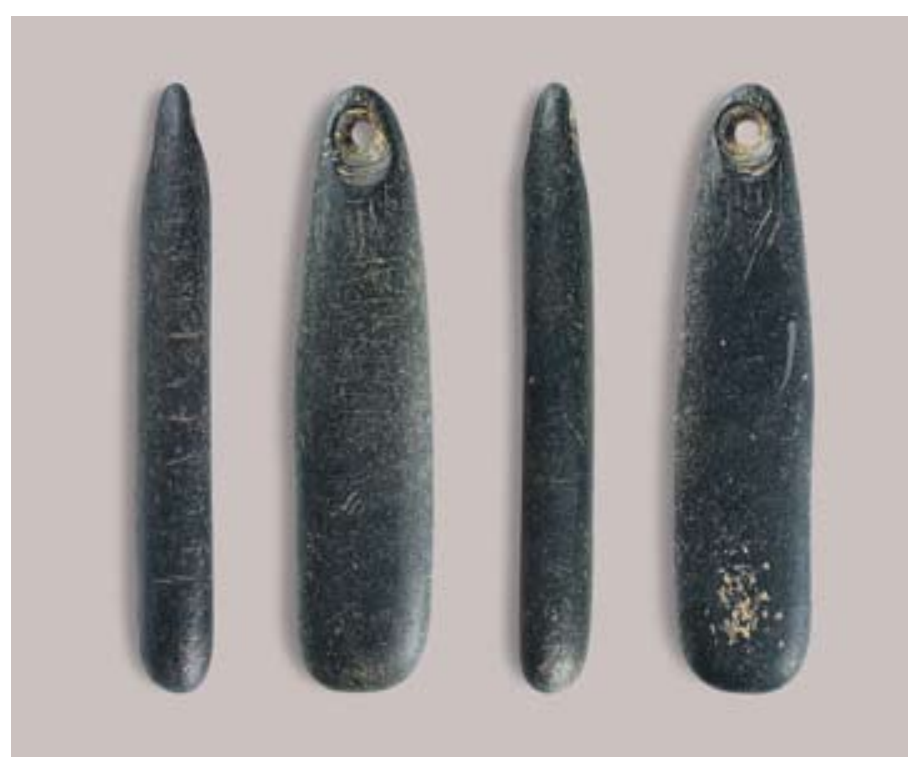

\section{Colgante no 18 (P.A.18D'-18E'.347.12)}

Colgante sobre canto rodado de color negro alargado y sección aplanada. El extremo más estrecho y delgado está perforado (Figs. 24 y 56). Aquí se aprecian líneas longitudinales de abrasión, así como pequeños orificios con el fin de preparar la superficie en la que incidir y perforar. El orificio bicónico está realizado por rotación, y en él se observan incisiones circulares concéntricas. Su diámetro exterior es de $7 \mathrm{~mm}$ y el interior de $3,2 \mathrm{~mm}$. Las dimensiones del colgante son $77,8 \times 17,8 \times 9,7 \mathrm{~mm}$ y su peso de 25,3 gr.

La pieza está decorada con incisiones transversales, profundas y regularmente distanciadas en una de las caras mayores. Estas 17 incisiones se disponen en $47 \mathrm{~mm}$, de las cuales 12 se quiebran formando amplios motivos angulares asimétricos. En uno de los laterales se aprecian dos incisiones oblicuas paralelas y en el opuesto 10 regularmente distanciadas, a veces dobles paralelas por rectificaciones o fuga. En algún caso hay agrupamientos de incisiones cortas transversales.

Finalmente, cabe señalar que en el extremo opuesto a la perforación, en una de las caras mayores y en uno de sus lados, se observan pequeñas melladuras en una cúpula de unos 10x8 mm por su uso a modo de retocador-compresor (BEAUNE, S.A. DE, 1997).

Fig. 24. Colgante $n^{\circ} 18$ (X. Otero). / Pendant no. 18 (X. Otero). 


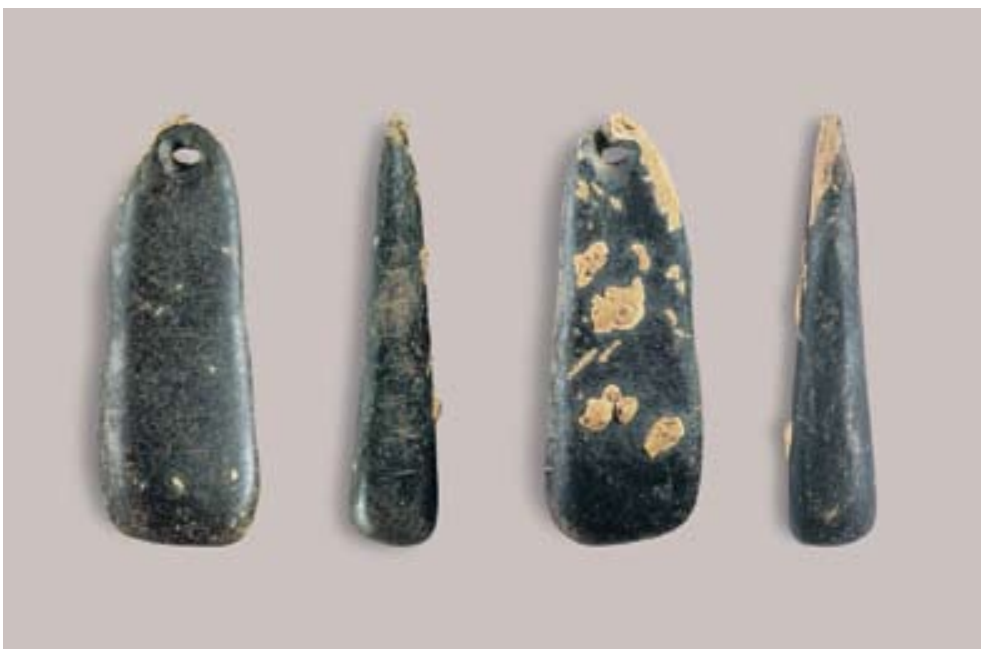

Fig. 25. Colgante $n^{\circ} 19$ (X. Otero). / Pendant no. 19 (X. Otero).

\section{Colgante n' 19 (P.A.18E'.336.4)}

Colgante sobre canto rodado de color negro. El extremo perforado es más apuntado y menos espeso, mientras que el opuesto se engrosa y ensancha notablemente, acabando en un plano perpendicular al eje longitudinal. Los bordes laterales son ligeramente sinuosos, uno de ellos de tendencia recta, y convexo el opuesto. Sus dimensiones máximas son: 55×20,9×11,5 mm. Su peso es de 19,1 gr (Figs. 25 y 57).

La perforación, de tipo bicónico, es irregular, asimétrica y perpendicular al eje longitudinal. Como en otros colgantes está elaborada en dos fases. En la primera se realizaron incisiones que convergían en la zona que posteriormente sería perforada por rotación. Su diámetro exterior es de 7,3×5,4 mm en una cara y de 5,6×5,6 mm en la opuesta, mientras que el diámetro interior es de $3,3 \times 1,8 \mathrm{~mm}$.

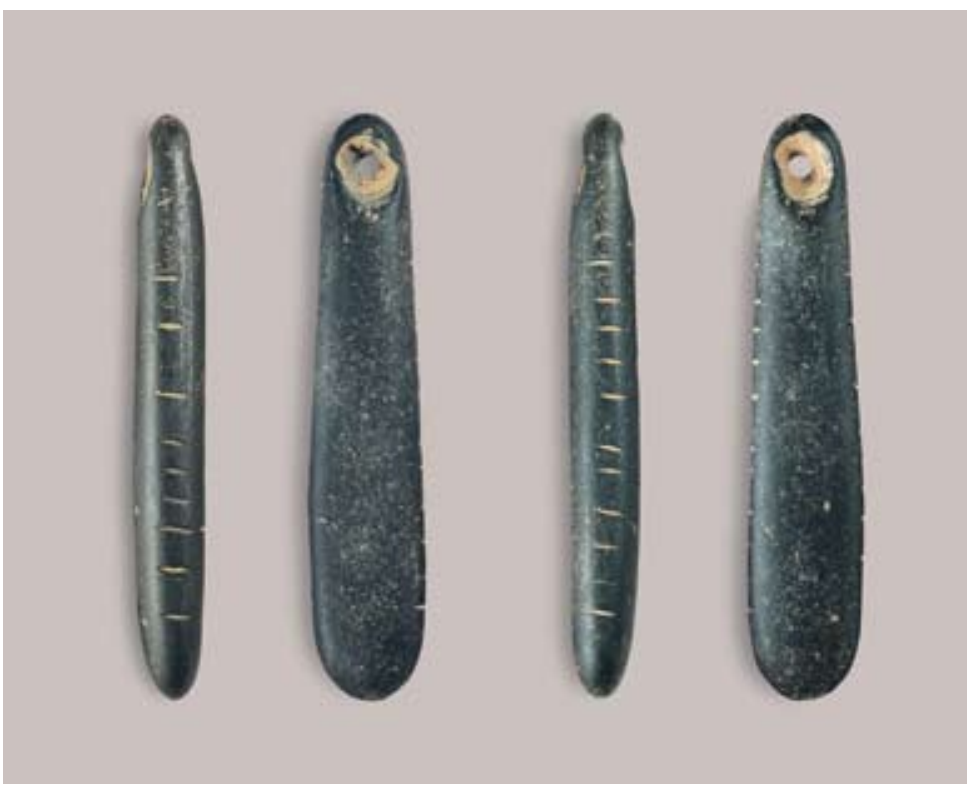
lateral son más profundas y anchas, y no llegan a entrar en contacto con las de la cara mayor, existiendo junto a ellas incisiones paralelas o divergentes originadas por rectificaciones o fugas. Presenta abundantes restos de concreción en una de sus caras.

\section{Colgante n' 20 (P.A.18E'.343.5)}

Canto rodado alargado de color negro, de extremos redondeados, y perforado en el más estrecho de ambos (Figs. 26 y 58). No se observan huellas de abrasión anteriores a la perforación, aunque en su periferia se aprecian restos de un pequeño piqueteado, probablemente relacionado con la preparación de la superficie a perforar. En el orificio, de tipo bicónico, se aprecian diferencias en el ángulo de ataque al rotar. Su diámetro exterior es de 9,2x7,2/9,2x6,3 mm y el interior de 3,1x2,6 $\mathrm{mm}$. Las dimensiones del colgante son $74,8 \times 14,8 \times 9,1 \mathrm{~mm}$, y su peso 18,5 gr.

La decoración, a base de cortos trazos transversales (de $4 \mathrm{~mm}$ ) más o menos regularmente dispuestos (entre 3,2 y $8 \mathrm{~mm}$ ), se centra en los bordes laterales, aunque sin alcanzar los extremos donde se aprecia un pequeño intervalo reservado. En uno de los lados, se contabilizan 11 incisiones transversales regularmente distanciadas, además de una rectificación, en un espacio de 43,7 mm. En el opuesto, se han realizado 9, además de al menos 3 cortas y menos profundas en $42 \mathrm{~mm}$.

Fig. 26. Colgante $n^{\circ} 20$ (X. Otero). / Pendant no. 20 (X. Otero). 


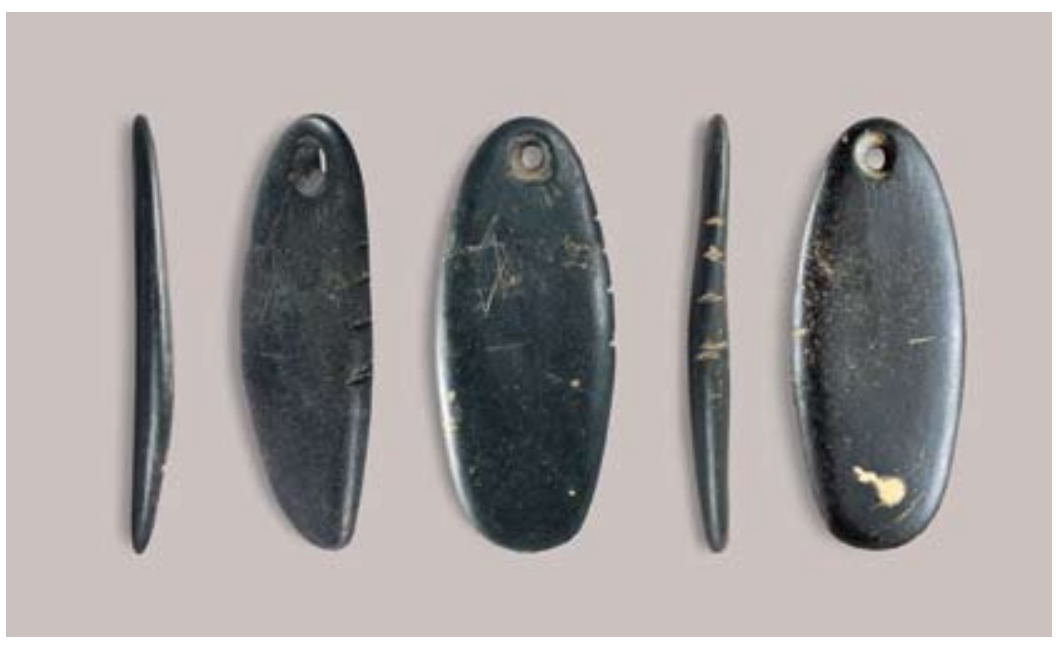

\section{Colgante $n^{\circ} 21$ (P.A.18D'.343.3)}

Colgante sobre canto rodado de color negro (Figs. 27 y 59). Su sección es muy aplanada, y su mayor espesor se localiza en la zona medial (5,6 mm), adelgazándose hacia los extremos, donde tiene aproximadamente 3,3 $\mathrm{mm}$. Sus dimensiones son $55,4 \times 23,2 \times 5,6 \mathrm{~mm}$ y su peso de $11,8 \mathrm{gr}$.

En su fabricación se repiten esquemas observados en otros ejemplares. En el extremo más delgado y estrecho se ubica ligeramente descentrado el orificio de tipo bicónico, que se ha efectuado en dos fases. Inicialmente, trataron de incidir sobre un punto realizando pequeñas incisiones longitudinales para, a continuación, profundizar mediante rotación. Las huellas de esta actividad se aprecian con claridad. Su diámetro exterior es de 5,5x6,7 $\mathrm{mm}$ en una cara y de $4,5 \times 5,7 \mathrm{~mm}$ en la otra, y el diámetro interior es de 2,5×2,7 mm.

En la cara convexa del canto, que tiene una forma abarquillada, se aprecia una especie de rombo de 10×3,5 $\mathrm{mm}$, realizado con dos cortas y finas incisiones paralelas que dos más profundas las cortan en sus extremos. Por otra parte, en una de las aristas laterales del canto, en unos $16,5 \mathrm{~mm}$ entre el inicio de la perforación y la mitad del borde lateral se aprecian cinco profundas incisiones (una de ellas, una posible rectificación). Desde dos de dichas incisiones parten varias finas líneas longitudinales paralelas que se prolongan en la cara cóncava del canto.

Fig. 28. Colgante $n^{\circ} 22$ (X. Otero). / Pendant no. 22 (X. Otero).
Fig. 27. Colgante $n^{\circ} 21$ (X. Otero). / Pendant no. 21 (X. Otero).

\section{Colgante nº 22 (P.A.18D'.342.4)}

Colgante sobre canto rodado aplanado, de color negro, y perforado en el extremo más apuntado y menos voluminoso (Figs. 28 y 60). El extremo opuesto es más abultado, como sucede en los otros colgantes, produciéndose un notable ensanchamiento, evocando a lo que sucede en los caninos atrofiados. Sus dimensiones son $59,1 \times 20,1 \times 9,1$ mm y su peso de 17,6 gr.

El orificio bicónico se ubica en el extremo más delgado, que ha sido adelgazado mediante abrasión longitudinal de las dos caras hasta crear sendas superficies biseladas. A continuación, la perforación, al igual que en los otros colgantes, se ha realizado en dos fases. En la primera se practicaron una serie de incisiones, de las cuales se conservan unos pocos restos que convergen en la zona que sería posteriormente perforada por rotación. El diámetro exterior de la perforación es de 5,6×4,7 $\mathrm{mm}$ en uno de sus lados y de 5,5×5,5 mm en el opuesto, mientras que el diámetro interior es de 2,3×2,5 mm.

La decoración consiste en profundas incisiones transversales ligeramente curvadas que se disponen a lo largo de un lateral y en el extremo más ancho del colgante. La distribución de las incisiones es diferente según la zona, más espaciadas y netas en ambos extremos (a una distancia de 5,5 mm entre sî) y más próximas o agrupadas en el tercio medio.

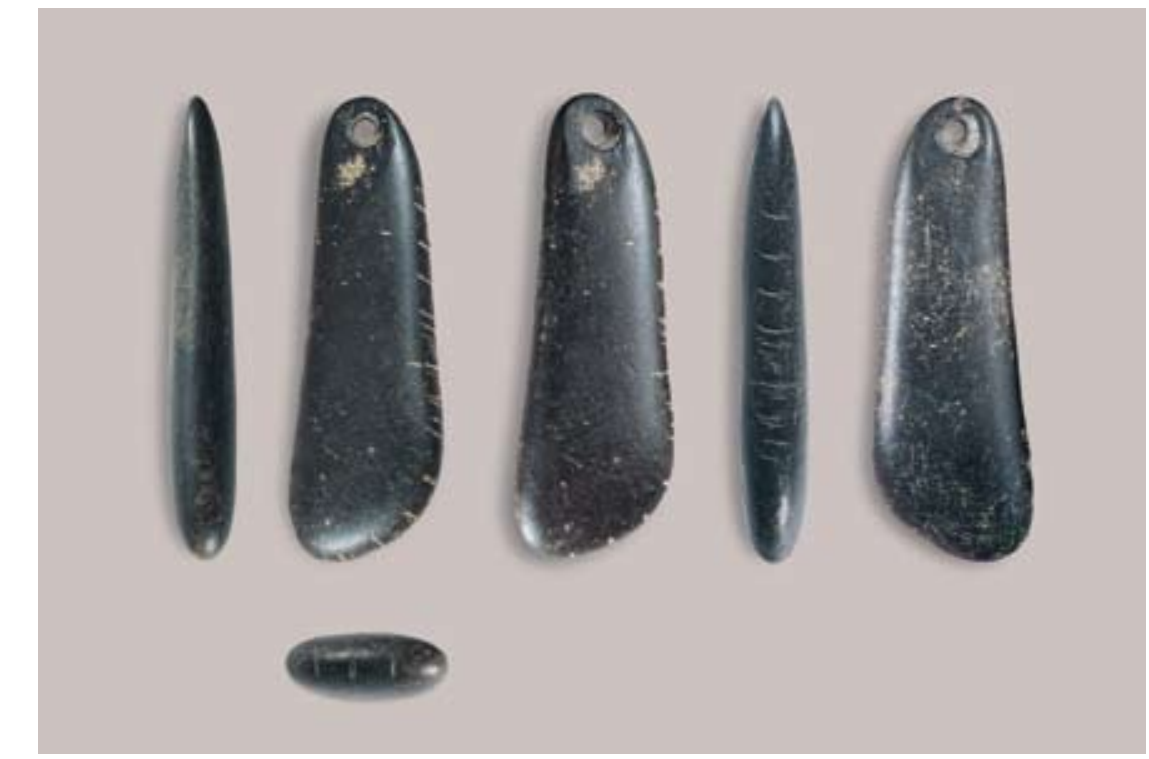



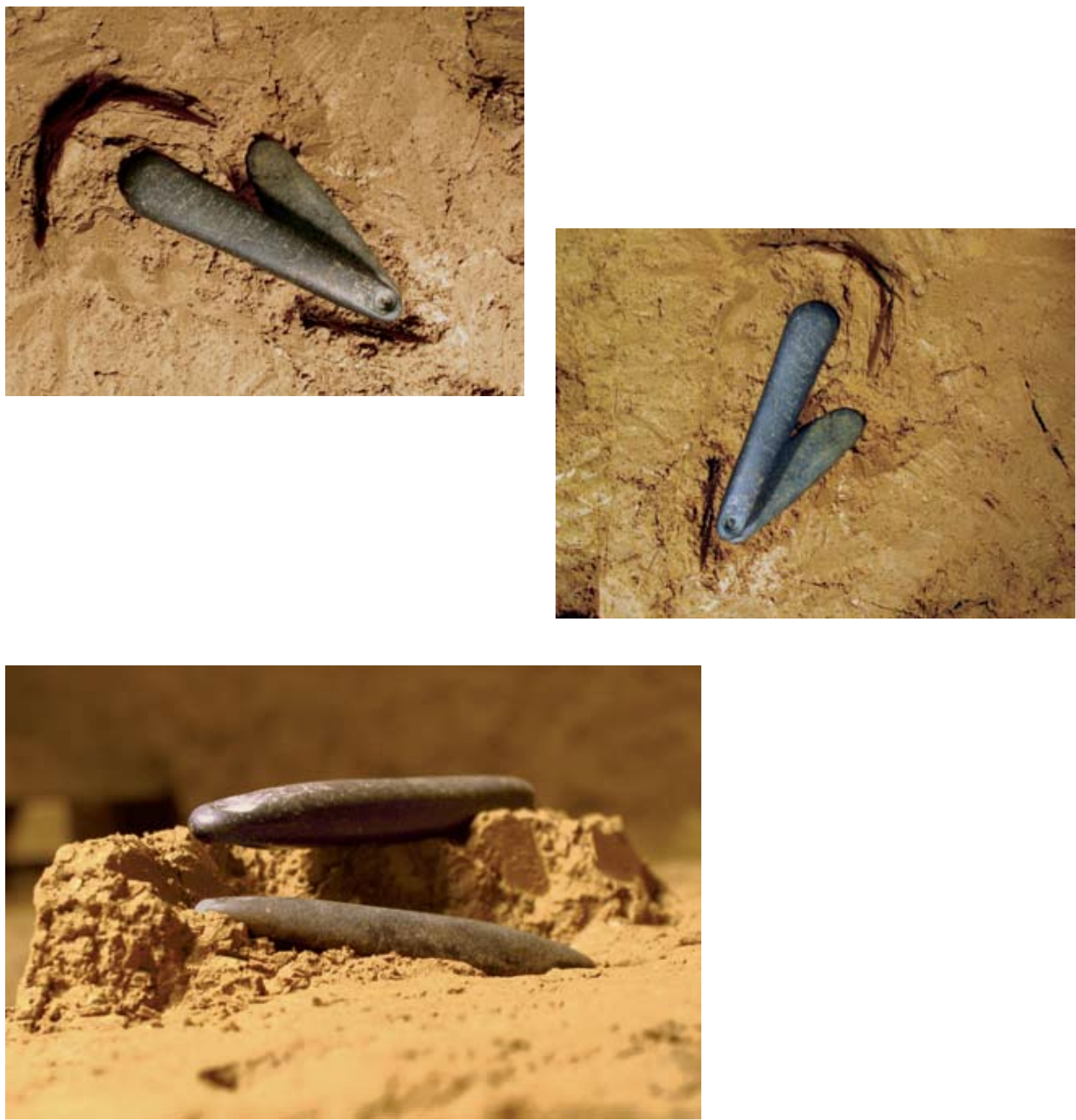

Figs. 29-32. Superposición de dos colgantes del conjunto de 14 piezas (n. 16 and 17). / Superposition of two pendants from the group of 14 pieces (no. 16 and 17).

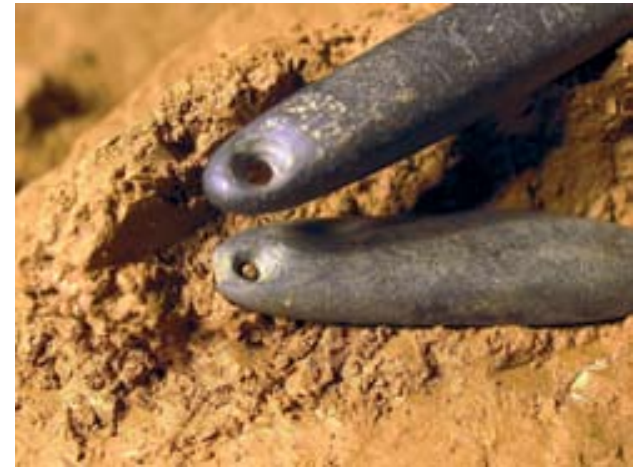




\section{Colgante $n^{\circ} 23$ (P.A.18D'.344.5)}

Nódulo de limonita de color negro con forma tendente a globular alargada, y que recuerda ligeramente a un canino atrofiado. Sus caras mayores son planas y presentan una perforación natural de aproximadamente $4,1 \times 4 \mathrm{~mm}$, que atraviesa la pieza. Las dimensiones máximas del colgante son $29,2 \times 20,1 \times 13,5 \mathrm{~mm}$ y su peso $10,1 \mathrm{gr}$ (Figs. 33 y 61 ).

\section{Colgante n 24 (P.A.14F'.349.2)}

Se trata de un grueso canto rodado alargado y de sección subtriangular, que en su extremo más estrecho

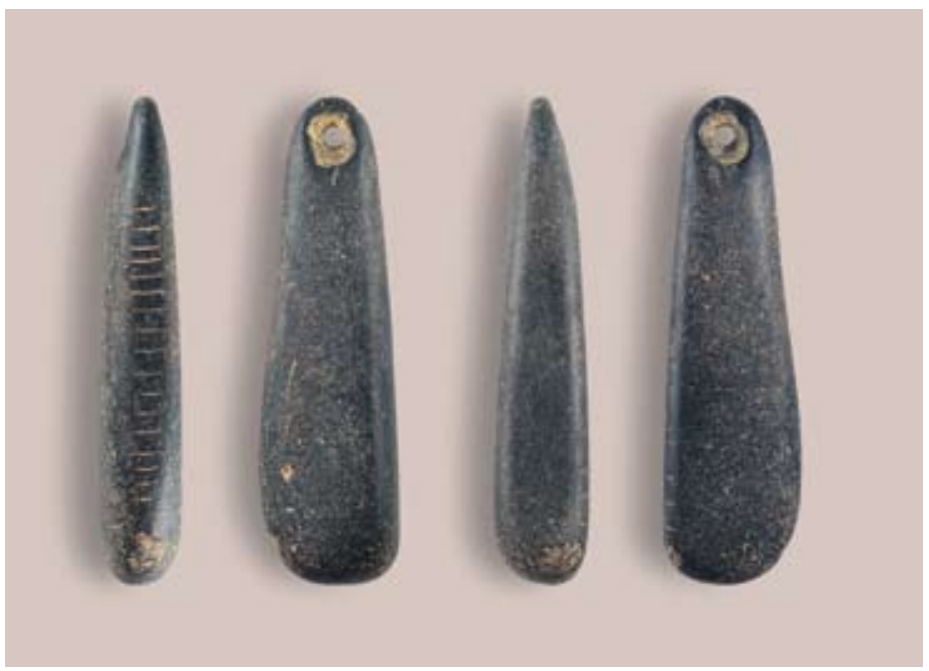

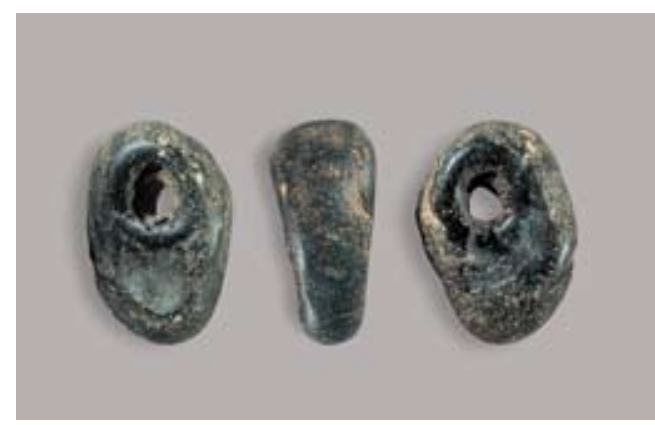

Fig. 33. Colgante $n^{\circ} 23$ (X. Otero). / Pendant no. 23 (X. Otero).

una roca blanca, por lo que su estado de conservación es deficiente. El proceso de perforación recuerda al observado en el colgante 17 y presenta en ambos laterales cortas incisiones perpendiculares regularmente dispuestas (GONZÁLEZ SÁlNZ: 2003). Otro ejemplar, en estudio, a señalar sería el colgante liso de cronología gravetiense hallado por en el yacimiento al aire libre de Irikaitz (Zestoa) (ARRIZABALAGA, IRIARTE, 2011).

\section{Colgante $n^{\circ} 25$ (P.A.14F'.347.3)}

Pequeño canto oblongo asimétrico de color negro, que presenta una gran perforación natural irregular alargada de $17 \mathrm{~mm}$ de longitud y 9 de anchura (Figs. 35 y 63). Las dimensiones de la pieza son: 51,6×26x19,6 mm. Su peso es de 26,9 gr.

Fig. 34. Colgante $n^{\circ} 24$ (X. Otero). / Pendant no. 24 (X. Otero).

y delgado muestra una perforación realizada por rotación bipolar (Figs. 34 y 62). El orificio es ligeramente ovalado, siendo su diámetro exterior de aproximadamente $8,0 \times 5,7 \mathrm{~mm}$ y el interior de 3,1 mm. Las dimensiones completas son $62,4 \times 20,6 \times 14,3 \mathrm{~mm}$ y su peso de 34,7 gr.

Uno de sus lados es recto y muestra 4 profundos trazos incisos transversales en la arista de convergencia con la cara mayor. En el lado paralelo a él presenta 17 trazos cortos transversales regularmente distribuidos a lo largo de $41 \mathrm{~mm}$.

Finalmente, cabe señalar que en el extremo más grueso se observan dos concentraciones de melladuras o incisiones como resultado de su uso como retocador.

La similitud entre algunos de los colgantes de la cueva de Praileaitz I es palpable, y no parece que hubiese siempre un especial interés en buscar cantos de siluetas concretas. Un paralelo de estos colgantes más comunes es uno de color gris oscuro con vetas blanquecinas hallado en la superficie de la cueva de El Arco B y, por tanto, de cronología incierta. Está fabricado sobre yesos triásicos,

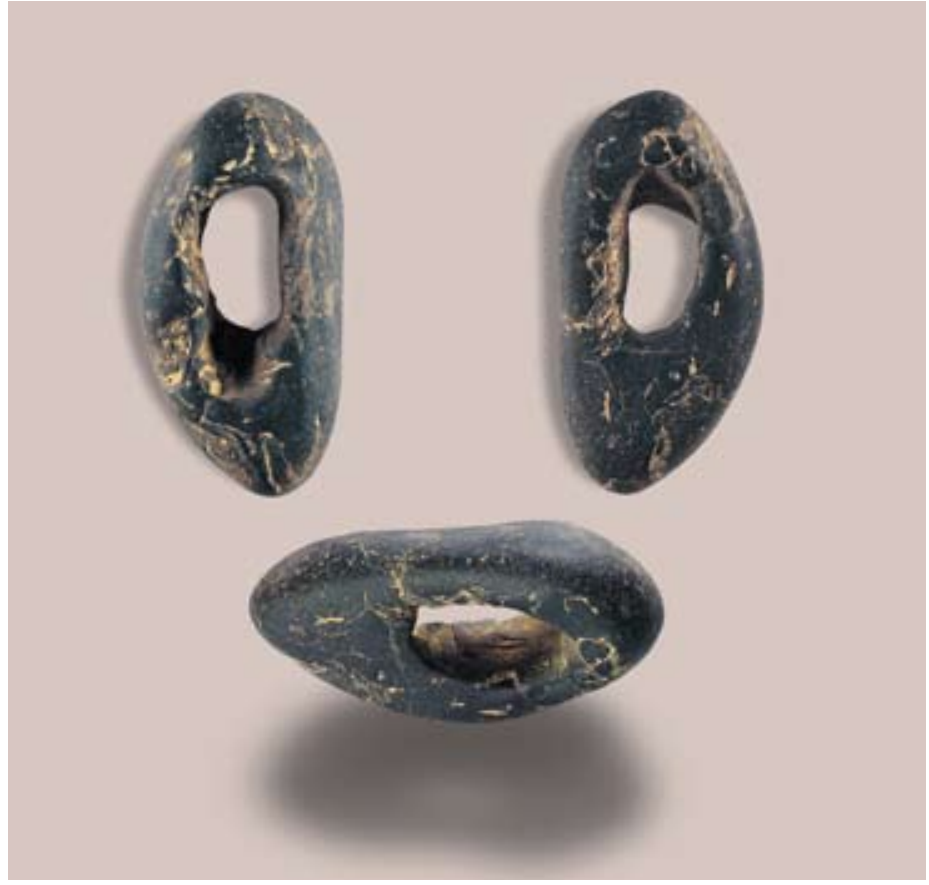

Fig. 35. Colgante $n^{\circ} 25$ (X. Otero). / Pendant no. 25 (X. Otero). 
Fig. 36. Colgante $n^{\circ} 26$ (X. Otero). / Pendant no. 26 (X. Otero).

\section{Colgante n 26 (P.A.16G'.329.3 + P.A. 14F'.342.1)}

Este colgante apareció roto en dos fragmentos al verse afectado por la realización de un pequeño agujero efectuado por clandestinos. Se trata de un nódulo de color granate oscuro y de forma semiesférica ligeramente asimétrica que muestra una perforación ligeramente descentrada de unos 7,5 $\mathrm{mm}$ (Figs. 36 y 64). Sus dimensiones son: $43,7 \times 40,1 \times 22,5 \mathrm{~mm}$. El peso del colgante es de 47,2 gr.

\section{Colgante n $^{\circ} 27$ (P.A.8F'.333.3)}

Canto rodado alargado de color negro (Figs. 37 y 65). Su sección es aplanada y prácticamente constante. Su forma es trapezoidal, los lados son prácticamente rectos y paralelos, si bien en el tercio superior se produce un progresivo, pero rápido estrechamiento por aproximación del extremo de uno de los lados hacia el centro. Aquí presenta un orificio bicónico, fracturado, siendo su diámetro exterior de 5,6 mm y el interior de 2,6 mm. La zona donde se sitúa el agujero fue, quizás, someramente abrasionada en una cara, con el fin de adelgazarla para ulteriormente perforarla por rotación. En ambas caras se observan los extremos de cortas incisiones longitudinales orientadas hacia la perforación, en ocasiones interrumpidas por las de rotación. La base es recta, aunque ligeramente oblicua. Las dimensiones máximas del colgante son: 77x19,4x8,3 mm. El peso de la pieza es de 24,6 gr.

La decoración se desarrolla a ambos lados; en el rectilíneo se observan 14 cortos trazos aislados regularmente distanciados, y los 4 más próximos a la base parecen realizados por parejas, y otros dos más, triples. En la arista opuesta se aprecia una sucesión de 12 cortes transversales que parecen formar agrupaciones o ritmos no muy estrictos, cuya sucesión de arriba a abajo es la siguiente: 2 / 2 /3 / 1/2/1/2/2/2/2/3/3.

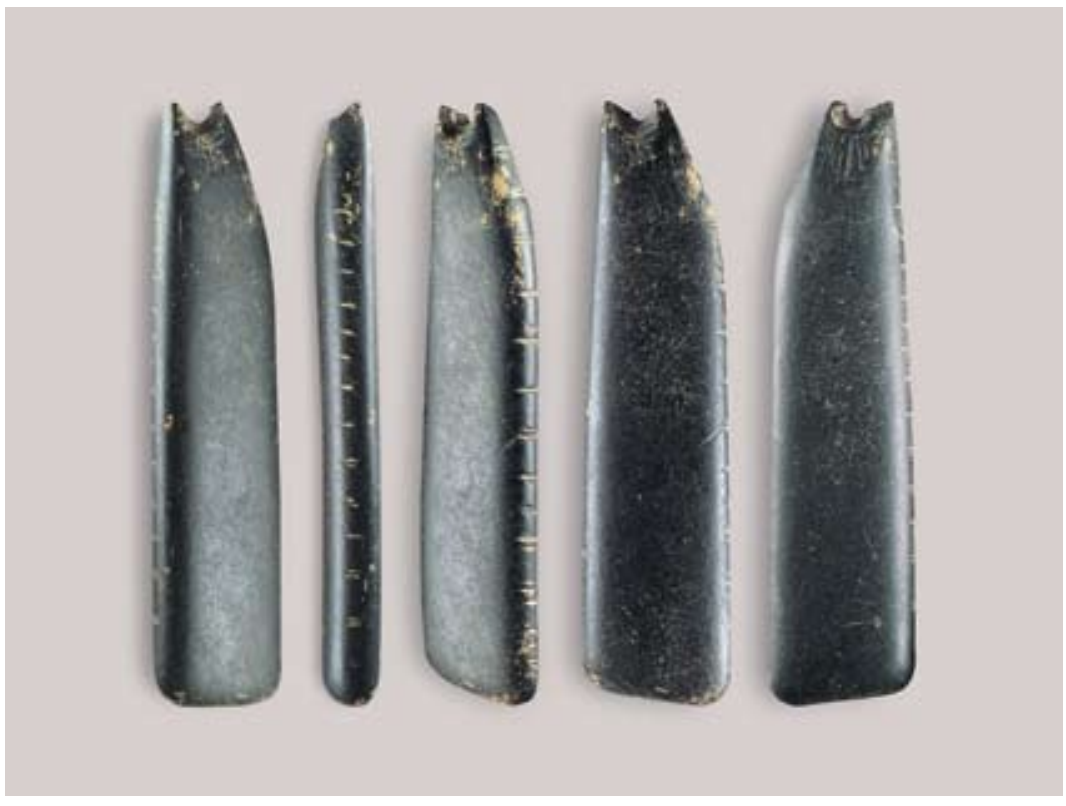

Fig. 37. Colgante $n^{\circ} 27$ (X. Otero). / Pendant no. 27 (X. Otero). 
Fig. 38. Colgante $n^{\circ} 28$ (X. Otero). / Pendant no. 28 (X. Otero).

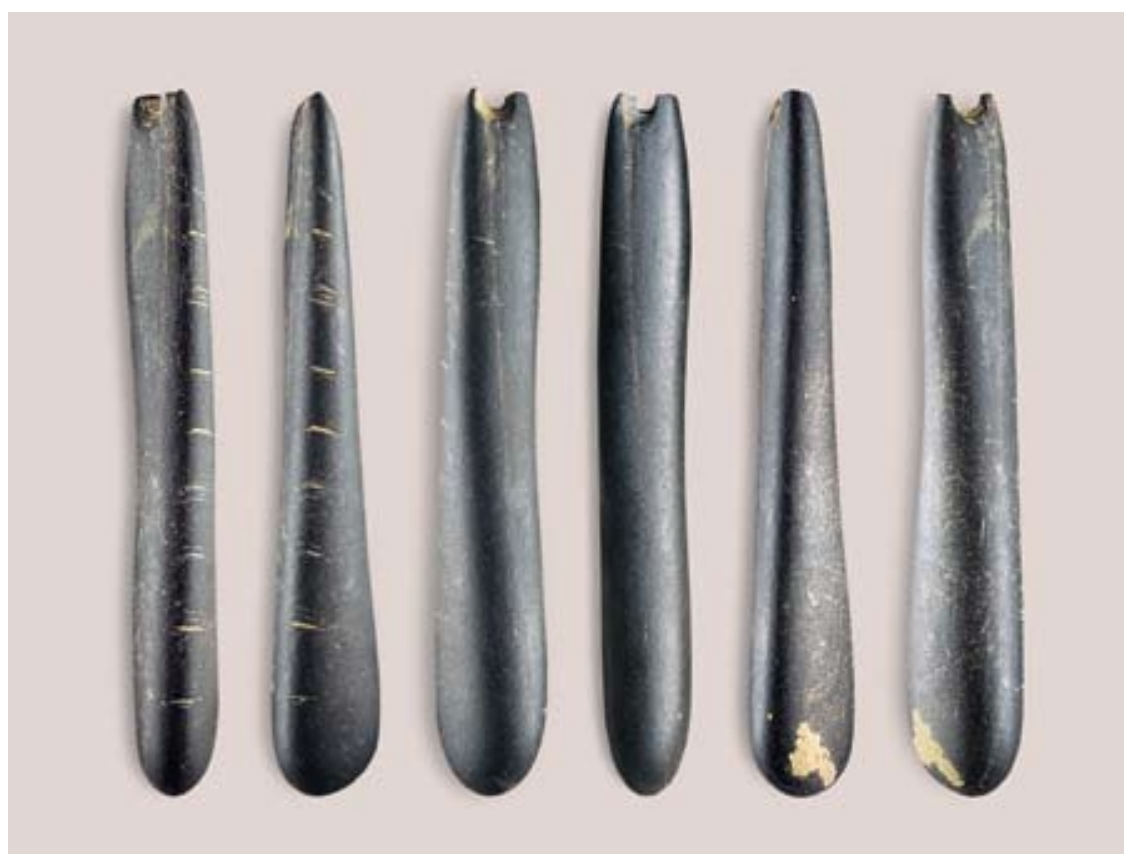

\section{Colgante nº 28 (P.A.10F'.331.19)}

Canto rodado alargado de forma helicoidal y color negro (Figs. 38 y 66). La perforación realizada por rotación bipolar, rota, se sitúa en el extremo más delgado y estrecho. En el orificio se definen dos zonas: una donde el plano del orificio es oblicuo y otra donde es más vertical. Su diámetro exterior es de 5,2 $\mathrm{mm}$ y el interior de 2,6 mm. Las dimensiones máximas del colgante son: $90,5 \times 16,2 \times 11 \mathrm{~mm}$. Su peso es de 24,0 gr.

La decoración se localiza en la arista frontal, que gira levemente, a modo de 9 incisiones transversales, que en ocasiones tienen una o dos paralelas formando agrupaciones. De arriba a abajo se suceden estas incisiones: 1 (más una rectificación) / 1 / 3 / 1 / 1 / 2 (más rectificación) / 2 / 1 y 1 (más una rectificación).

\section{Colgante nº 29 (P.A.8D'.333.5)}

Colgante sobre robusto canto rodado alargado y fracturado en la perforación, realizada por rotación bipolar, que se localiza en el extremo más delgado. Las dimensiones de la pieza son: 84,6×26,6×14,1 mm. El peso del colgante es de 50,5 gr (Figs. 39 y 67).

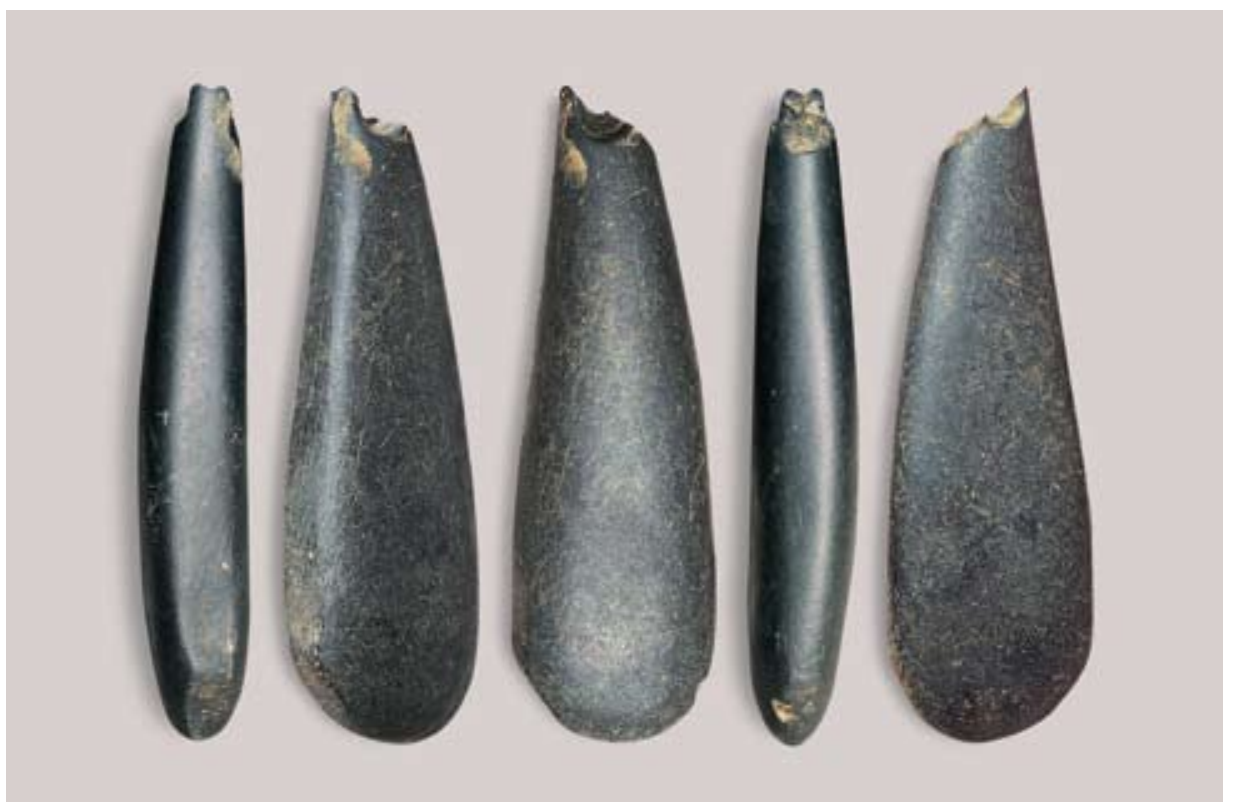

Fig. 39. Colgante $n^{\circ} 29$ (J. Alonso). / Pendant no. 29 (J. Alonso). 
Esta pieza no presenta decoración, pero sí líneas desordenadas en una de sus caras, y en la mitad proximal de uno de los lados una agrupación de incisiones longitudinales, como de raspado, convergiendo en dos pequeños planos donde se observan melladuras que proponemos se deben a su uso como retocador. El mismo tipo de huellas se observan en el borde convexo.

\section{2.- DISTRIBUCIÓN DE LOS COLGANTES DE PRAILEAITZ I}

Los 29 colgantes recuperados se situaban en un mismo nivel arqueológico formando la mayor parte de ellos agrupaciones claramente diferenciables. Todos ellos estaban dispuestos en la zona este del vestíbulo, en el pequeño cubículo próximo al asiento y al hogar del Magdaleniense Inferior y sobre todo en la primera sala interior. Tan solo uno $\left(n^{\circ} 3\right)$ se localizó en una zona más centrada del vestíbulo, dándose la circunstancia de que un fragmento del mismo se halló en la zona oeste de la primera sala interior.

De las piezas recogidas en el vestíbulo se pueden establecer claramente tres agrupaciones: la situada más al exterior formada por los colgantes $n^{\circ} 4,8$ y 9. La compuesta por tres dientes de cabra perforados y decorados ( $n^{\circ} 5,6$ y 7 ) ya dentro del cubículo y la localizada en ese mismo espacio, constituida por los colgantes $n^{\circ} 1$ y 2 .

Dentro de la primera sala interior, en la zona este, destaca el conjunto de 14 piezas (Fig. 14 y 19), compuesto por los colgantes $n^{\circ} 10,11,12,13,14,15,16$, 17, 18, 19, 20, 21, 22 y 23. Más centrados, en esa sala, se hallaron los tres colgantes que, muy próximos entre sí, se corresponden con los $n^{\circ} 24,25$ y 26 del estudio.

Finalmente, en la zona oeste de la sala se localizaron tres colgantes ( $n^{\circ} 27,28$ y 29) cada uno de ellos con una rotura a la altura de la perforación, así como un pequeño fragmento del colgante $n^{\circ} 3$ hallado en el vestíbulo, al que ya hemos hecho referencia.

\section{3.- AGRADECIMIENTOS}

El estudio se ha desarrollado en el marco del Grupo de Investigación del Sistema Universitario Vasco IT-62213 al cual J. A. Mujika pertenece.

\section{4.- BIBLIOGRAFÍA}

ABRAMOVA, A.

1990 Bases objectives de la chronologie de l'art mobilier paléolithique en Sibérie, en L'art des objets au Paléolithique. 143-154. Foix-Le Mas d’Azil.

ALLARD, M.

1989 Collection R. et S. de Saint-Périer à Lespugue (HauteGaronne). Préhistoire Ariégeoise 44, 203-224.
ARIAS, P., ONTAÑÓN, R.

2004 La materia del lenguaje prehistórico. El arte mueble paleolitico de Cantabria en su contexto. Liébana.

ARRIZABALAGA, A., IRIARTE, M.J.

2011 Ehiztari-biltzaileak Gipuzkoako Historiaurrean = Los grupos de cazadores-recolectores en la Prehistoria de Gipuzkoa. Gipuzkoako Foru Aldundia. Donostia.

BARANDIARÁN. I.

1971 Hueso con grabados paleolíticos, en Torre (Oyarzun, Guipúzcoa). Munibe 23, 37-69.

1972 Algunas convenciones de representación en las figuras animales del arte paleolítico. Actas del Symp. Intern. de Arte Prehistórico. 345-381. Santander.

1973 Arte mueble del Paleolítico Cantábrico. Monografías Arqueológicas XIV.

1985 Industria ósea paleolítica de la cueva del Juyo, excavaciones de 1978 y 1979, en BARANDIARÁN. I., FREEMAN, L.G., GONZÁLEZ ECHEGARAY, J. \& KLEIN, R.G. EXcavaciones en la cueva del Juyo. 161-195. Centro de Inv. y Museo de Altamira. Madrid.

2006 Imágenes y adornos en el arte portátil paleolítico. Ariel Prehistoria. Madrid.

BARGE, $H$.

1982 Les parures du Néolithique ancien au debut de l'Age des Métaux en Languedoc. CNRS. Paris.

BEAUNE, S.A. DE

1997 Les galets utilisés au Paléolithique Supérieur. Gallia Prehistoire, supl. XXXII.

BOSINSKI, G., SCHILLER, P.

1998 Représentations féminines dans la grotte du Planchard (Vallon Pont d'Arc, Ardèche) et les figures féminines du type Gönnersdorf dans l'art pariétal. Bulletin de la Société Préhistorique de l'Ariège LIII, 99-140.

CARBALLO, J., GONZÁLEZ-ECHEGARAY, J.

1952 Algunos objetos inéditos de la Cueva de "El Pendo". Ampurias 14, 37-48.

CHOLLOT, M.

1964 Musée des Antiquités Nationales. Collection Piette. Ed. des Musées Nationaux. Paris.

CHOLLOT-VARAGNAC, M.

1980 Les origines du graphisme symbolique. Fondation SingerPolignac. Paris.

CORCHÓN, S.

1981 Cueva de Las Caldas. San Juan de Priorio (Oviedo). Excavaciones Arqueológicas en España 115

1986 El arte mueble paleolítico cantábrico: contexto y análisis interno. Centro de Investigaciones y Museo de Altamira. (Monografía; 16). 
1990a La Cueva de Las Caldas (Priorido, Oviedo). Investigaciones científicas efectuadas entre 1980 y 1986. Excavaciones Arqueológicas en Asturias 1983-86, 37-53.

1990b Iconografía de las representaciones antropomorfas paleolíticas: a propósito de la "venus" magdaleniense de Las Caldas (Asturias). Zephyrus 43, 17-37.

1994 Últimos hallazgos y nuevas interpretaciones del arte mueble paleolítico en el occidente asturiano. Complutum 5, 235-264.

\section{COURAUD, C.L.}

1985 L'art azilien. Origine-survivance. Gallia Préhistoire, supl. XX. C. N. R. S. Paris.

CRÉMADES, M.

1990 Analyse et reconstitution technologiques en art mobilier paléolithique. Nouvelles figurations d'oiseaux de La Madeleine (Dordogne). Paleo 2, 203-210.

CRÉMADES, M.

1994 L'art mobilier paléolithique: Analyse des procédés technologiques, en CHAPA, T. \& MENENDEZ, M. Arte paleolitico. 369-384. (Complutum; 5).

DELPORTE, $\mathrm{H}$.

1982 La imagen de la mujer en el arte prehistórico. Istmo. Madrid.

GONZÁLEZ ECHEGARAY, J., BARANDIARÁN, I.

1981 El Paleolítico Superior de la cueva de Rascaño (Santander). Monografía 3. Centro de Investigaciones y Museo de Altamira.

GONZÁLEZ MORALES, M.R.

1990 El abrigo de Entrefoces (1980-1986). Excavaciones Arqueológicas en Asturias 1983-86, 29-36.

\section{GONZÁLEZ SÁlNZ, C.}

2003 Nuevos materiales arqueológicos de la cueva de «El Arco B» (Ramales de la Victoria, Cantabria). Veleia 20, 123-141.

GORROTXATEGI, X.

2000 Arte paleolítico parietal en Bizkaia. Kobie, Anejo 2.

HAHN, J.

1990 Fonction et signification des statuettes du Paléolithique Supérieur européen. L'art des objets au Paléolithique 3 (1987), 173-183.

LEROI-GOURHAN, A.

1984a Símbolos, artes y creencias de la Prehistoria. Istmo. Madrid.

1984b Arte y grafismo en la Europa prehistórica. Istmo. Madrid.

LUQUET, G.H.

1926 L'art et la religion des hommes fossiles. Masson. Paris.
MOURE, A.

1975 Excavaciones arqueológicas en la cueva de Tito Bustillo (Ribadesella, Asturias). Campaña de 1972 y 1974. Instituto de Estudios Asturianos. Oviedo.

1984 Representaciones femeninas en el arte mueble de la cueva de Tito Bustillo. Boletín del Museo Arqueológico Nacional 2, 69-76.

1995 Les représentations humaines dans l'art paléolithique de l'Espagne Cantabrique. Actes du Colloque de Brassempouy (1994). ERAUL 74, 149-167.

MUJIKA, J.A.

2007-8 La gestión de la materia prima ósea en la fabricación de objetos durante la Prehistoria. Veleia 24-25, 531-568.

MUJIKA, J.A., TARRIÑO, A.

2009 Las industrias líticas y óseas de Santa María la Real de Zarautz (País Vasco), en IBAÑEZ, A (Dir.). Santa María La Real de Zarautz (País Vasco) Continuidad y discontinuidad en la ocupación de la costa vasca entres los siglos V a.C. y XIV d.C. Munibe. Suplemento 27, 164-174.

OTTE, M.

1981 Le Gravetien en Europe Centrale. Dissertationes Archaeologicae Gandenses XX.

PASSEMARD, E.

1944 La caverne d'Isturitz en Pays Basque. Prehistoire IX.

PALES, L.

1972 Les ci-devant venus stéatopyges aurignaciennes. Symposium, Actas del Symposium Internacional de Arte Prehistórico. 217-261. Santander.

PEÑALVER, $X$.

2014 Praileaitz I haitzuloa. La cueva de Praileaitz I (Deba, Gipuzkoa). Gipuzkoako Foru Aldundia. Donostia. (Arkeologia; 04).

PEÑALVER, X., MUJIKA, J.A.

2003 Suelo de ocupación magdaleniense en la cueva de Praile Aitz I (Deba, Gipuzkoa): evidencias de arte mobiliar. Veleia 20, 157-181.

2005 Praile Aitz I (Deba, Gipuzkoa): evidencias arqueológicas y organización espacial en un suelo Magdaleniense. IV Congresso de Arqueologia Peninsular (Faro, 2004). Actas do IV Congresso de Arqueologia Peninsular. O Paleolítico. Promontoria Monográfica 02, 143-157. Universidade do Algarve. Faro.

2007-2008 ¿Actividad cotidiana o práctica ritual?. Agrupación de 14 colgantes líticos del Magdaleniense Inferior en la cueva de Praileaitz I (Deba, Gipuzkoa). Veleia 24-25, 209-228,

PEÑALVER, X., SAN JOSE, S., MUJIKA, J.A.

2006 Praileaitz I haitzuloko (Deba) Madeleine aldiko zintzilikarioak. Gipuzkoako Foru Aldundia. Donostia. (Bertan; 22). 
RIPOLL, E.

1958 Las representaciones antropomórficas en el arte paleolítico español. Ampurias 19-20, 167-192.

ROUSSOT, A.

1990 Colloque International Foix - Le Mas-d'Azil. L'art des objets au Paléolithique I. Art mobilier et pariétal de Périgord et de la Gironde: comparaison stylistiques. 173-189. Foix-Le Mas d'Azil.

SACCHI, D.

1990 L'art des objets au Paléolithique I, Bases objectives de la chronologie de l'art mobilier paléolithique dans les Pyrénées septentrionales, Colloque International. 13-31. FoixLe Mas d'Azil.

SÁENZ DE BURUAGA, A.

1989 Colgantes y otras manifestaciones artísticas en los niveles del Paleolítico Superior Inicial de la Cueva de Gatzarria (Zuberoa, Euskal Herria). Veleia 6, 21-48.

1991 El Paleolitico Superior de la cueva de Gatzarria (Zuberoa, País Vasco). Veleia. Anejos - Series Maior 6.

SAINT-PÉRIER, R. DE

1930 La grotte d'Isturitz. I: Le Magdalénien de la Salle SaintMartin. (Archives de l'Institut de Paléontologie Humaine ; 7).
1936 La grotte d'Isturitz. II: Le Magdalénien de la Grande Salle. (Archives de l'Institut de Paléontologie Humaine ; 17).

\section{SAINT-PÉRIER, R. ET S.}

1952 La grotte d'Isturitz. III: Les Solutréens, les Aurignaciens et les Moustériens. Archives de l'Institut de Paléontologie Humaine 25.

TABORIN, Y.

1990 L'art des objets au Paléolithique 2. Le décor des objets de parure. Colloque International. 19-39. Foix-Le Mas d'Azil.

VALOCH, K.

1961 Benützte und Gravierte Schiefergerolle im Magdalénien Mährens. Acta Musei Moraviae XVI, 5-29.

2001 Das Magdalénien in Mähren. Jahrbuch des RömischGermaischen Zentralmuseums Mainz 48, 103-159.

ZAPATA, L.

1995 La excavación del depósito sepulcral calcolítico de la cueva Pico Ramos (Muskiz, Bizkaia). La industria ósea y los elementos de adorno. Munibe Antropologia-Arkeologia $47,35-90$.

ZERVOS, $\mathrm{CH}$.

1959 L'Art de l'époque du renne en France. Cahiers d'Art. Paris. 


\section{ILUSTRACIONES(1)}
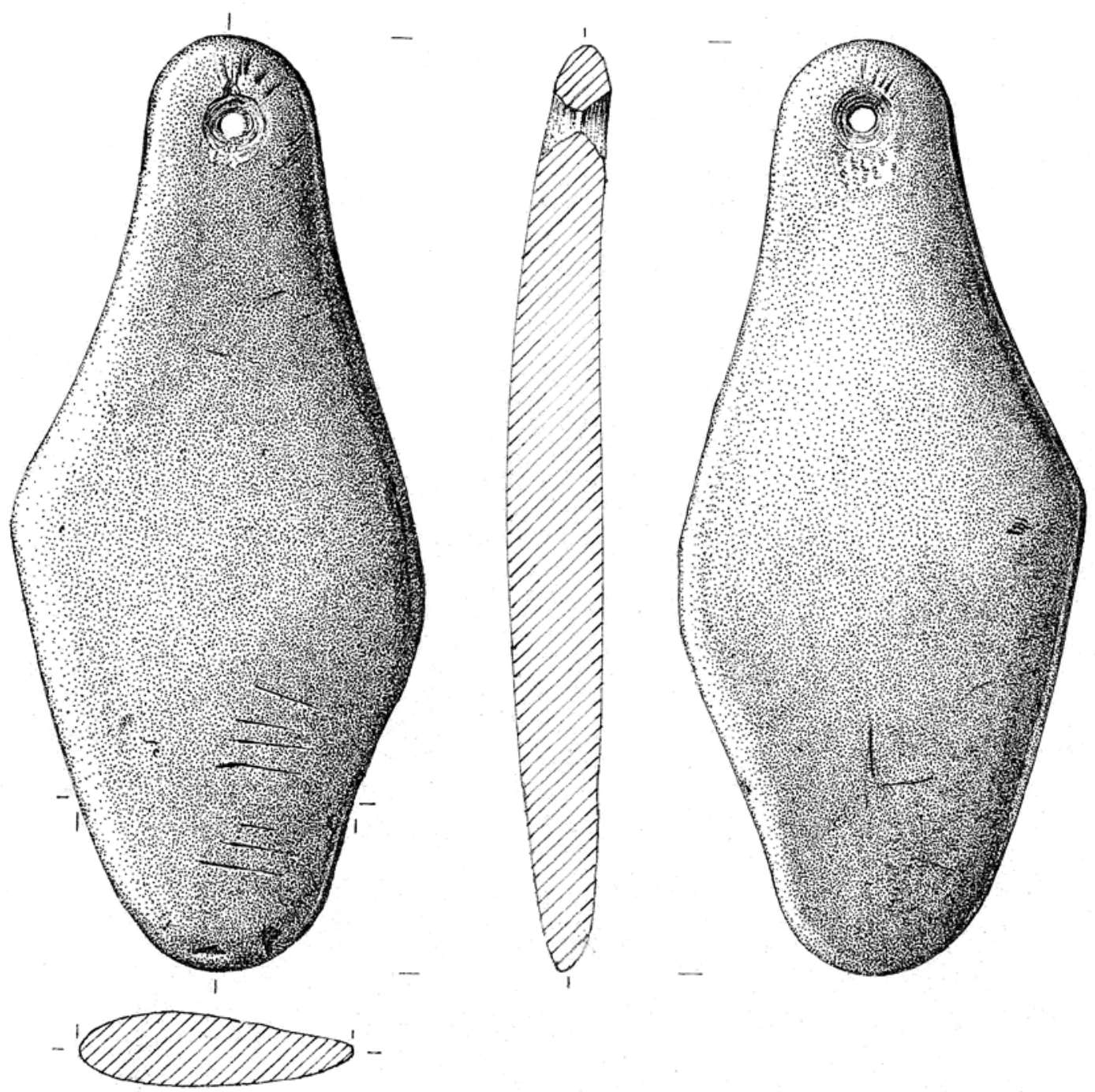

Fig. 40. Colgante $n^{\circ} 1$ (J. Alonso). / Pendant no. 1 (J. Alonso). 

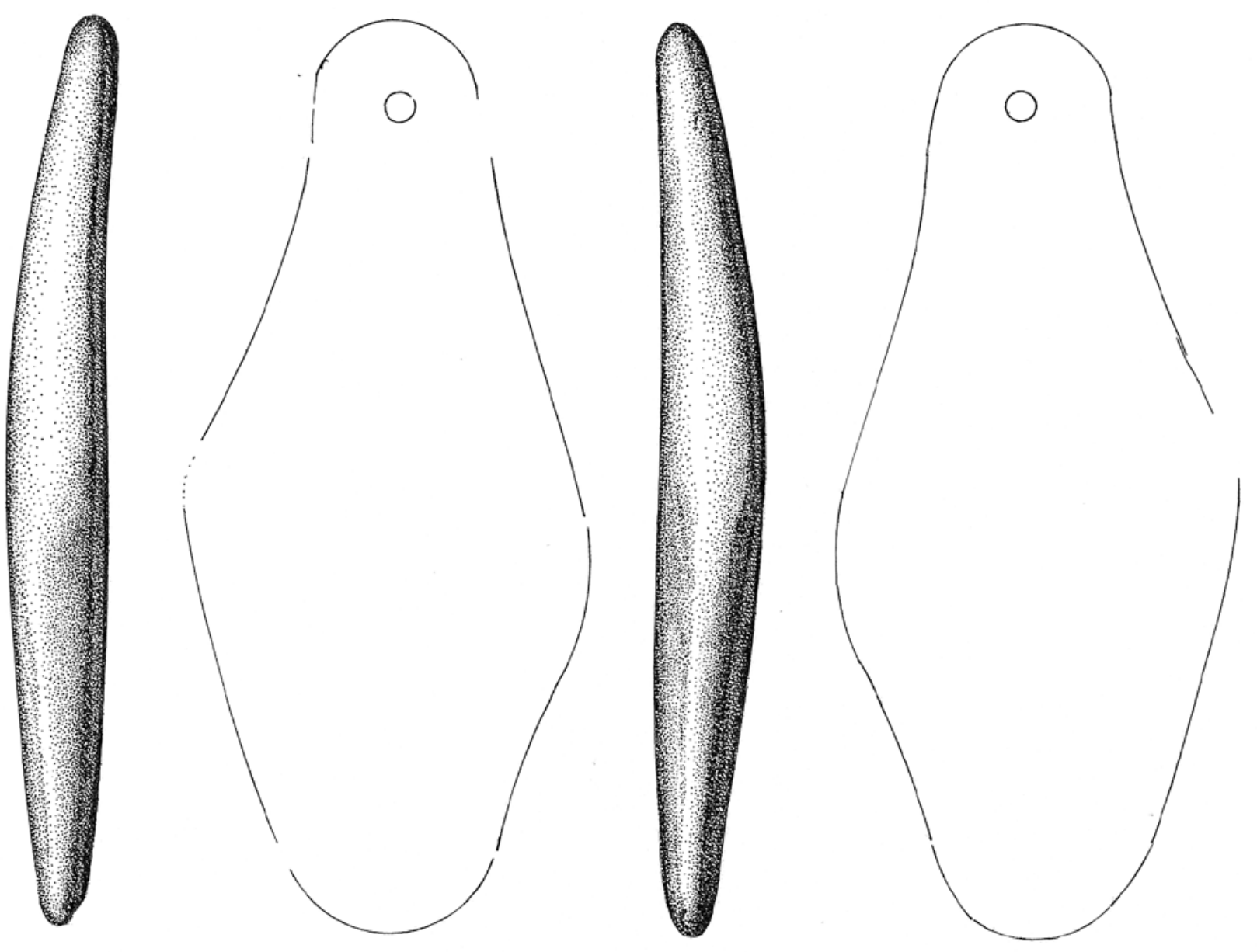

Fig. 41. Colgante $n^{\circ} 1$ (J. Alonso). / Pendant no. 1 (J. Alonso). 

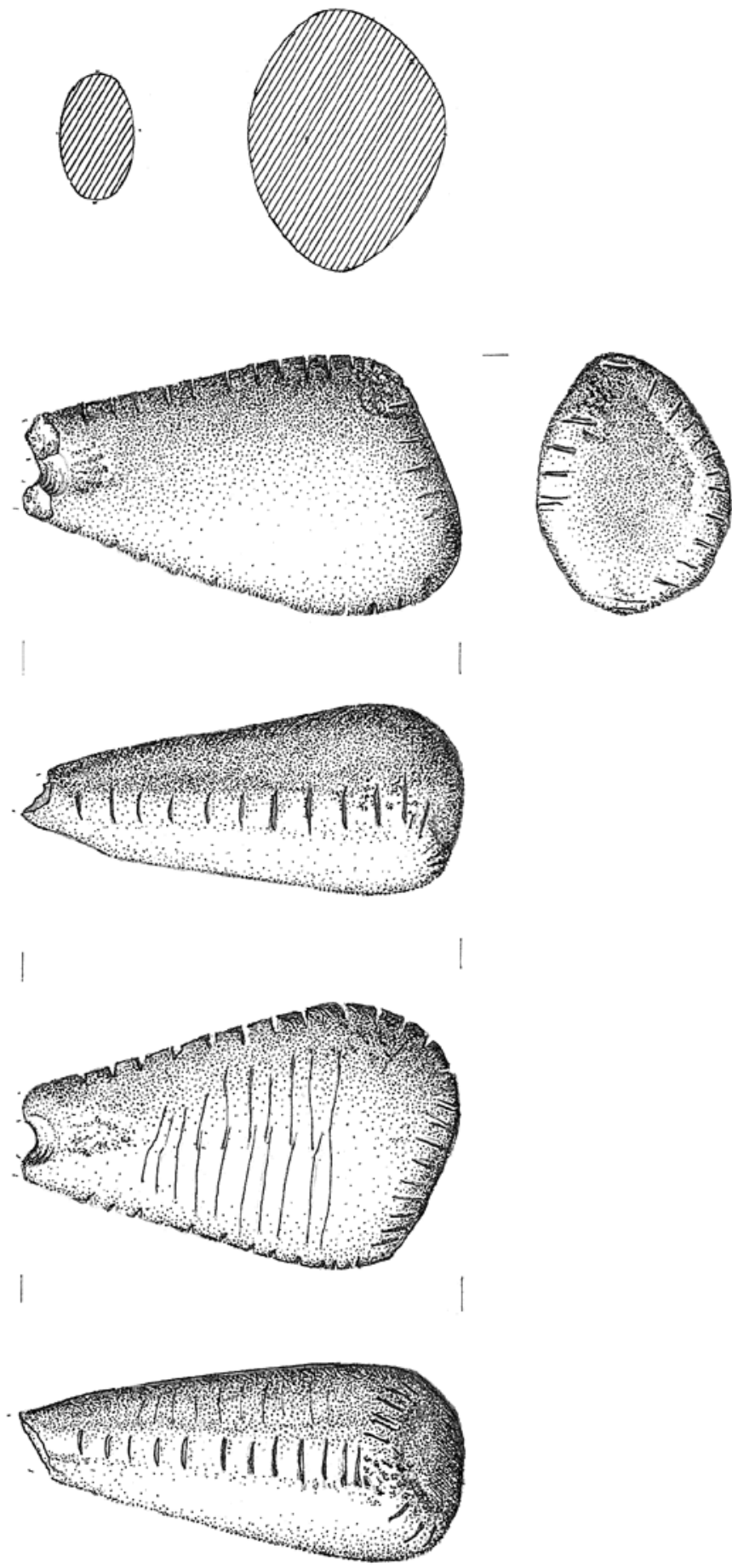

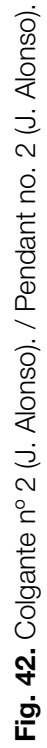



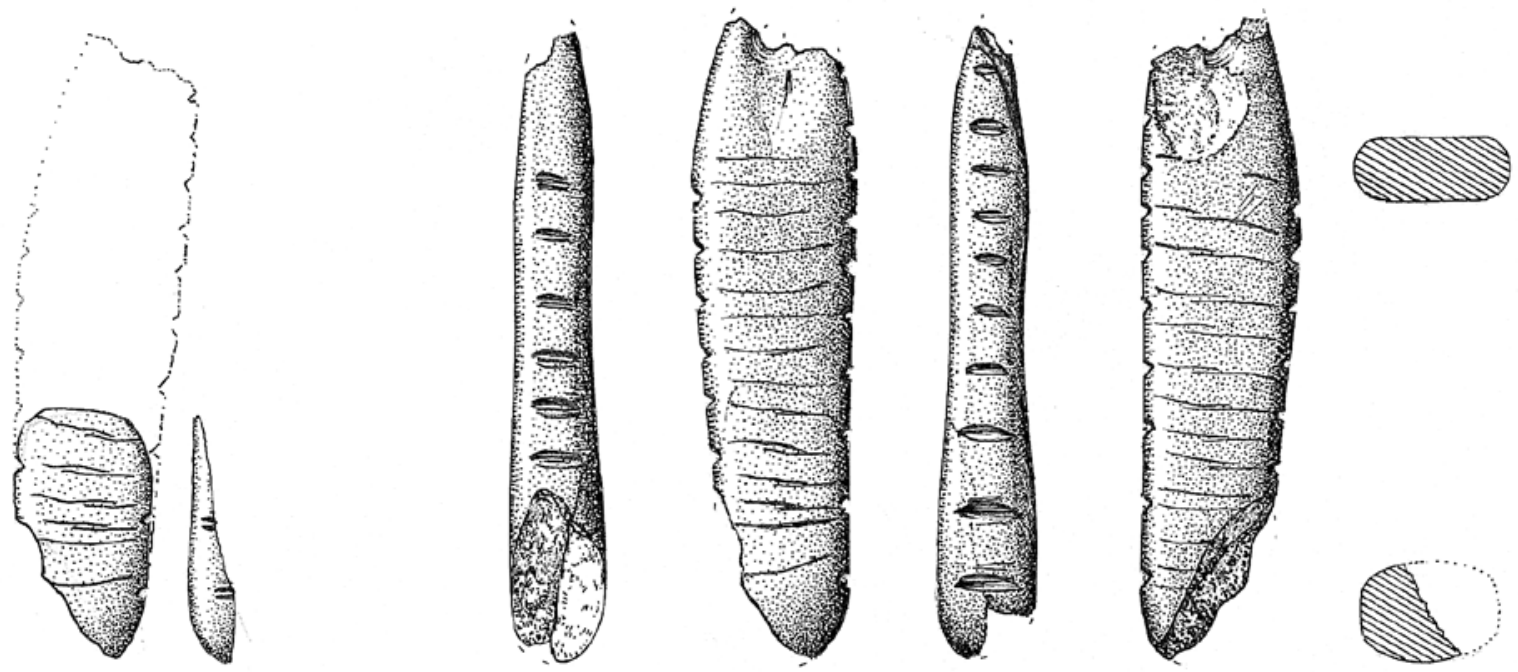

Fig. 43. Colgante $n^{\circ} 3$ (J. Alonso). / Pendant no. 3 (J. Alonso).
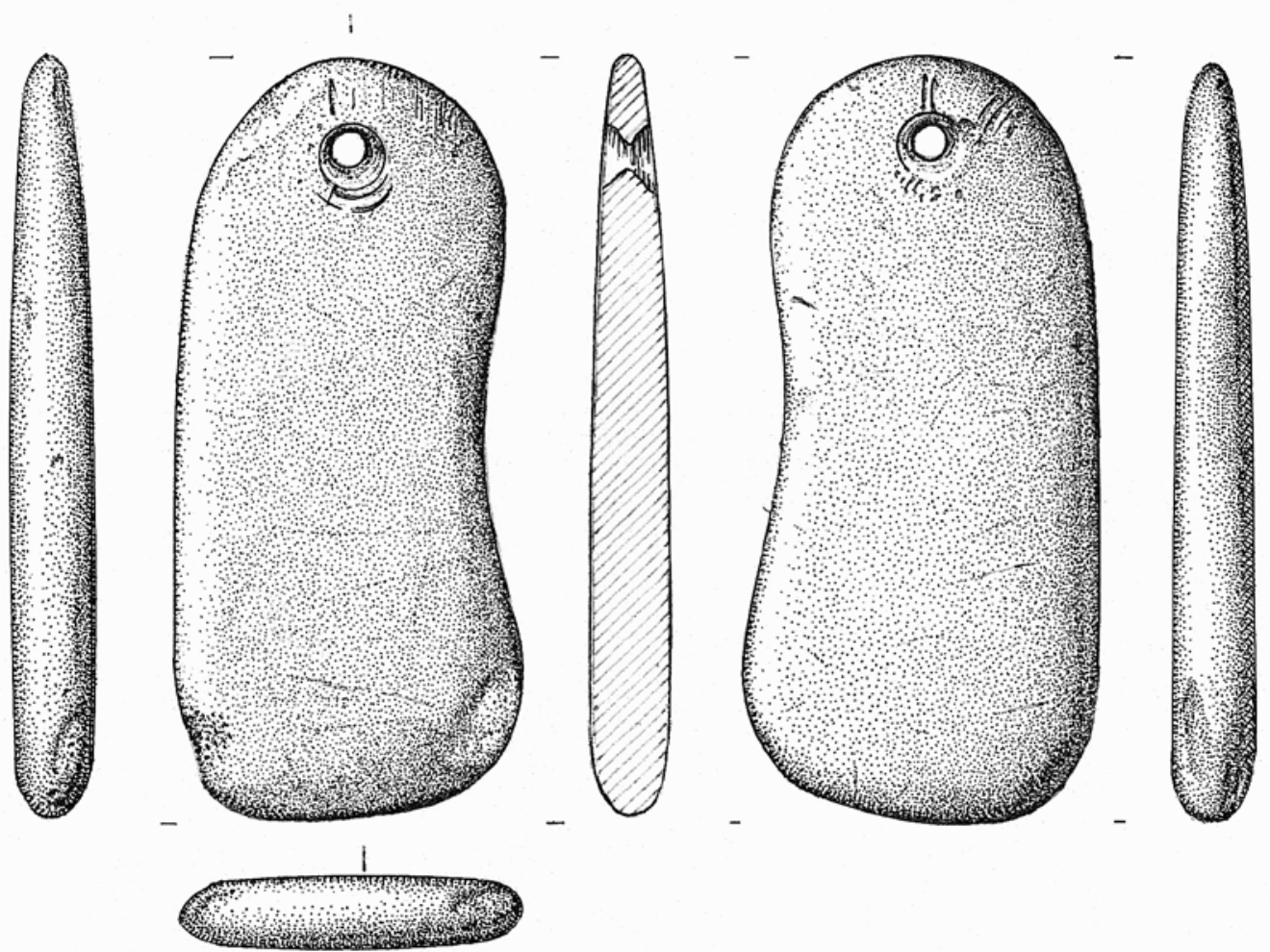

Fig. 44. Colgante $n^{\circ} 4$ (J. Alonso). / Pendant no. 4 (J. Alonso). 

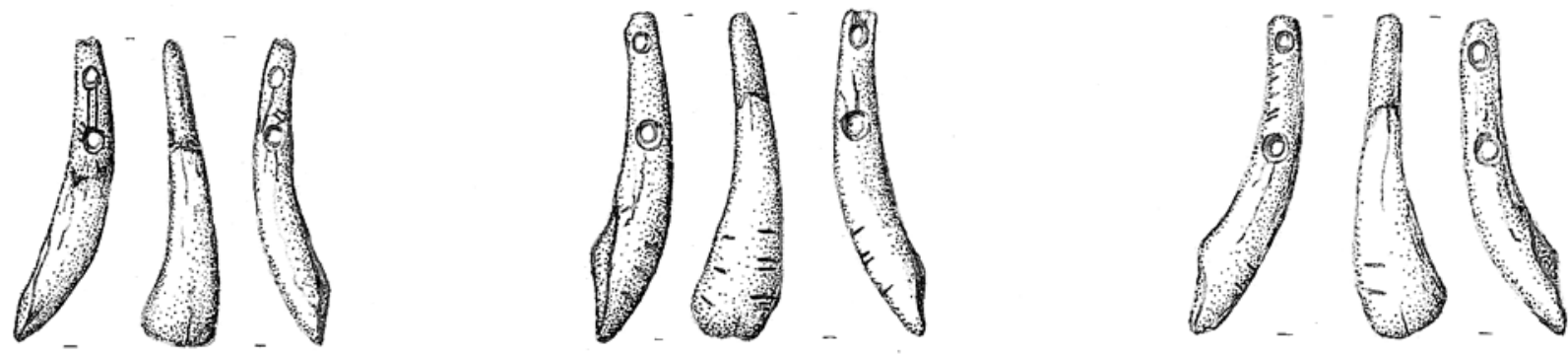

Fig. 45. Colgantes $n^{\circ}$ 5, 6 y 7 (J. Alonso). / Pendants no. 5, 6 and 7 (J. Alonso).

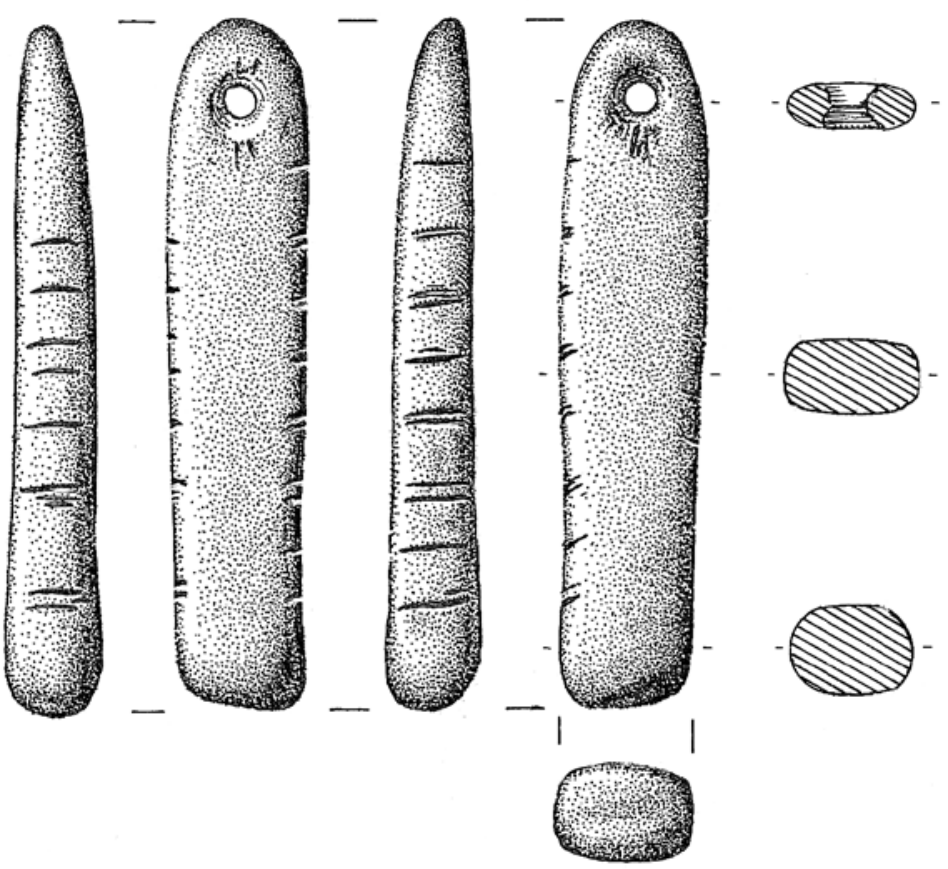

Fig. 46. Colgante $n^{\circ} 8$ (J. Alonso). / Pendant no. 8 (J. Alonso). 


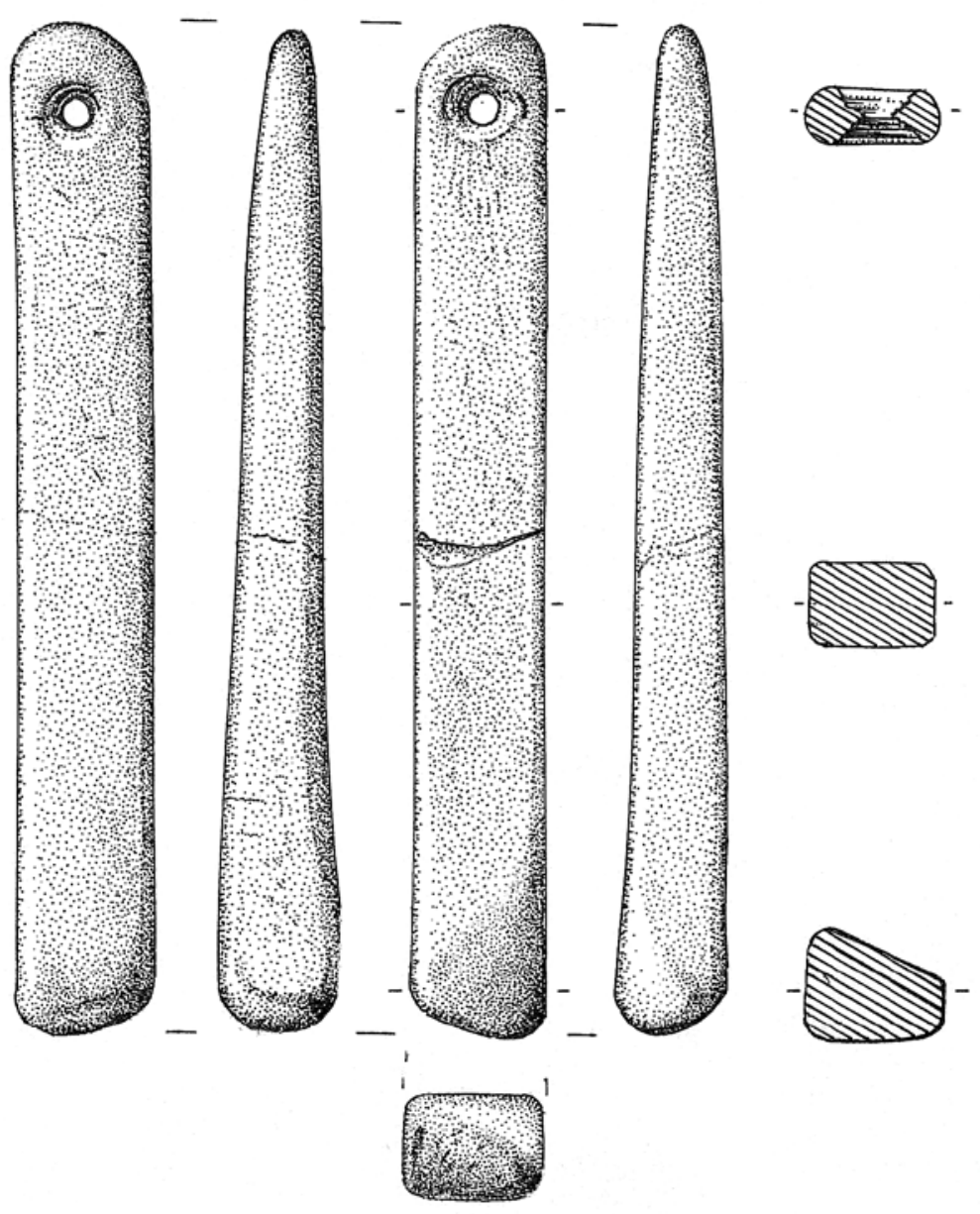

Fig. 47. Colgante $n^{\circ} 9$ (J. Alonso). / Pendant no. 9 (J. Alonso).

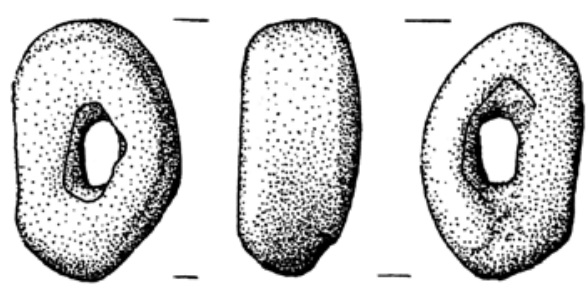

Fig. 48. Colgante $\mathrm{n}^{\circ} 10$ (J. Alonso). / Pendant no. 10 (J. Alonso). 


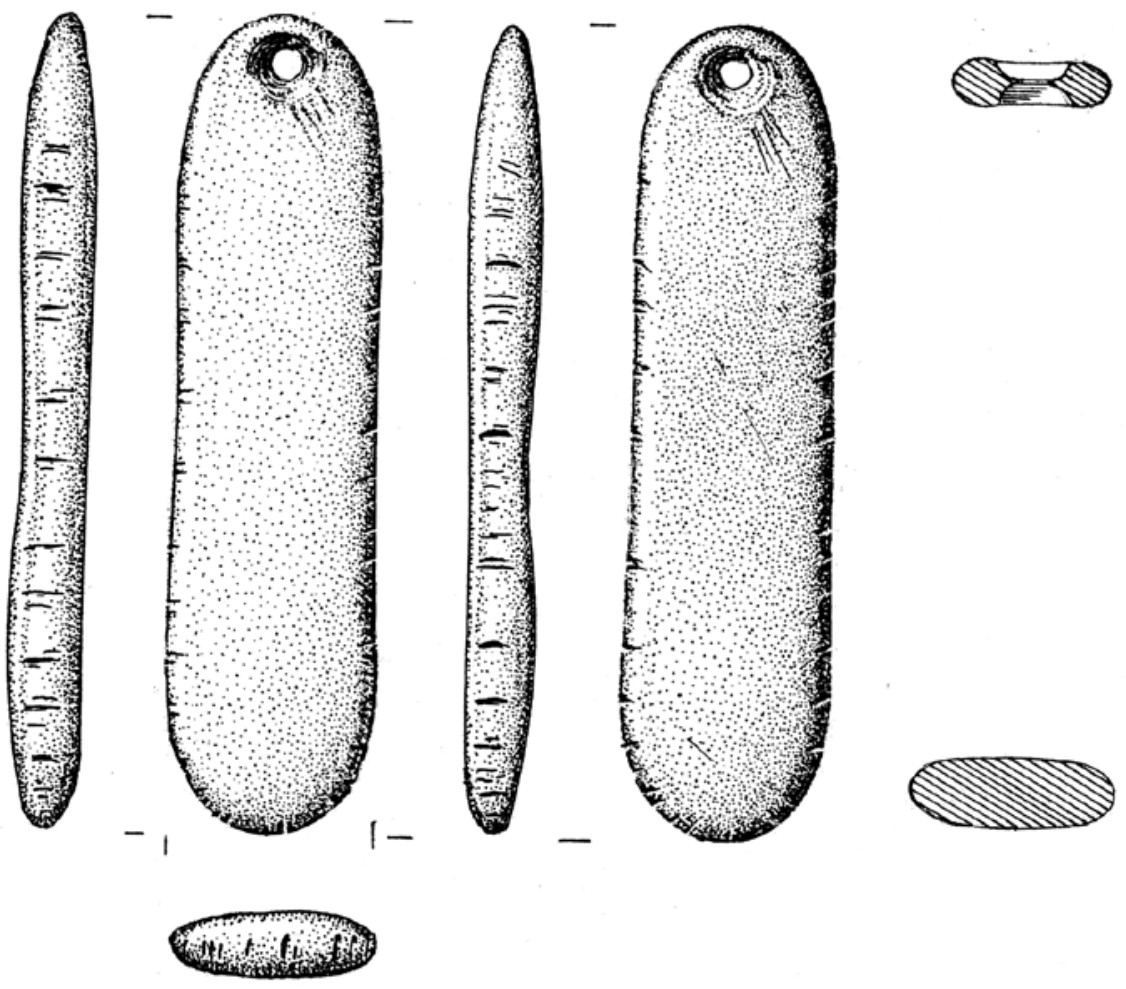

Fig. 49. Colgante $\mathrm{n}^{\circ} 11$ (J. Alonso). / Pendant no. 11 (J. Alonso).

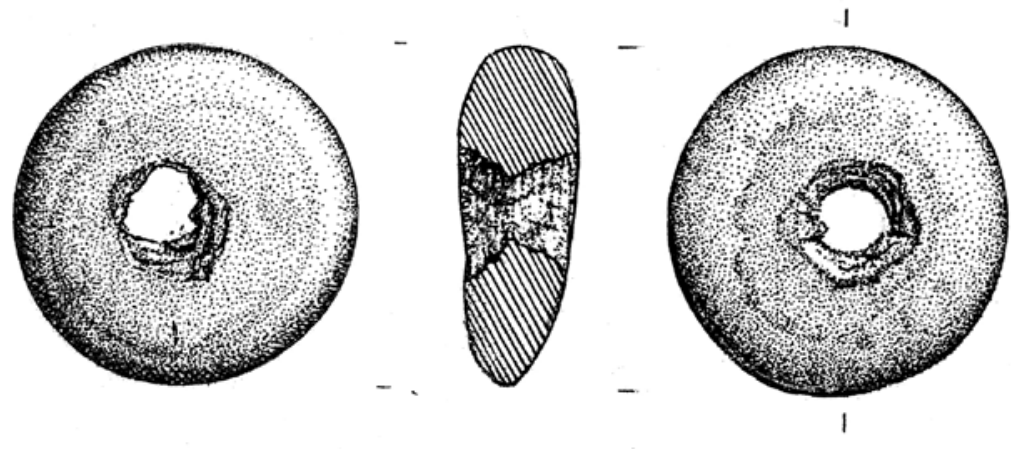

Fig. 50. Colgante $n^{\circ} 12$ (J. Alonso). / Pendant no. 12 (J. Alonso). 

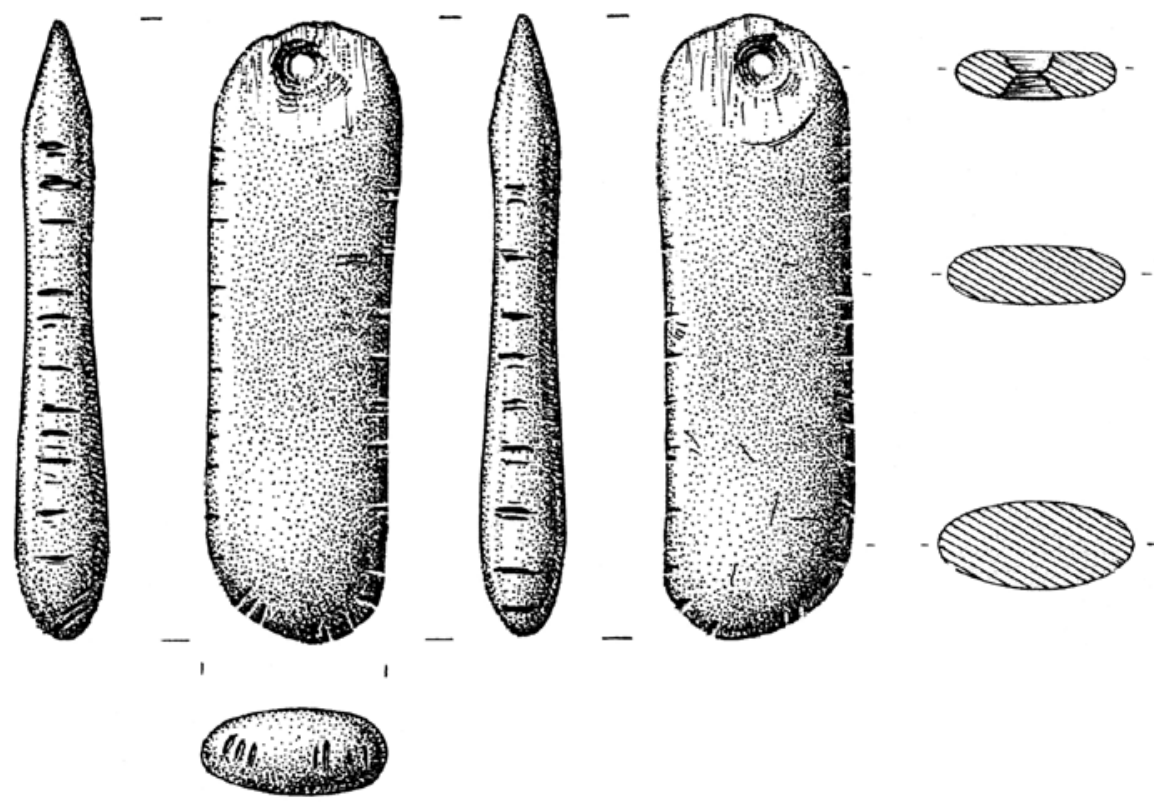

Fig. 51. Colgante $n^{\circ} 13$ (J. Alonso). / Pendant no. 13 (J. Alonso)
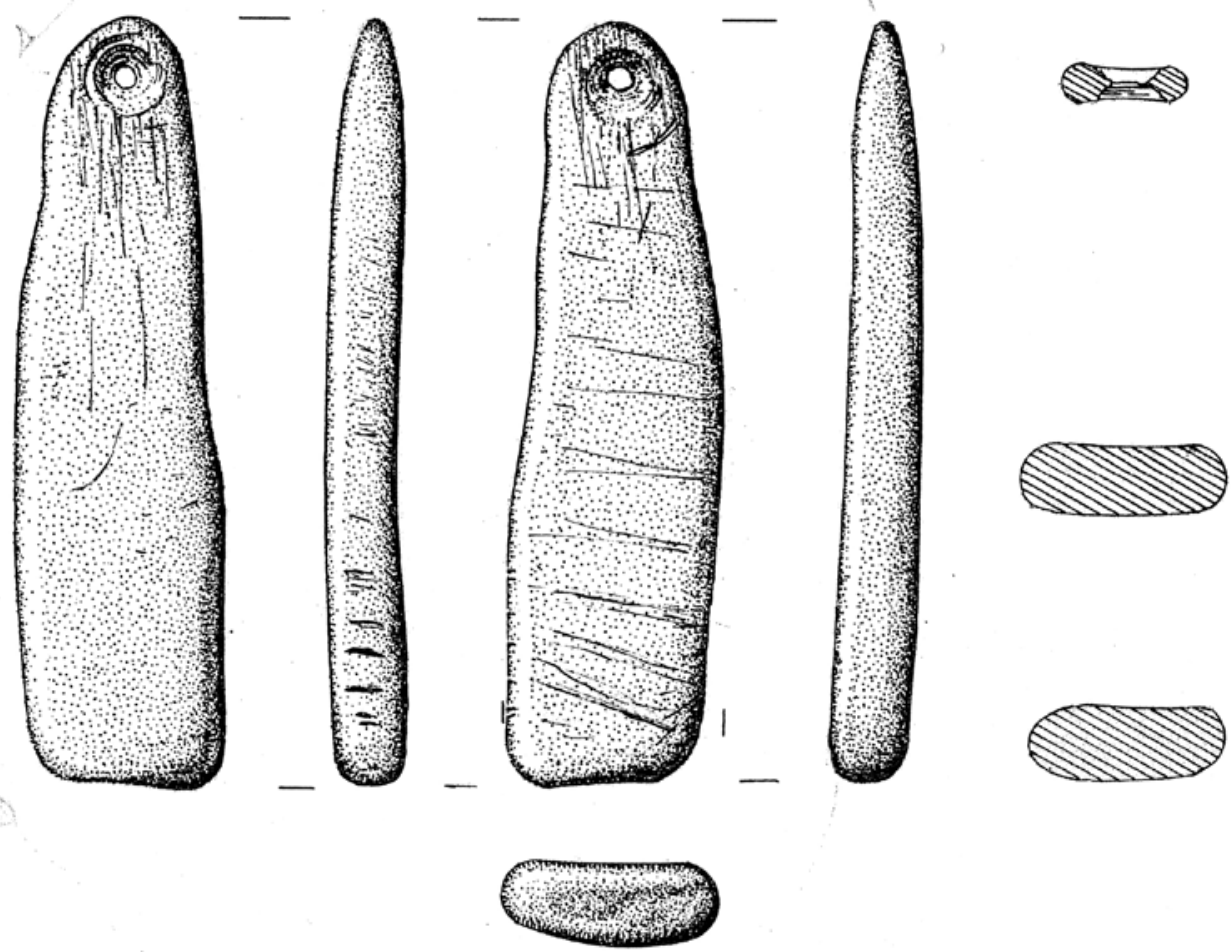

Fig. 52. Colgante $\mathrm{n}^{\circ} 14$ (J. Alonso). / Pendant no. 14 (J. Alonso). 

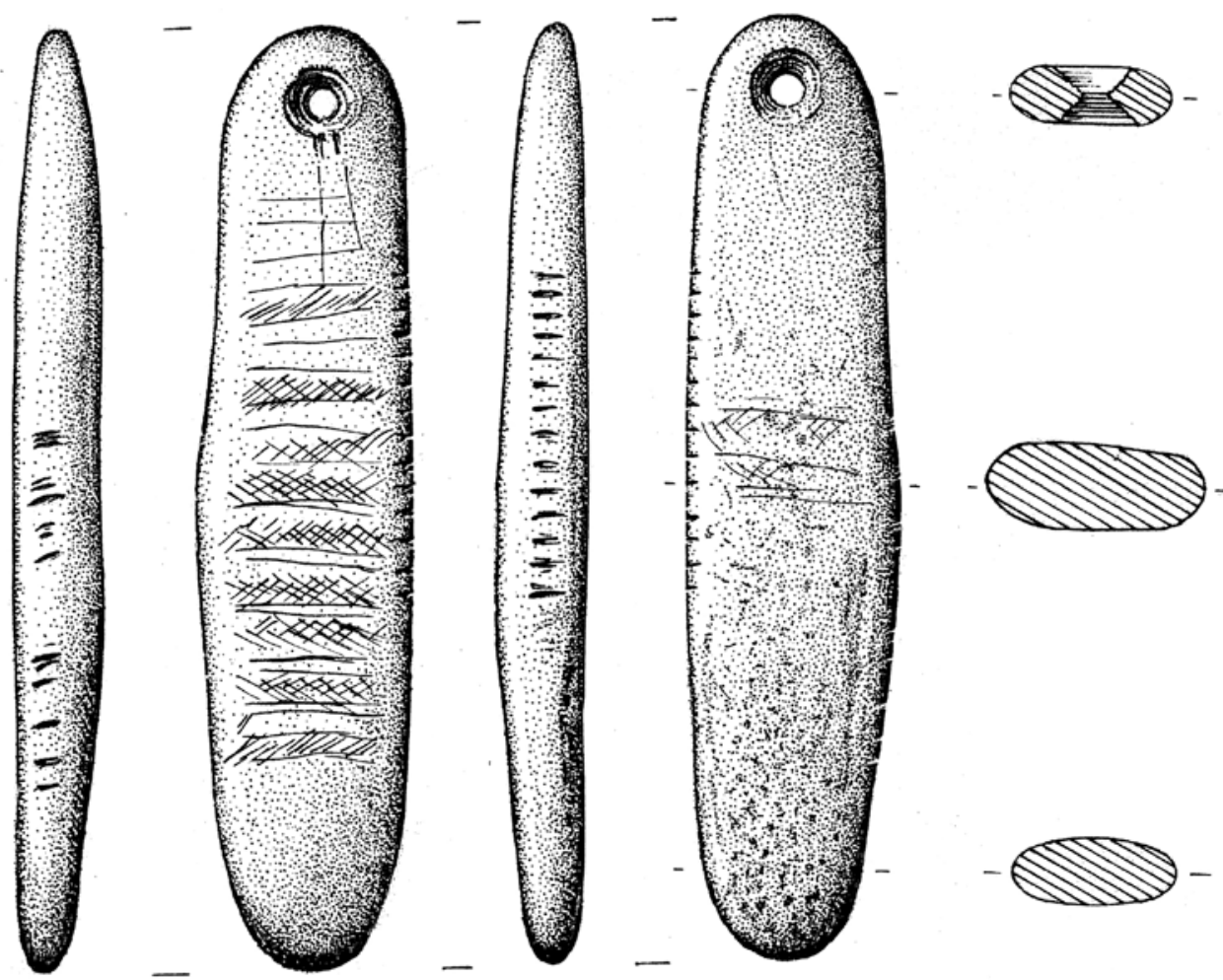

Fig. 53. Colgante $\mathrm{n}^{\circ} 15$ (J. Alonso). / Pendant no. 15 (J. Alonso).
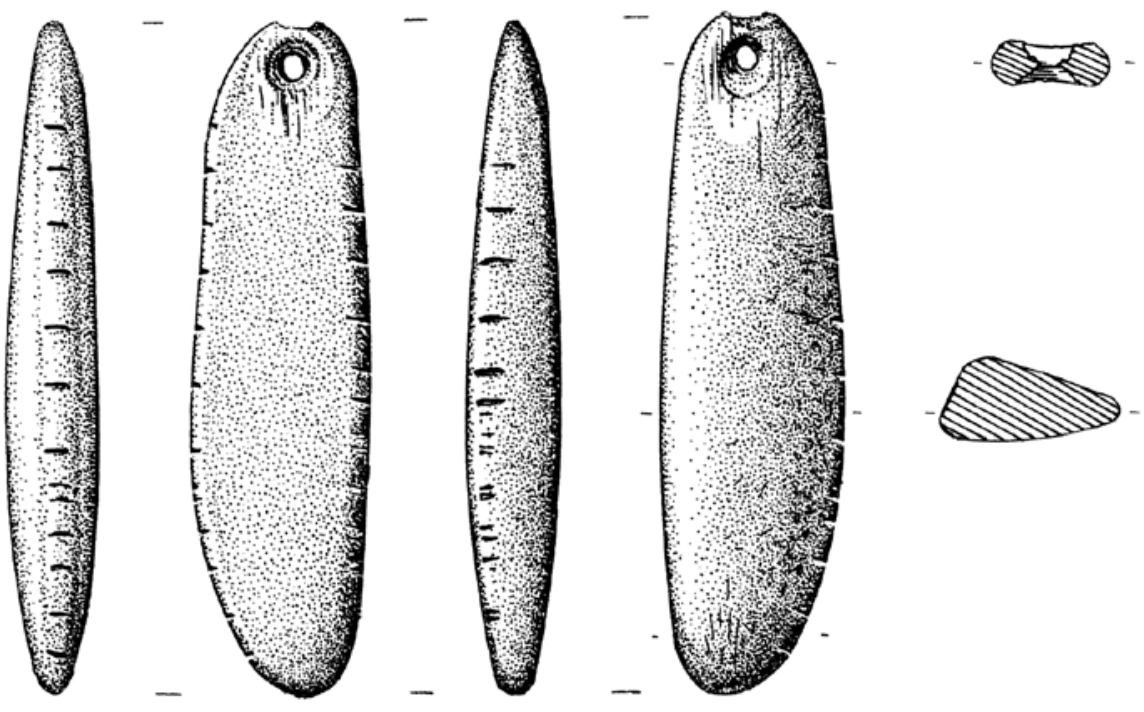

Fig. 54. Colgante $\mathrm{n}^{\circ} 16$ (J. Alonso). / Pendant no. 16 (J. Alonso).

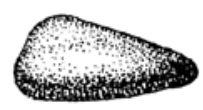



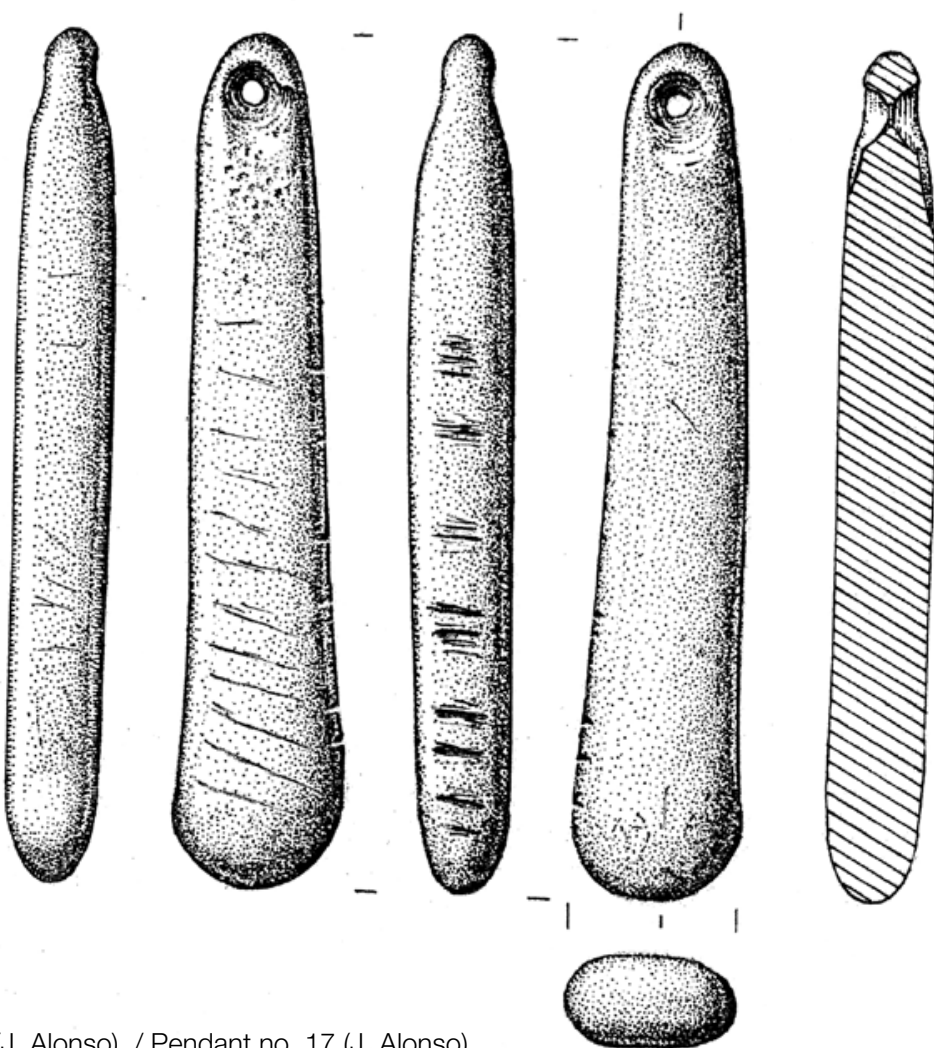

Fig. 55. Colgante $\mathrm{n}^{\circ} 17$ (J. Alonso). / Pendant no. 17 (J, Alonso).
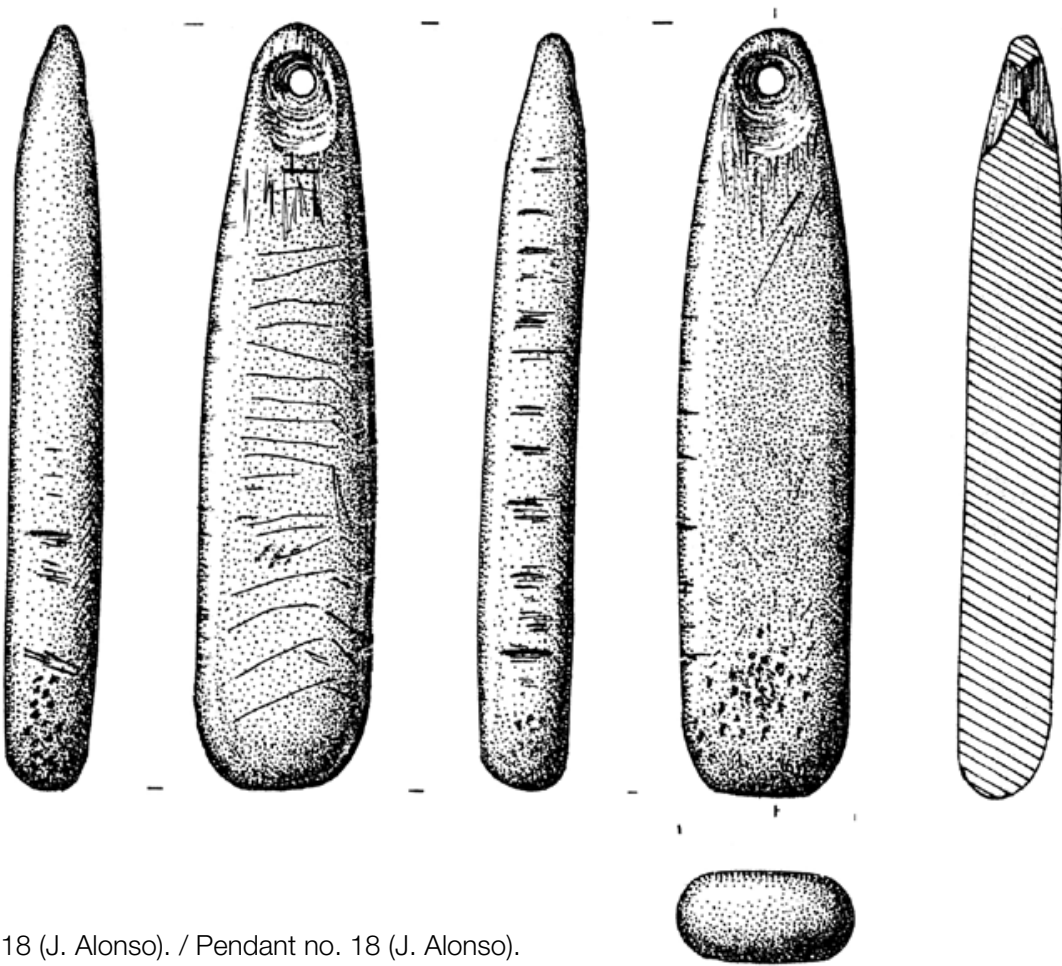

Fig. 56. Colgante $\mathrm{n}^{\circ} 18$ (J. Alonso). / Pendant no. 18 (J. Alonso). 

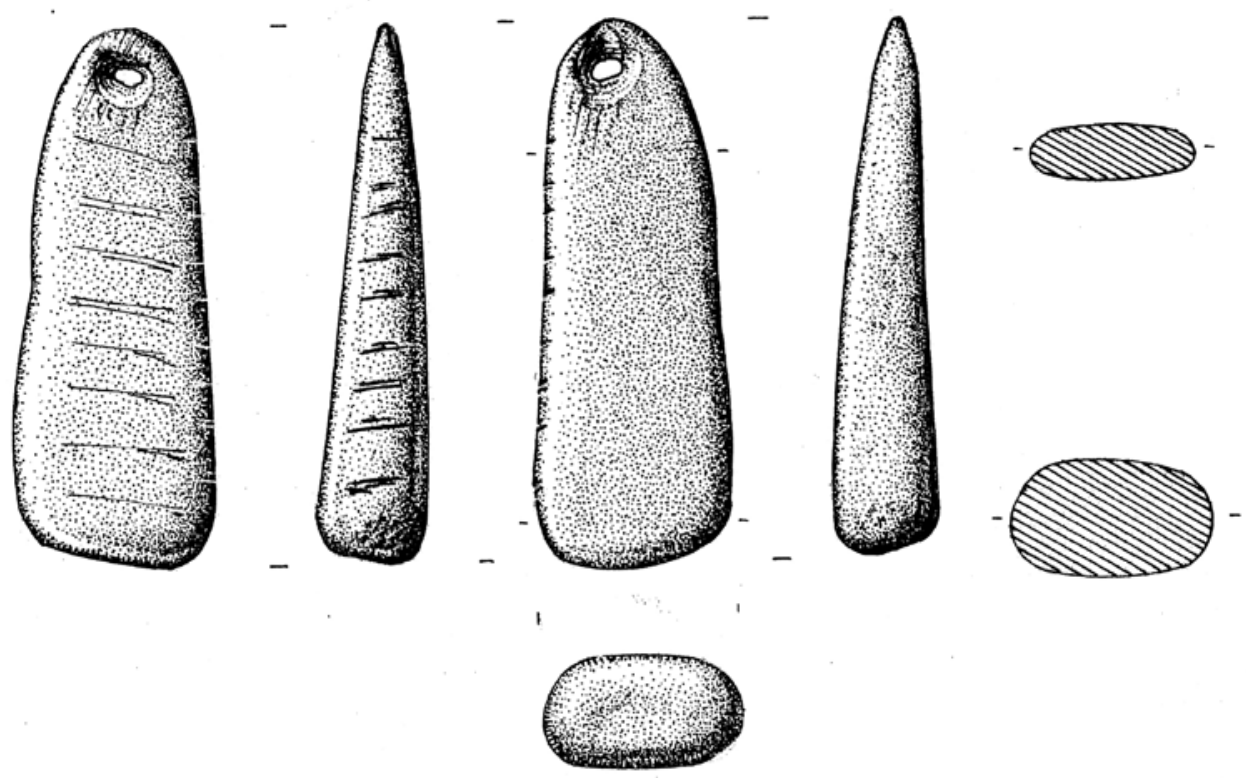

Fig. 57. Colgante $\mathrm{n}^{\circ} 19$ (J. Alonso). / Pendant no. 19 (J. Alonso).
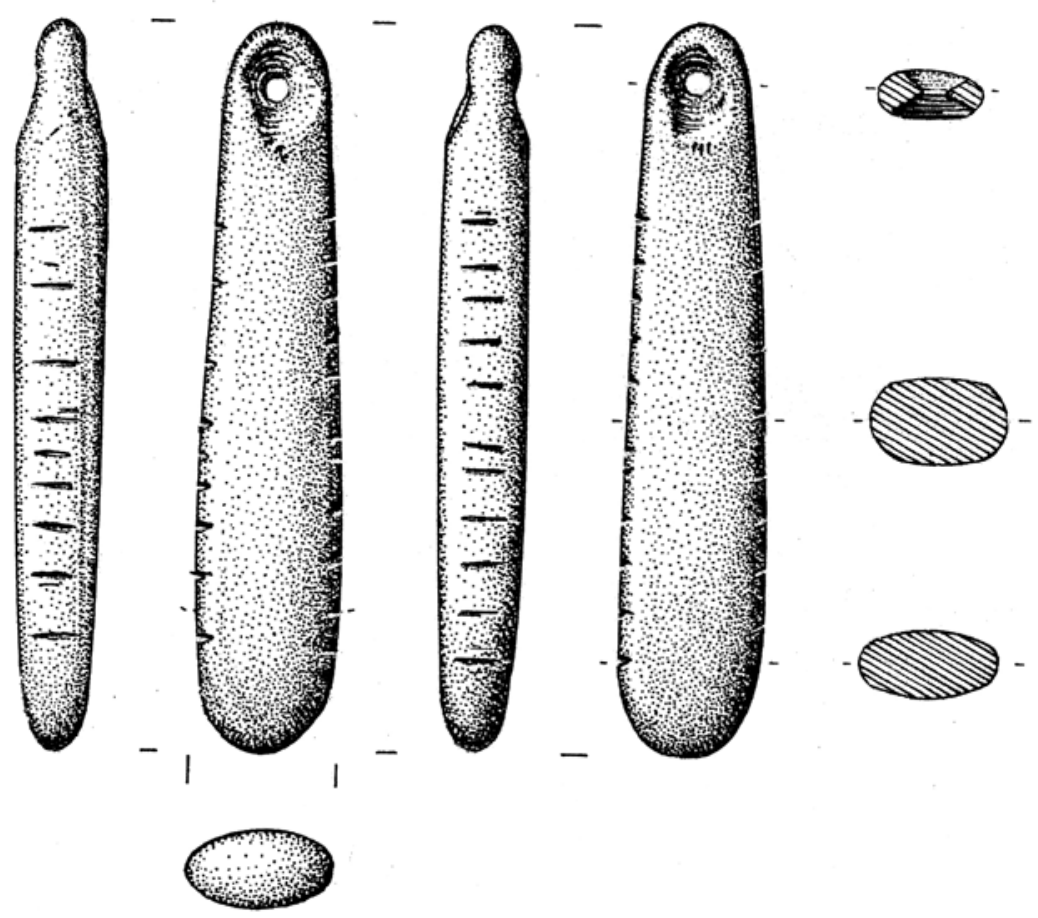

Fig. 58. Colgante $n^{\circ} 20$ (J. Alonso). / Pendant no. 20 (J. Alonso). 

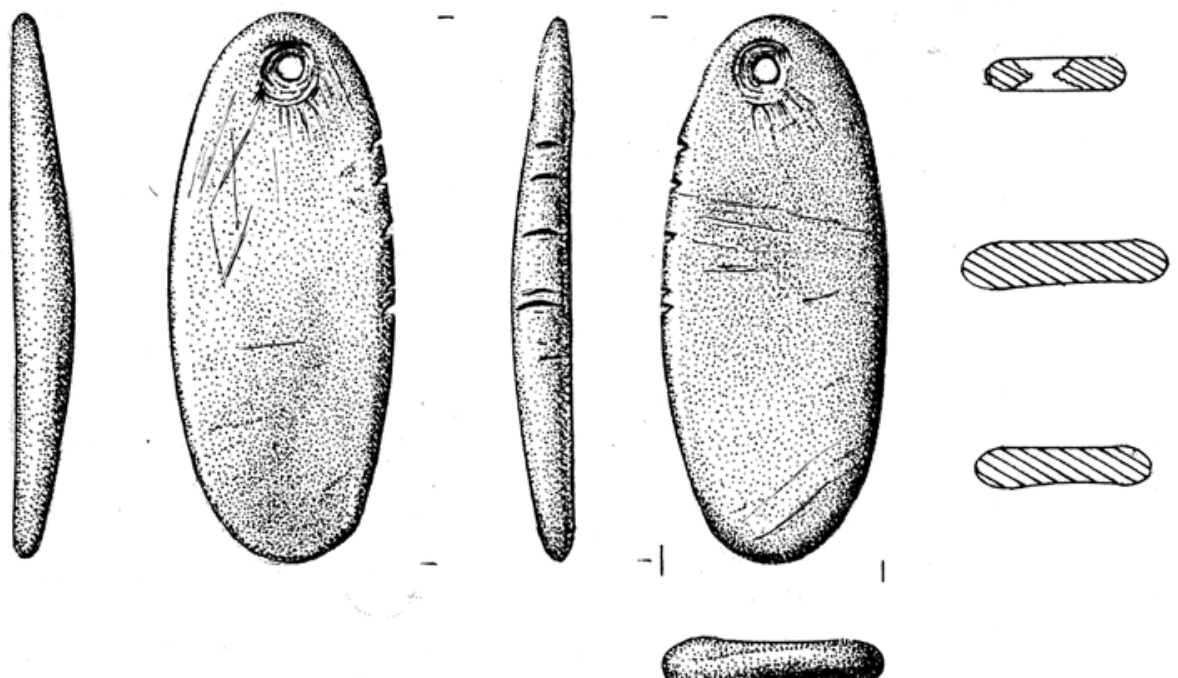

Fig. 59. Colgante $n^{\circ} 21$ (J. Alonso). / Pendant no. 21 (J. Alonso).

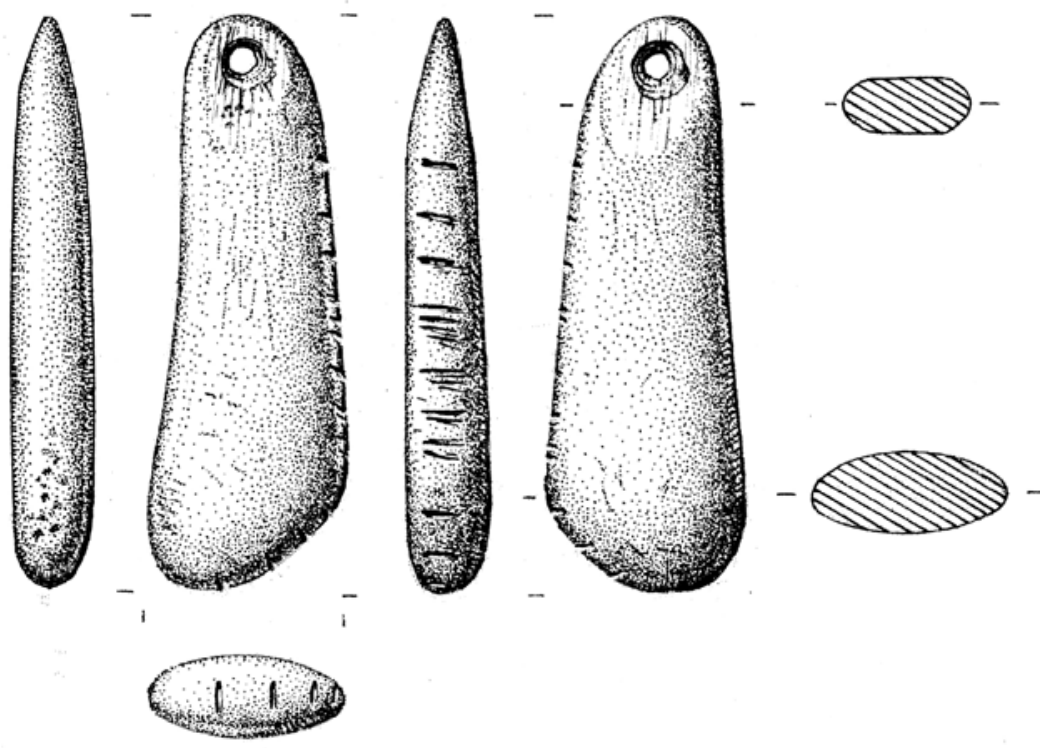

Fig. 60. Colgante nº 22 (J. Alonso). / Pendant no. 22 (J. Alonso). 


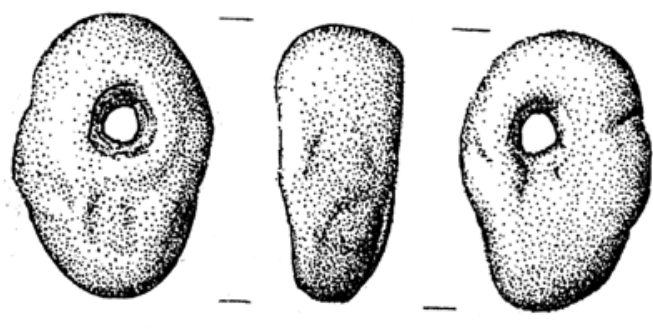

Fig. 61. Colgante $\mathrm{n}^{\circ} 23$ (J. Alonso). / Pendant no. 23 (J. Alonso).

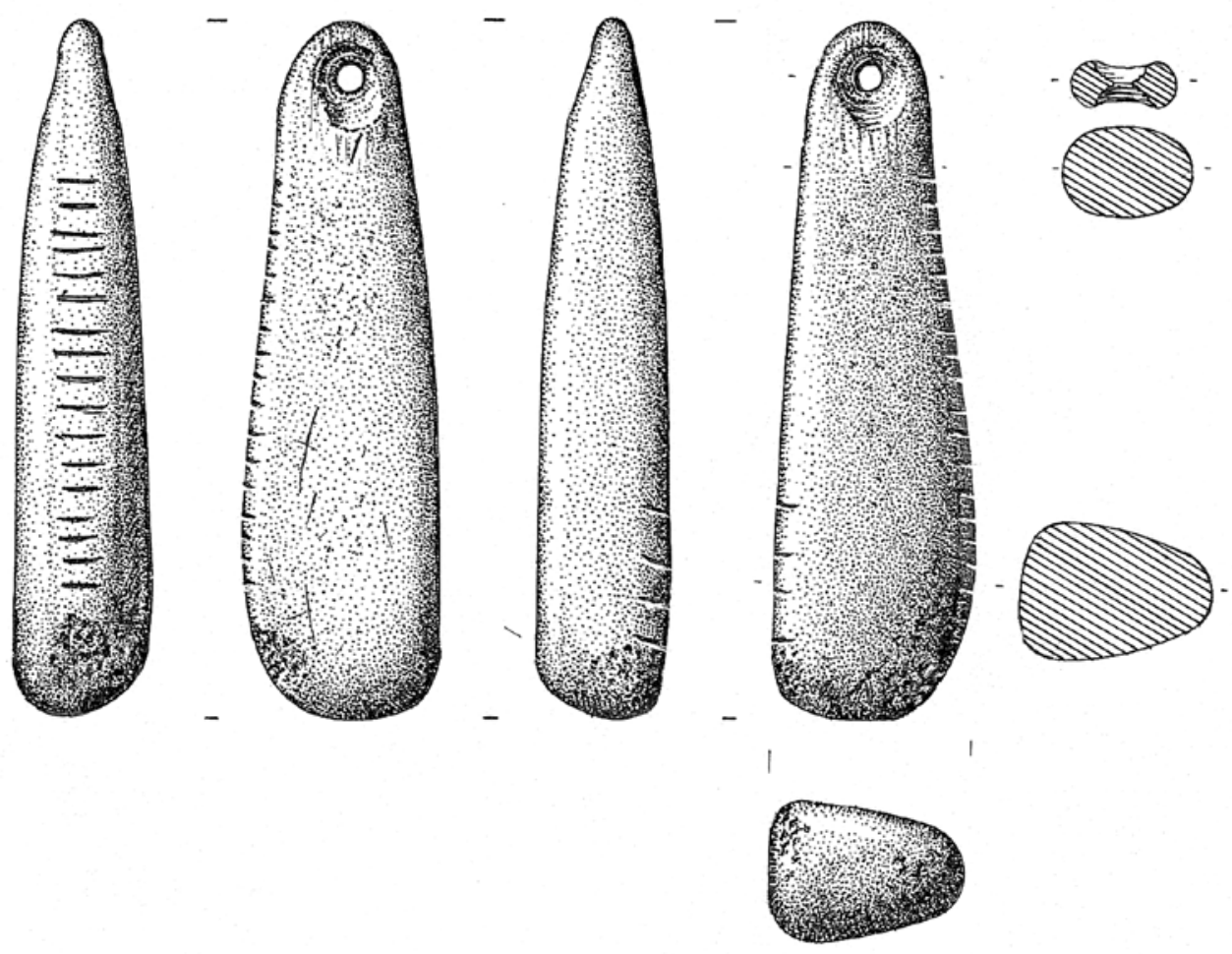

Fig. 62. Colgante $\mathrm{n}^{\circ} 24$ (J. Alonso). / Pendant no. 24 (J. Alonso). 


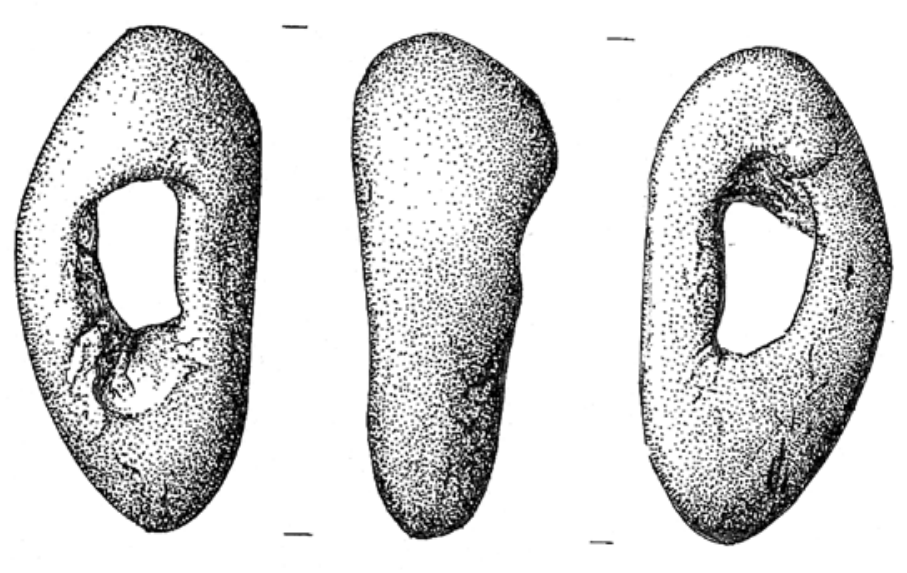

Fig. 63. Colgante $\mathrm{n}^{\circ} 25$ (J. Alonso). / Pendant no. 25 (J. Alonso).

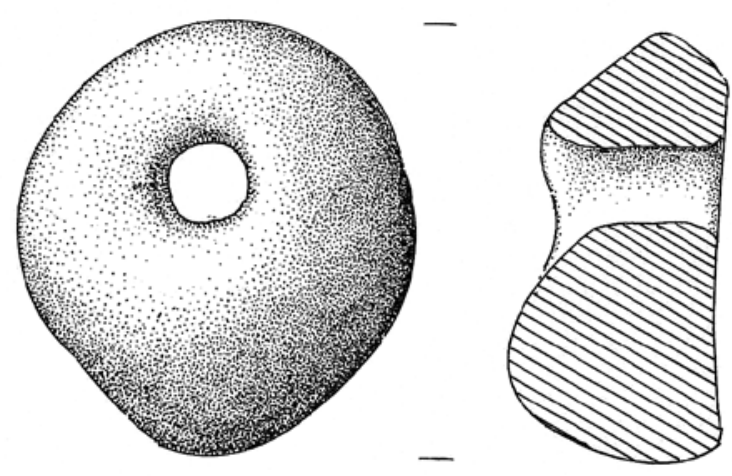

Fig. 64. Colgante $\mathrm{n}^{\circ} 26$ (J. Alonso). / Pendant no. 26 (J. Alonso). 


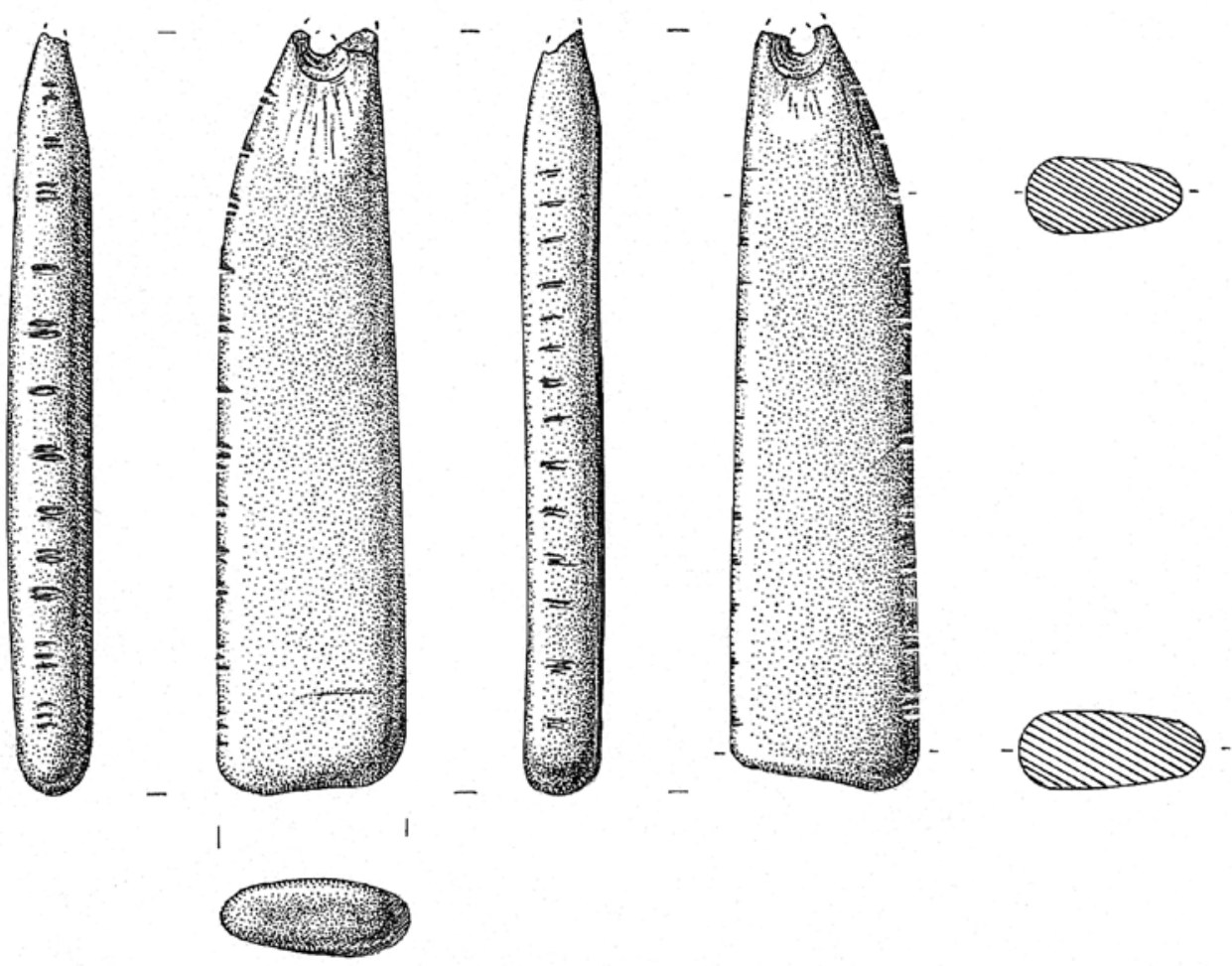

Fig. 65. Colgante n 27 (J. Alonso). / Pendant no. 27 (J. Alonso).

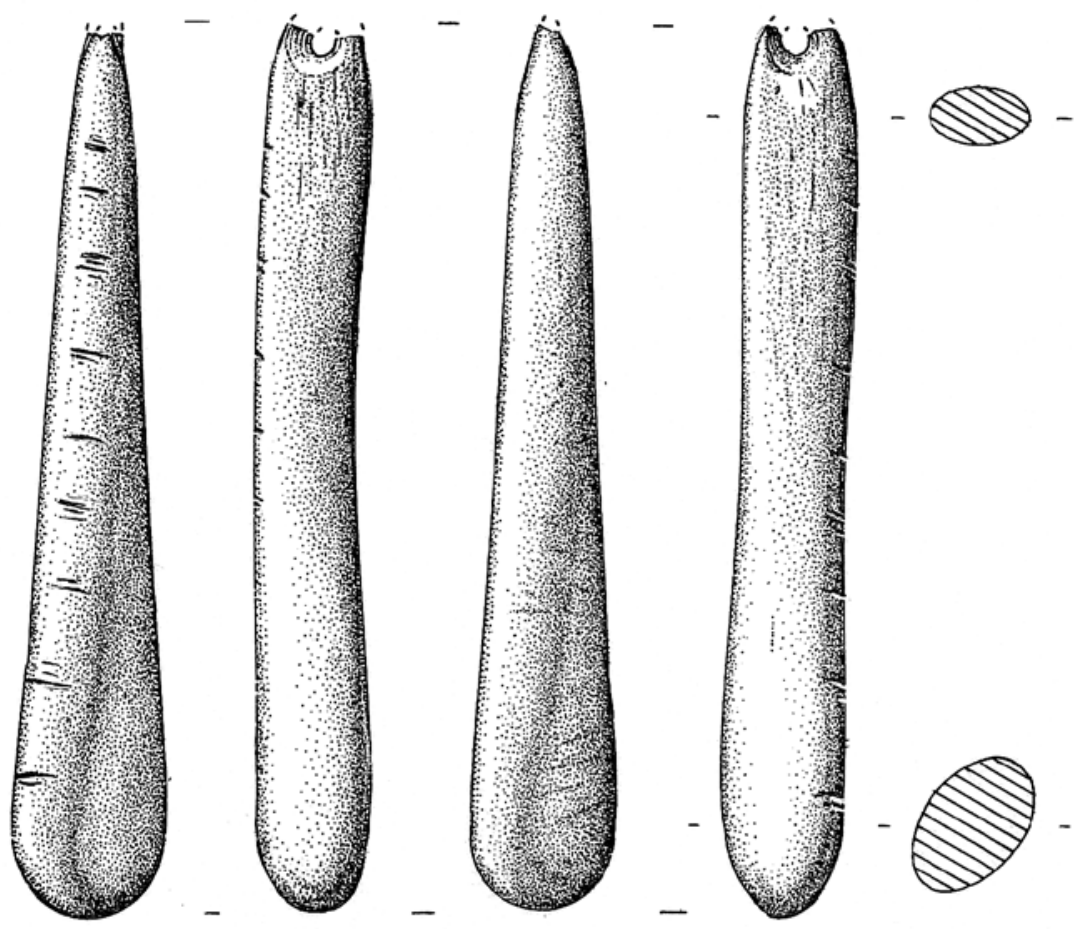

Fig. 66. Colgante $\mathrm{n}^{\circ} 28$ (J. Alonso). / Pendant no. 28 (J. Alonso). 

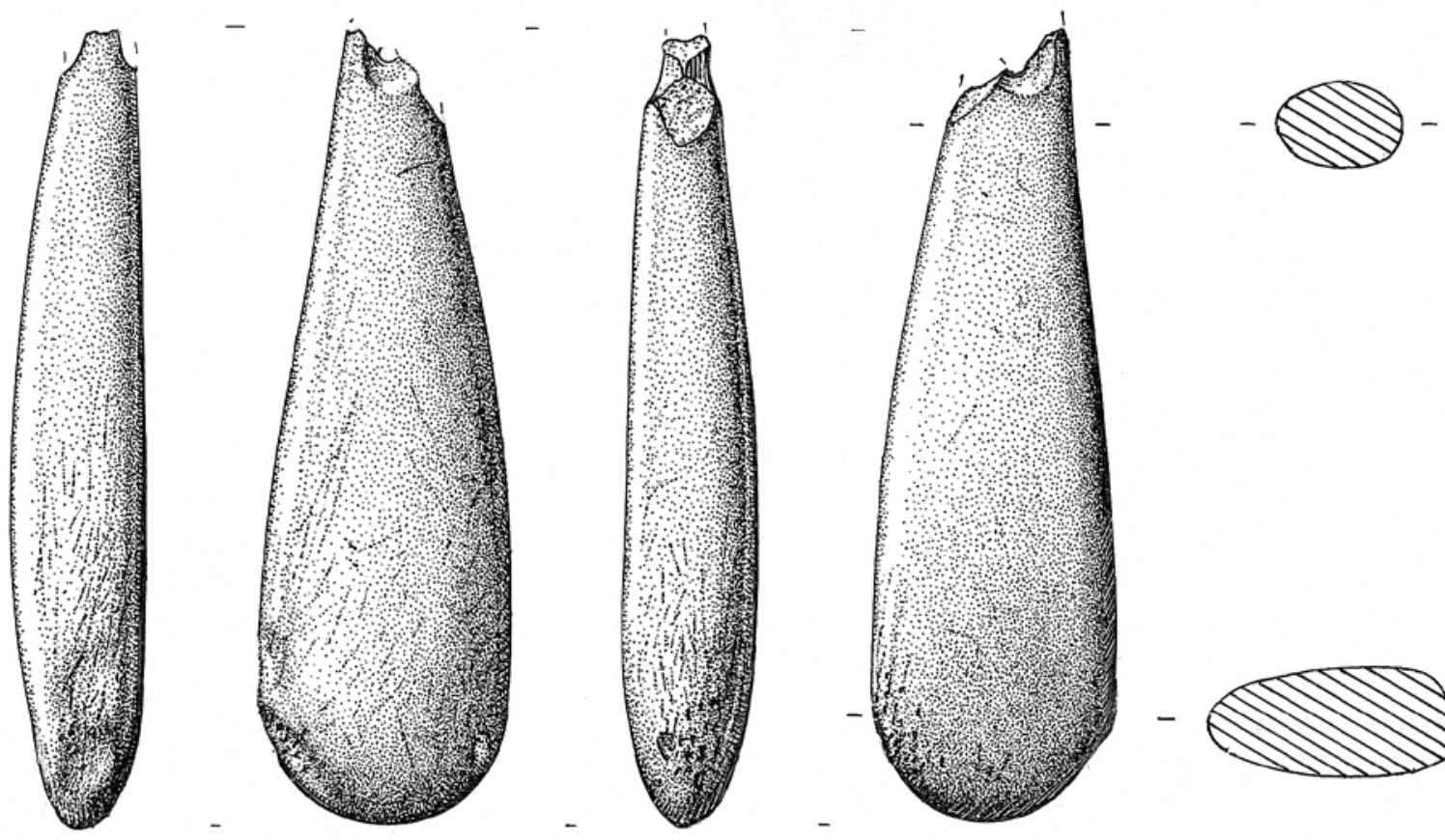

Fig. 67. Colgante n 29 (J.Alonso). / Pendant no. 29 (J. Alonso). 
